Tito Conte

\title{
Dinâmica sedimentar e resiliência às marés meteorológicas em ambientes costeiros da baixada santista: abordagem numérica
}

\author{
Dissertação apresentada ao Instituto \\ Oceanográfico da Universidade de São \\ Paulo, como parte dos requisitos para \\ obtenção do título de Mestre em \\ Ciências, Programa de Oceanografia, \\ área de Oceanografia Geológica..
}

Orientador: Prof. Dr. Eduardo Siegle

Agosto - 2016 


\section{Universidade de São Paulo \\ Instituto Oceanográfico}

Dinâmica sedimentar e resiliência às marés meteorológicas em ambientes costeiros da baixada santista: abordagem numérica

Tito Conte

Dissertação apresentada ao Instituto Oceanográfico da Universidade de São Paulo, como parte dos requisitos para obtenção do título de Mestre em Ciências, área de Oceanografia Química e Geológica

Julgada em

Conceito

$\operatorname{Prof}(\mathrm{a}) . \operatorname{Dr}(\mathrm{a})$.

Conceito

$\operatorname{Prof}(\mathrm{a}) . \operatorname{Dr}(\mathrm{a})$.

Conceito

Prof(a). Dr(a). 


\section{Sumário}

AGRADECIMENTOS ........................................................................ 1

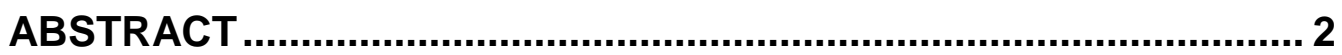

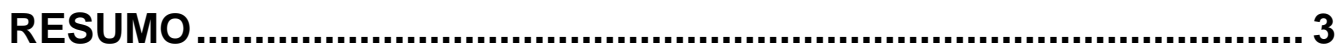

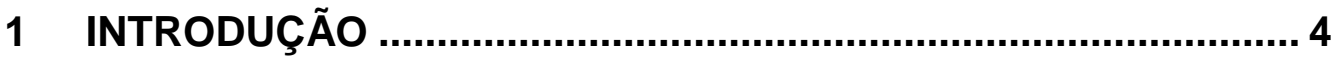

1.1 Sedimento e Modelagem NumÉRICA .................................. 5

1.2 MARÉS METEOROLÓGICAS .............................................. 7

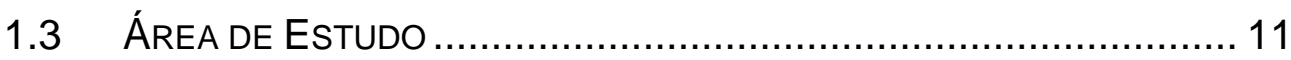

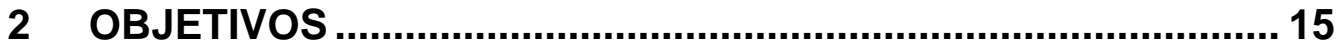

3 METODOLOGIA

3.1 DETECÇÃO DAS FRENTES FRIAS ....................................... 16

3.2 MODELAGEM NUMÉRICA ................................................ 20

3.2.1 Grade numérica ......................................................... 21

3.2.2 Implementação do modelo numérico ............................... 26

Constantes físicas................................................................ 26

3.2.3 Processos Hidrodinâmicos ............................................ 28

3.2.4 Processos de transporte sedimentar .............................. 35

3.2.5 Avaliação do modelo numérico ........................................ 40

4 RESULTADOS E DISCUSSÃO .............................................. 43

4.1 DETECÇÃO DE FRENTES FRIAS ............................................ 43

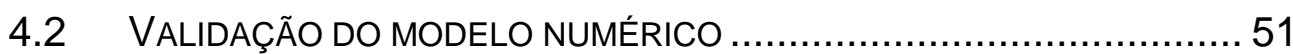

4.3 ELABORAÇÃO DOS CENÁRIOS............................................ 56

4.3.1 Cenário sem a presença de frente fria............................ 57

4.3.2 Cenários com presença de frente fria ............................. 61

4.4 RESULTADOS DA MODELAGEM NUMÉRICA..............................63

4.4.1 Descrição da dinâmica sedimentar do cenário sem frentes frias $\quad 63$

4.4.2 Análise do efeito das frentes frias médias 76

4.4.3 Análise do efeito das frentes frias extremas 87 
5 CONCLUSÕES

6 LIMITAÇÕES E SUGESTÕES PARA TRABALHOS FUTUROS 100

7 REFERÊNCIAS BIBLIOGRÁFICAS 101 


\section{Lista de Figuras}

Figura 1 - Localização da área de estudo........................................ 11

Figura 2 - Localização dos Estuários de São Vicente, Santos e Bertioga e da Baía de Santos (Datum WGS84 Projeção UTM Zona 23S) (Roversi, 2012).

Figura 3 - Localização das Praias de Santos e São Vicente. 14

Figura 4 - Exemplo da disposição das bordas do modelo XBeach em função das coordenadas da grade numérica. 21

Figura 5 - Grade numérica utilizada na modelagem mostrando a totalidade do domínio. Em vermelho a representação da linha de costa utilizada para elaboração da grade - projeção UTM zona 23 datum WGS84. 22

Figura 6 - Zoom na grade numérica utilizada na modelagem mostrando o adensamento nas regiões das praias e dos canais. Em vermelho a representação da linha de costa utilizada para elaboração da grade - projeção UTM zona 23 datum WGS84.

Figura 7 - Elevação de todo o domínio da modelagem, observa-se o canal de navegação aprofundado no processo de dragagem do porto de Santos ao longo do Canal do Porto, as ilhas de Santos e Guarujá, e as regiões de manguezais ao norte da ilha de Santos que foram criadas permitindo o alagamento das mesmas - projeção UTM zona 23 datum WGS84.

Figura 8 - Elevação do domínio da modelagem com zoom na região dos canais e praias de Santos e São Vicente, observa-seclaramente a representação do canal do porto da ilha de urubuqueçaba e de alguns rios, do quebramar e de uma área alagável na ilha do Guarujá ao norte - projeção UTM zona 23 datum WGS84. 25 
Figura 9 - Série temporal dos dados filtrados do período representativo de frente fria extrema. As linhas sólidas representam os períodos onde foi detectado frente. A linha azul representa o nível do mar em relação ao geoide (descontado a maré) em metros, a linha vermelha a componente meridional do vento em $\mathrm{m} / \mathrm{s}$, a linha lilás a temperatura em kelvin, a linha verde a anomalia da pressão atmosférica em milibares, a linha preta a anomalia do geopotencial em metros. O período representado na série corresponde ao dia primeiro de julho de 1996 a primeiro de agosto de 1996, o período da frente fria extrema encontra-se entre 19 a 24 de julho de 1996.

Figura 10 - Campo instantâneo com vetores de vento sobrepostos as isolinhas de pressão em milibar para as 00 horas do dia 23 de julho de 1996 projeção Mercator datum WGS84.

Figura 11 - Série temporal dos dados filtrados do período representativo de frente fria média. As linhas sólidas representam os períodos onde foi detectado frente. A linha azul representa o nível do mar em relação ao geoide (descontado a maré) em metros, a linha vermelha a componente meridional do vento em $\mathrm{m} / \mathrm{s}$, a linha lilás a temperatura em kelvin, a linha verde a anomalia da pressão atmosférica em milibares,a linha preta a anomalia do geopotencial em metros. O período representado na série corresponde ao dia 20 de maio de 1998 a 20 de junho de 1998, o período da frente fria média encontra-se entre 31 de maio a 03 e junho de 1998.

Figura 12 - Campo instantâneo com vetores de vento sobrepostos as isolinhas de pressão em milibar para as 18 horas do dia 02 de junho de 1998 projeção Mercator datum WGS84. 50

Figura 13 - Campo instantâneo com vetores de vento sobrepostos as isolinhas de pressão em milibar para as 18 horas do dia 04 de junho de 1998 projeção Mercator, Datum WGS84.

Figura 14 - Comparação entre a série temporal da componente zonal para os dados de corrente de superfície de Santos coletado com o ADCP e o ponto mais próximo do modelo numérico para o período de 09 de junho a 01 de julho de 2014. 
Figura 15 - Comparação entre a série temporal da componente meridional para os dados de corrente de superfície de Santos coletado com o ADCP e o ponto mais próximo do modelo numérico para o período de 09 de junho a 01 de julho de 2014.

Figura 16 - Comparação entre a série temporal da componente zonal para os dados de corrente de superfície de São Vicente coletado com o ADCP e o ponto mais próximo do modelo numérico para o período de 08 de junho a 01 de julho de 2014 54

Figura 17 - Comparação entre a série temporal da componente meridional para os dados de corrente de superfície de São Vicente coletado com o ADCP e o ponto mais próximo do modelo numérico para o período de 08 de junho a 01 de julho de 2014. 54

Figura 18 - Comparação entre a série temporal da componente zonal para os dados de corrente de superfície de Bertioga coletado com o ADCP e o ponto mais próximo do modelo numérico para o período de 09 de junho a 01 de julho de 2014 55

Figura 19- Comparação entre a série temporal da componente meridional para os dados de corrente de superfície de Bertioga coletado com o ADCP e o ponto mais próximo do modelo numérico para o período de 09 de junho a 01 de julho de 2014. 55

Figura 20 - Série de maré astronômica proveniente do modelo TOPEX/POSSEIDON 7.2 para o período de 01 de junho a 15 de junho de 2014 para os cantos direito e esquerdo da borda offshore do domíno de modelagem. A figura abaixo representa o zoom nas primeiras 120 horas da modelagem para ambas as bordas.

Figura 21 - Histograma direcional da intensidade dos ventos para o período de 1979 a 2015, convenção meteorológica. 58

Figura 22 - Histogramas direcionais de onda para o período de 1979 a 2015, a esquerda apresentado o período de pico e a direita é apresentado a altura significativa, convenção meteorológica. 60

Figura 23 - Série temporal do nível do mar para a condição de FFM. Zoom nas primeiras 120 horas para demonstração das frente inserida (período de 01 de juho de 2014 00:00 a 06 de junho de 2014 00:00) . 
Figura 24 - Série temporal do nível do mar para a condição de FFE. Zoom nas primeiras 120 horas para demonstração das frente inserida .. período de 01 de juho de 2014 00:00 a 06 de junho de 2014 00:00). 62

Figura 25 - Série de ondas para as 120 primeiras horas de modelagem para o cenário de FFE, período de 01 a 06 de junho de 2014 .

Figura 26 - Série de ondas para as 120 primeiras horas de modelagem para o cenário de FFM, período de 01 a 06 de junho de 2014 . 63

Figura 27 - Campos das regiões de deposição e erosão da Baía de Santos para o final da simulação, as cores azul e vermelhas representam os valores em metros, as setas verdes as direções residuais do transporte as linhas pretas representam as cotas batimétricas de 20,15,10,0 e -2 metros projeção UTM zona 23 datum WGS84.

Figura 28 - Campos das regiões de deposição e erosão da desembocadura do Canal de Bertioga para o final da simulação, as cores azul e vermelhas representam os valores em metros, as setas verdes as direções residuais do transporte as linhas pretas representam as cotas batimétricas de 20,15,10,0 e -2 metros - projeção UTM zona 23 datum WGS84.

Figura 29 - Campos das regiões de deposição e erosão da região norte do Canal do Porto para o final da simulação, as cores azul e vermelhas representam os valores em metros, as setas verdes as direções residuais do transporte as linhas pretas representam as cotas batimétricas de 20,15,10,0 e 2 metros - projeção UTM zona 23 datum WGS84 70

Figura 30 - Campos das regiões de deposição e erosão da região norte do Canal do Porto para o final da simulação, as cores azul e vermelhas representam os valores em metros, as setas verdes as direções residuais do transporte as linhas pretas representam as cotas batimétricas de 20,15,10,0 e 2 metros - projeção UTM zona 23 datum WGS84. 72

Figura 31 - Campos das regiões de deposição e erosão da região das praias deSantos para o final da simulação, as cores azul e vermelhas representam os valores em metros, as setas verdes as direções residuais do transporte as linhas pretas representam as cotas batimétricas de 20,15,10,0 e 2 metros - projeção UTM zona 23 datum WGS84 
Figura 32 - Campos das regiões de deposição e erosão da região dos arredores da llha Porchat para o final da simulação, as cores azul e vermelhas representam os valores em metros, as setas verdes as direções residuais do transporte as linhas pretas representam as cotas batimétricas de 20,15,10,0 e 2 metros - projeção UTM zona 23 datum WGS84

Figura 33 - Taxa de sedimentação em milímetros por dia para a Baía de Santos nas 120 primeiras horas de simulação (figura superior) e das 240 últimas horas (figura inferior) para a condição de frente fria média - projeção UTM zona 23 datum WGS84 78

Figura 34 - Taxa de sedimentação em milímetros por dia para a Praia de Bertioga nas 120 primeiras horas de simulação (figura superior) e das 240 últimas horas (figura inferior) para a condição de frente fria média - projeção UTM zona 23 datum WGS84. 80

Figura 35 - Taxa de sedimentação em milímetros por dia para a região norte do Canal do Porto nas 120 primeiras horas de simulação (figura superior) e das 240 últimas horas (figura inferior) para a condição de frente fria média projeção UTM zona 23 datum WGS84. 81

Figura 36 - Taxa de sedimentação em milímetros por dia para a região sul do Canal do Porto nas 120 primeiras horas de simulação (figura superior) e das 240 últimas horas (figura inferior) para a condição de frente fria média .... 83

Figura 37 - Taxa de sedimentação em milímetros por dia para a região das praias de Santos e São Vicente nas 120 primeiras horas de simulação (figura superior) e das 240 últimas horas (figura inferior) para a condição de frente fria média - projeção UTM zona 23 datum WGS84.

Figura 38 - Taxa de sedimentação em milímetros por dia para a região da desembocadura do estuário de São Vicente nas 120 primeiras horas de simulação (figura superior) e das 240 últimas horas (figura inferior) para a condição de frente fria média - projeção UTM zona 23 datum WGS84. 86

Figura 39 - Taxa de sedimentação em milímetros por dia para a Baía de Santos nas 120 primeiras horas de simulação (figura superior) e das 240 últimas horas (figura inferior) para a condição de frente fria extrema - projeção UTM zona 23 datum WGS84.

Figura 40 - Taxa de sedimentação em milímetros por dia para a praia 
de Bertioga nas 120 primeiras horas de simulação (figura superior) e das 240 últimas horas (figura inferior) para a condição de frente fria extrema - projeção UTM zona 23 datum WGS84.

Figura 41 - Taxa de sedimentação em milímetros por dia para a região norte do Canal do Porto nas 120 primeiras horas de simulação (figura superior) e das 240 últimas horas (figura inferior) para a condição de frente fria extrema projeção UTM zona 23 datum WGS84.

Figura 42 - Taxa de sedimentação em milímetros por dia para a região sul do Canal do Porto nas 120 primeiras horas de simulação (figura superior) e das 240 últimas horas (figura inferior) para a condição de frente fria extema.. 91

Figura 43 - Taxa de sedimentação em milímetros por dia para a região das praias de Santos e São Vicente nas 120 primeiras horas de simulação (figura superior) e das 240 últimas horas (figura inferior) para a condição de frente fria extrema - projeção UTM zona 23 datum WGS84. 93

Figura 44 - Taxa de sedimentação em milímetros por dia para a região da desembocadura do estuário de São Vicente nas 120 primeiras horas de simulação (figura superior) e das 240 últimas horas (figura inferior) para a condição de frente fria extrema - projeção UTM zona 23 datum WGS84. 94 


\section{Lista de Tabelas}

Tabela 1 - Datas dos perfis de corrente coletados por ADCP 40

Tabela 2 - Classificação do ERMA segundo (Van Rijn, et al., 2003)... 41

Tabela 3 - Mediana da ocorrência de frentes frias por mês para 0 período de 01 de janeiro de 1979 a 31 de dezembro de 2015.

Tabela 4 - Ocorrência de frentes frias por ano para o período de 01 de janeiro de 1979 a 31 de dezembro de 2015.

Tabela 5 - Parâmetros estatísticos dos ventos, duração e nível do mar para as frentes frias encontradas no período de 01 de janeiro de 1979 a 31 de dezembro de 2015. 45

Tabela 6 - Períodos de frentes frias selecionados para a modelagem, o primeiro período representa a frente fria típica e o segundo período a frente fria extrema.

Tabela 7 - Pontos de coleta dos dados de ADCP e pontos do modelo utilizados para comparação. Zona UTM 23, datum WGS84, o período de comparação corresponde a data de início da coleta a 01 de julho de 2014 .... 52

Tabela 8 - Tabela com os parâmetros estatísticos de avaliação do modelo numérico implementado. 52

Tabela 9 - Coordenadas dos cantos das bordas onde foram extraídas as constantes de maré do modelo TOPEX/POSSEIDON, Zona UTM 23 DATUM - WGS84.

Tabela 10 - Tabela de ocorrência conjunta de direção e intensidade dos dados de vento para o período de 1979 a 2015.

Tabela 11 -Tabela de ocorrência conjunta de direção e período de pico de onda para o período de 1979 a 2015. 60

Tabela 12 - Tabela de ocorrência conjunta de direção de pico e altura significativa de onda para o período de 1979 a 2015 60

Tabela 13 - Valores de onda e vento para o cenários sem frentes frias. 


\section{Agradecimentos}

Ao professor Eduardo Siegle, por aceitar o desafio de me orientar, pela confiança e por ser presente e participativo até o último momento deste trabalho.

Ao professor Michel por ter possibilitado o princípio deste trabalho durante o inicio do mestrado

À empresa Tetra Tech e aos colegas pelos ensinamentos, em especial a Márcio e Moysés por serem ótimos palpiteiros e motivadores.

Ao João por não se queixar do estado do apartamento nem pela barulheira durante a madrugada.

À Luiza por ter me permitido consolidação dos conhecimentos sobre modelagem de ondas.

À Marina por ter acompanhado a gênese deste trabalho até o seu parto mesmo gripada e doente.

Aos que me aguentaram as crises, durante as reclamações e afins... 


\begin{abstract}
Among the coastal environments, the estuaries are the main sediment source for oceans. Its sensible dynamic is widely susceptible to changes of natural and anthropogenic impacts the sediment balance of those environments. This work applies the Xbeach numerical model in Santos estuary to understand the storm surges forced by cold fronts on the sediment transport through three scenarios. The first scenario input was astronomic tide sea surface high, the second scenario input was the median cold front and the last scenario input was an extreme cold front. To get the cold front condition we use the NCEP/NCAR reanalysis data. We applied the five most intense days from each cold front condition in the beginning astronomic tide series. With the numerical model results we could understand the erosive action from the cold fronts and how it compensates the depositional period without any cold fronts. The extreme cold fronts intensify the depositional/erosion process unbalancing the system beyond the resilience capacity
\end{abstract}

Key words: Santos, São Vicente, Estuary, XBeach, storm surge, sediment transport, cold fronts, costal erosion. 


\section{Resumo}

Dentre os ambientes costeiros, os estuários são as principais fontes de sedimento para os oceanos. Sua dinâmica sensível é amplamente suscetível a modificações de origem natural e antrópica impactando no balanço sedimentar destes ambientes. O presente trabalho busca compreender a importância da maré meteorológica causada por frentes frias sobre os processos sedimentares do complexo estuarino de Santos aplicando o modelo numérico XBeach com três cenários. O primeiro foi forçado apenas pela maré astronômica outro representando uma condição de frente fria média e um terceiro representando uma frente fria extrema. Buscou-se detectar as frentes utilizando dados de reanálise do NCEP/NCAR. Foram extraídos os cinco dias mais intensos das frentes escolhidas e aplicaram-se ao inicio da série de dados de input do modelo para os ensaios numéricos. Os resultados permitiram compreender que os sistemas frontais atuam como agentes essenciais no balanço sedimentar tendo um papel erosivo compensando os processos deposicionais atuantes no período sem frentes. Frentes muito intensas agravam as feições erosivas e deposicionais, desbalanceando o sistema além da sua capacidade de recuperação.

Palavras-chave: Santos, São Vicente, Estuário, XBeach, maré meteorológica, frentes frias, transporte de sedimento, erosão costeira. 


\section{Introdução}

Diferentes características geomorfológicas observadas em sistemas costeiros são resposta à composição de processos distintos espaçotemporalmente relativos à herança geológica, variações do nível do mar e dinâmica costeira atual. Destes, a última responde por processos de menor escala temporal (de segundos a algumas décadas), aos quais, vento, chuvas, ondas, gelo, rios, e maré são os agentes responsáveis pelo transporte de sedimento autóctone e alóctone e a feição topográfica emersa e submersa da zona costeira.

A combinação da energia, tempo de incidência, e frequência destes agentes junto à disponibilidade $\mathrm{e}$ as características físico-químicas do sedimento (densidade, mineralogia, granulometria, esfericidade, grau de seleção, potencial de dissolução e potencial de desagregação) determinam as feições instantâneas observadas na costa (Davis Jr \& FitzGerald, 2003). O desenvolvimento dos sistemas costeiros é influenciado pelo fluxo resultante dos agentes atuantes que modelam a topografia que, por sua vez, altera a intensidade e direção dos agentes transportadores de forma que o sistema se encontra em constante modificação.

Neste contexto, a variabilidade dos agentes transportadores fornece e remove quantidades de sedimentos podendo alterar a localização da linha d'água. Em caso de um maior fornecimento de sedimento a região costeira encontra-se em estado de progradação, no caso de uma situação de remoção a feição encontra-se em estado de erosão. Por vezes, a energia de incidência dos agentes transportadores é afetada decorrente da ação de eventos energéticos distintos aos usuais afetando o balanço de sedimentar (Kriebel \& Dean, 1985).

Em meados do século $X X I$, o crescimento populacional e a globalização da economia intensificaram as intervenções antropogênicas na costa, consequentemente houve um aumento do interesse no entendimento da dinâmica sedimentar de regiões costeiras, principalmente no que diz respeito a estabilidade da linha de costa para uso comercial e urbano das regiões banhadas pelos oceanos (Gupta, et al., 2005; Erlandson \& Rick, 2008), neste 
ínterim é válido ressaltar que $47 \%$ das cidades mais populosas do mundo (acima de 5 milhões de habitantes) se encontram diretamente conectadas com menos de $3 \%$ da área total dos oceanos (ONU, 2014).

No intuito de obter uma maior compreensão da dinâmica sedimentar tem-se buscado a combinação de diferentes técnicas e ferramentas e.g. geoprocessamento, sensoriamento remoto e modelagem numérica, sendo a última utilizada para simular o movimento das partículas sedimentares ao longo do ambiente e a evolução topobatimétrica das regiões costeiras, permitindo o entendimento da estabilidade e vulnerabilidade à eventos de tempestade e intervenções antropogênicas.

Embora eficaz, o uso da modelagem numérica exige cautela. Os resultados obtidos são aproximações da realidade decorrente da simplificação dos fenômenos para a representação numérica e quando se trata de valores absolutos em função da não representação de fenômenos de escalas espaciais inferiores à grade do modelo ou aos intervalos de tempo utilizados devido à limitação computacional ou ao próprio conjunto de equações. Todavia, os resultados numéricos permitem o entendimento das tendências das principais forçantes. No que diz respeito à sua aplicação para o estudo de transporte de sedimento, os resultados possibilitam entender as feições que possuem caráter erosivo, estável ou deposicional, bem como um resultado qualitativo da velocidade dos processos.

\subsection{Sedimento e Modelagem Numérica}

Sedimentos oceânicos são predominantemente oriundos de descargas continentais, sendo transportados para região abissal, plataforma continental ou permanecendo na zona costeira. A composição é majoritariamente composta de quartzo em frações que variam de cascalho $(>2 \mathrm{~mm})$ a argila $>(4 \mu \mathrm{m})$. Para a modelagem numérica da dinâmica sedimentar, o material é classificado de acordo com o comportamento da partícula em um meio iônico, tal qual a água do mar. A diferenciação se dá entre o material que possui (coesivos) e não possui (não coesivos) capacidade aglutinadora por interação eletroquímica. Geralmente esta classificação é atribuía a fração fina do sedimento transportada em suspensão (Mitchener \& Torfs, 1996). 
As implicações numéricas da diferenciação supracitada têm efeitos diretos sobre o tipo de transporte. $O$ sedimento não coesivo é parametrizado matematicamente como uma partícula esférica inerte sob ação de um fluído, sendo transportado por rolamento, arrasto e saltação (salvo regiões de fluxos muito intensos e.g. a desembocadura do Rio Amazonas, onde o sedimento desta granulometria pode ser transportado em suspensão). Por sua vez 0 sedimento coesivo apresenta variabilidade temporal no tamanho da partícula devido a capacidade aglutinadora consequentemente esta mesma esfera tem variabilidade de tamanho (Mitchener \& Torfs, 1996). Outro efeito sobre 0 transporte causado por este tipo de sedimento diz respeito a estratificação do fluido por elevada concentração de partículas em camadas logo acima do leito marinho que estratifica e altera a propriedade da água no que diz respeito à reologia da mesma, caso das formações de lama fluida em regiões estuarinas (Toorman, 2001) .

As representações para os cálculos numéricos do transporte de sedimentos derivam da discretização espacial e temporal do processo ao longo dos pontos de grade as quais independe do esquema escolhido da grade de Arakawa (Arakawa \& Lamb, 1977). O sedimento é parametrizado como elemento lagrangeano que tem suas propriedades advectadas e difundidas em blocos, e as características granulométricas e de massa destes mesmos blocos variam temporalmente e espacialmente de acordo com a hidrodinâmica dissociando-se em outros blocos ou aglomerando-se em um novo. Este método de solução numérica implica em aproximação do transporte de massa. Os erros associados no caso do transporte de sedimentos coesivos estão na variabilidade comportamental do mesmo no fluido e na variabilidade das propriedades das partículas, pois, estas mudanças de propriedade implicam na advecção de uma informação (e.g erodibilidade do fundo) distinta da anterior, e que implica no comportamento do fluido que a transporta. No caso do transporte de sedimentos não coesivos, os erros associados correspondem à forma geométrica que é assumida no modelo numérico (blocos de partículas perfeitamente esféricas) e ao cálculo do transporte como concentração (Toorman 2001). 


\subsection{Marés meteorológicas}

Dentre os estudos realizados na zona costeira, a previsão de eventos de tempestades responsáveis pelas marés meteorológicas e aumento da energia de ondas tem apresentado importância com relação a políticas publicas no que diz respeito a alertas de evacuação e manejo da costa relacionada com efeitos de erosão costeira e alagamento de cidades litorâneas (Kriebel \& Dean, 1985; Flather, 1994; Verlaan, et al., 2005).

Especificamente sobre a mobilização de sedimentos, os efeitos de marés meteorológicas são perturbações de alta energia que amplificam a magnitude do fluxo aumentando a competência do transporte. Este fato propicia a remobilização de material com maior granulometria e/ou densidade do que o usual, além de possibilitar temporariamente a alteração das zonas de deposição e remoção de sedimentos.

A definição de maré meteorológica (storm surge) consiste na subida abrupta no nível médio do mar por cerca de algumas horas a alguns dias em resposta à passagem de sistemas meteorológicos energéticos tais como furacões, frentes frias, monções, ciclones e tempestades extratropicais. Esses processos são intensificados em casos de regiões rasas com baixa declividade, baias ou deltas, causando inundações em regiões costeiras e erosão costeira acarretando prejuízos para o governo e mortes (Dean \& Dalrymple, 2004).

A magnitude e o potencial destrutivo deste fenômeno dependem da intensidade, direção e duração dos ventos, amplitude das marés astronômicas e do regime de ondas incidentes. Desde 1903, organizações governamentais tem se dedicado a estudos de previsão destes fenômenos e desenvolvido estruturas para proteção de cidades com potencial risco de inundação. Três dos principais exemplos de cidades que dedicaram grandes esforços para o desenvolvimento de estruturas de engenharia e previsão destes fenômenos são as barreiras nos canais da laguna de Veneza- Itália, as barreiras do Rio Tamisa- Inglaterra e as comportas do Rio Osterschelde na cidade de Roterdã Holanda (Dean \& Dalrymple, 2004).

Maré meteorológica é uma resposta do oceano ao efeito resultante entre tempestades com centros de baixa pressão, tensão de cisalhamento do vento, força de Coriolis e a quebra de ondas (Dean \& Dalrymple, 2004; 
Weisberg \& Zheng, 2006).

Os gradientes de baixa pressão dos centros de tempestade são margeados por centros de alta, o que consequentemente permite a elevação do nível do mar no centro da tempestade. Quando próximos da costa em relação à distância da costa este fenômenos meteorológicos elevam o nível do mar para permitir que a água invada o continente. Matematicamente este processo é descrito por:

$$
\eta=\frac{\Delta p}{\gamma}
$$

Onde $\eta$ é a elevação do nível do mar $\Delta p$ é a variação de pressão do centro até os limites da tempestade e $\gamma$ é a massa específica da água

A tensão de cisalhamento do vento é gerada através da fricção do vento, esta friç̧ão que transfere momentum para a superfície da água gerando movimento. Empiricamente a equação que calcula esta transferência de momentum é dada por:

$$
\tau_{s}=\rho c_{f} W^{2}
$$

Onde $\mathrm{W}$ é a velocidade do vento, $\rho$ é a densidade da água, $\tau_{s}$ é a tensão de cisalhamento e $c_{f}$ é o coeficiente de fricção. Para entender o processo que se dá devido à tensão de cisalhamento do vento supondo uma variação de energia ao longo de uma distância $x$ perpendicular à costa e uma coluna de água dada por $h+\eta$ com atrito com o fundo igual a $\tau_{b}$ (onde $\tau_{b}<\tau_{s}$ ), podemos assumir que a subida do nível do mar empurrada pelo vento é causada por:

$$
\frac{d \eta}{d x}=\frac{\left(\tau_{s}-\tau_{b)}\right.}{\rho g(h+\eta)}
$$

Onde $g$ corresponde a aceleração da gravidade

Portanto, o aumento do nível do mar em direção à costa depende da tensão de cisalhamento na mesma direção, onde a profundidade da coluna de água é suficientemente rasa em relação à pista e intensidade do vento.

Outra forma da ocorrência de maré meteorológica provém da ocorrência de ventos intensos paralelos à costa, que por transporte de Ekman associados à força de Coriolis, movimentam a água em direção ao continente empilhando água na costa. A descrição matemática para este movimento é 
dada por:

$$
\frac{d \eta}{d x}=\frac{f V}{g}
$$

Onde $V$ é a intensidade média da corrente integrada na coluna d'água e $f$ é o parâmetro de Coriolis em função da latitude.

Por fim, a incidência das ondas causa marés meteorológicas quando as ondas são suficientemente grandes para elevar a coluna de água, em geral este fenômeno é associado a passagens de eventos meteorológicos extremos que transmitem grandes quantidades de energia para as ondas tais como furacões e ciclones. De modo geral as marés meteorológicas são resultado da interação entre estas quatro forçantes, sendo o vento perpendicular à costa a mais eficiente para a subida abrupta do nível do mar (Dean \& Dalrymple, 2004).

No que diz respeito à remobilização de sedimentos, a subida abrupta do nível do mar leva à retrogradação da linha de costa e altera as características sedimentológicas de um determinado sistema costeiro (Esteves, et al., 2002). Estes efeitos se dão pela progradação da zona de arrebentação de ondas e da zona se remobilização de sedimentos, intensificação dos ventos e consequente intensificação das ondas geradas. Em geral esses estudos são aplicados para verificar impactos de furacões ou frentes meteorológicas.A título de exemplo dos efeitos de marés meteorológicas sobre a dinâmica sedimentar, o trabalho de Siegle e Calliari (2008) apresenta a observação da erosão costeira e variabilidade granulométrica e mineralógica do litoral gaúcho após a passagem de três sistemas meteorológicos energéticos. Abordagens numéricas tem sido realizadas por diversos pesquisadores para a previsão de impactos de marés meteorológicas ou os estudos de suas consequências, dentre estes pode-se mencionar o caso do estuário de Volta, em Gana, que verificou a estabilidade das barras de areia da desembocadura (Bollen, et al., 2011); no rompimento e reconstrução de ilha barreira na costa leste dos Estados Unidos (Gutierrez, et al., 2015); efeitos das assimetrias de maré causados por maré meteorlógica no mar do norte sobre a região do estuário de Roterdã, na Holanda (Dronkers, 1986). Estes estudos discutem a possibilidade de recomposição do sistema ao estado anterior a passagem da maré meteorológica. $\mathrm{O}$ entendimento das consequências da dinâmica praial sobre 
estes efeitos auxiliam a engenharia e gestão costeira no entendimento de obras de proteção ou fixação da linha de costa.

Devido à relevância econômica e social, as regiões portuárias/estuarinas tem sido alvo de estudos sobre as alterações dos fenômenos hidrodinâmicos associados às mudanças climáticas e as implicações destas alterações dos processos sedimentares. Neste ínterim, o presente trabalho buscará compreender o transporte de sedimento no complexo estuarino santista associado à passagem de marés meteorológicas.

A escolha da área de estudo (Figura 1) foi motivada pela relevância do Porto de Santos para o Brasil, visto que este é considerado o maior terminal de carga e descarga de produtos em volume absoluto de material. Quanto ao cunho oceanográfico, o complexo estuarino santista apresenta uma larga quantidade de desembocaduras que provém material sedimentar. Possui três canais interligados (Canal do Porto e Canal de São Vicente que rodeiam a ilha de Santos e o Canal de Bertioga que separa a Ilha de Guarujá do resto do continente), e um embaiamento voltado para sul, região de maior de conexão entre o sistema estuarino e o oceano. A subida do nível do mar além da maré meteorológica na região e associada à passagem de frentes frias, em geral esse fenômeno e responsável pela intensificação das correntes e alagamentos nas proximidades das orlas das praias santistas além de erosão costeira (Castro \& Lee, 1995; Harari \& Camargo, 2006; Farinnaccio, et al., 2009; Campos, et al., 2010).

Neste contexto buscaremos compreender as implicações das marés meteorológicas associadas ao transporte de Ekman perpendicular à costa e os gradientes de pressão atmosférica sobre o transporte de sedimento. No que diz respeito à permanência dos resultados destas perturbações sobre as feições topobatimétricas do Complexo Estuarino de Santos. 

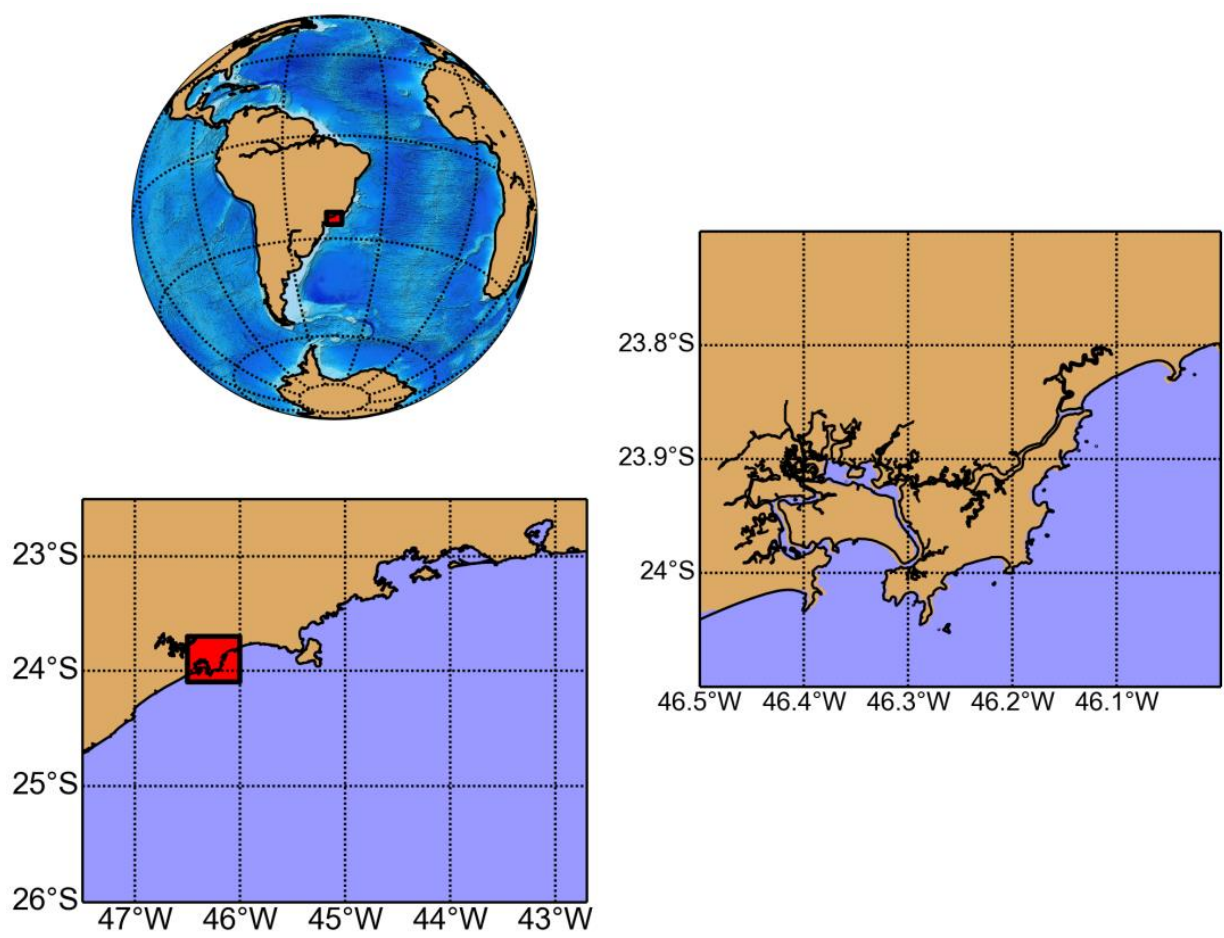

Figura 1 - Localização da área de estudo.

\section{3 Área de Estudo}

A região restringe-se ao Complexo Estuarino de Santos e a Baía de Santos ambas inseridas na Baixada Santista, parte central do litoral do Estado de São Paulo. Embora a orientação preferencial do litoral paulista seja NNESSO, a área de estudo encontra-se com orientação E-O e a Baía de Santos apresenta orientação Norte Sul (Rodrigues, et al., 1999).

O Complexo Estuarino de Santos é subdividido em três sistemas estuarinos interligados, Sistema Estuarino do Canal do Porto de Santos, Sistema Estuarino de São Vicente e Sistema Estuarino Canal de Bertioga (Figura 2). O Sistema Estuarino do Canal do Porto de Santos compõe a região do Canal do Porto, Canal de Piaçaguera e Largo do Canaéu, os principais rios que deságuam no sistema são o rio Cubatão Mogi, Piaçaguera e Quilombo. Este sistema conecta-se ao Sistema Estuarino de São Vicente por um canal denominado rio Casqueiro. O Sistema Estuarino de São Vicente, por sua vez, é composto do canal de São Vicente, Mar Pequeno, Largo de São Vicente e Largo da Pompeda, os seus principais afluentes são os rios Boturoca, dos Bagres, Caxeta e Acaráu. O Sistema Estuarino Canal de Bertioga estende-se desde o Largo do Candinho até o município de Bertioga, separando a llha de 
Santo Amaro do continente, e os seus principais afluentes são os rios Cumau, Cabuçu,Trindade e Itapanhau. Estes três sistemas encontram-se interligados, e se ligam ao oceano em regiões distintas (CODESP, 2008).

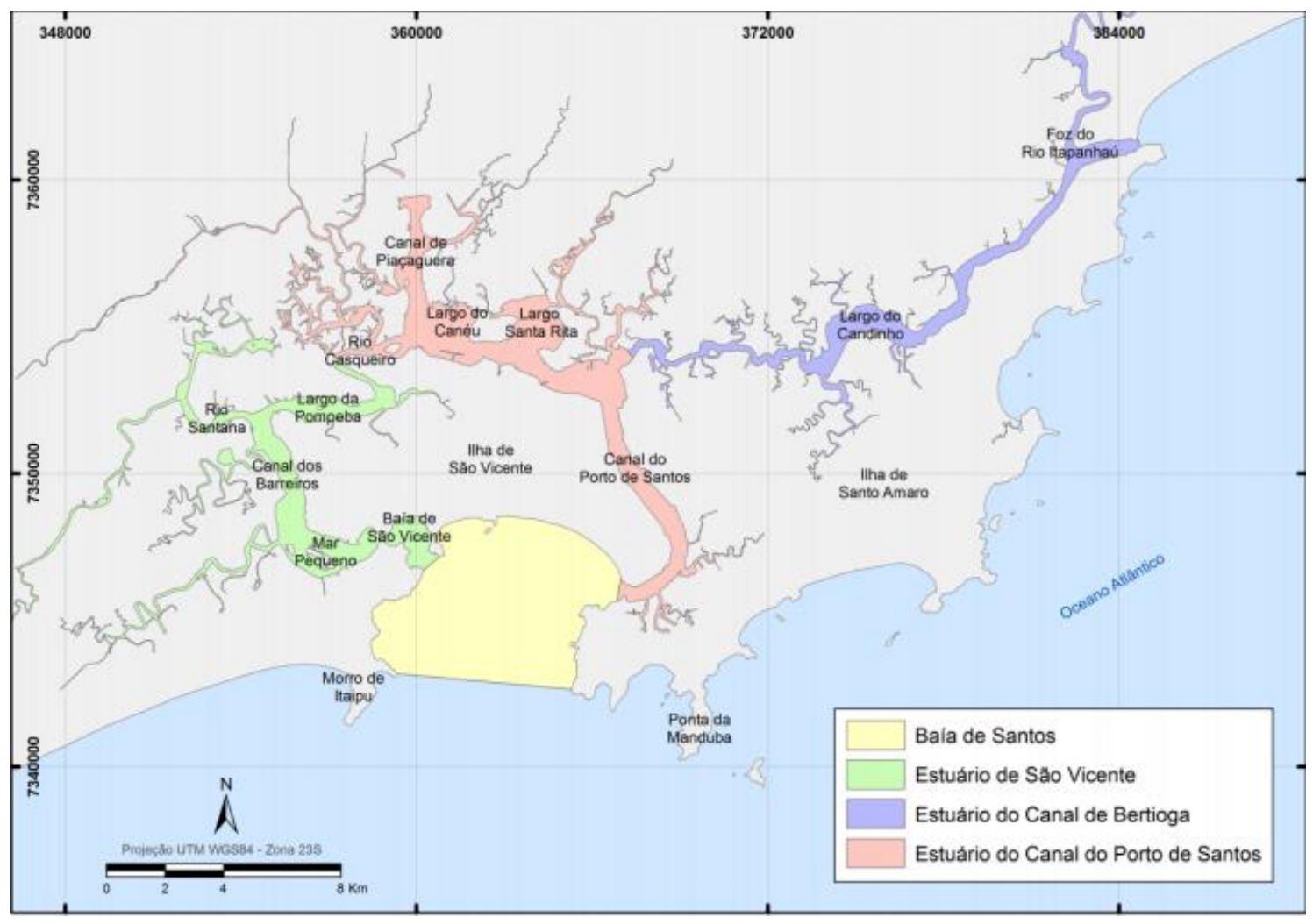

Figura 2 - Localização dos Estuários de São Vicente, Santos e Bertioga e da Baía de Santos (Datum WGS84 Projeção UTM Zona 23S) (Roversi, 2012).

A comunicação do Complexo Sistema Estuarino de Santos ocorre na porção noroeste da llha de Santo Amaro e na comunicação dos Canais de Santos e São Vicente com a Baía de Santos. Essa última tem sua hidrodinâmica influenciada baroclinicamente pela descarga de águas mixohalinas e barotropicamente pelas entradas de sistema frontais e pelo sinal de maré astronômica, principalmente nas variações semidiurnas solares e lunares (Harari, et al., 2002). As forçantes barotrópicas regem a circulação da baía e dos canais, dentre os quais o Canal do Porto apresenta as maiores velocidades do sistema estuarino, principalmente próximo à baía (Harari \& Camargo, 1998; Roversi, 2012). 
A Baía de Santos possui orientação Norte-Sul, estando exposta a ação de ondas de sul. Consequentemente, ondas provenientes deste quadrante atingem a costa com maior energia do que as oriundas de outras direções. Após a dragagem do canal, estudos de modelagem numérica de ondas, demonstram que a maior energia e altura de onda esta na porção leste da Baía de Santos (Cassiano, et al., 2008).

A linha de costa é elaborada em um único arco praial orientada LesteOeste e as praias da orla são divididas em canais de drenagem e pelo emissário submarino, todos construídos perpendicularmente a linha de costa (Figura 3). As praias que dividem o arco praial de oeste para leste são: Itararé, José Menino, Pompéia, Gonzaga, Boqueirão, Embaré, Aparecida e Ponta da Praia. Com exceção da Ponta da Praia, as outras praias apresentam aproximadamente um quilômetro de extensão (Manzano, 2009). Quanto a característica da Ponta da Praia, a mesma se encontra em situação erosiva com comportamento dissipativo (Italiani, 2014). Em frente a praia de José Menino encontra-se a ilha de Urubuqueçaba que atua como zona de sombra formando periodicamente um tombolo natural decorrente da difração de onda (Rocha, 2003). No município de São Vicente está à praia de Itararé e no canto oeste desta praia a llha Porchat.O tombolo que foi artificialmente fixado para ligar a ilha ao continente barrando os sedimentos transportados até a Praia dos Milionários, esta última está em estado erosivo avançado (Farinnaccio, et al., 2009). A noroeste da llha Porchat, no município de São Vicente, encontra-se a praia do Gonzaguinha. Na ilha de Santo Amaro, em frente a Ponta da Praia, encontra-se a Praia do Góes com características dissipativas e dinâmica de rotação praial (Souza, 2015). 


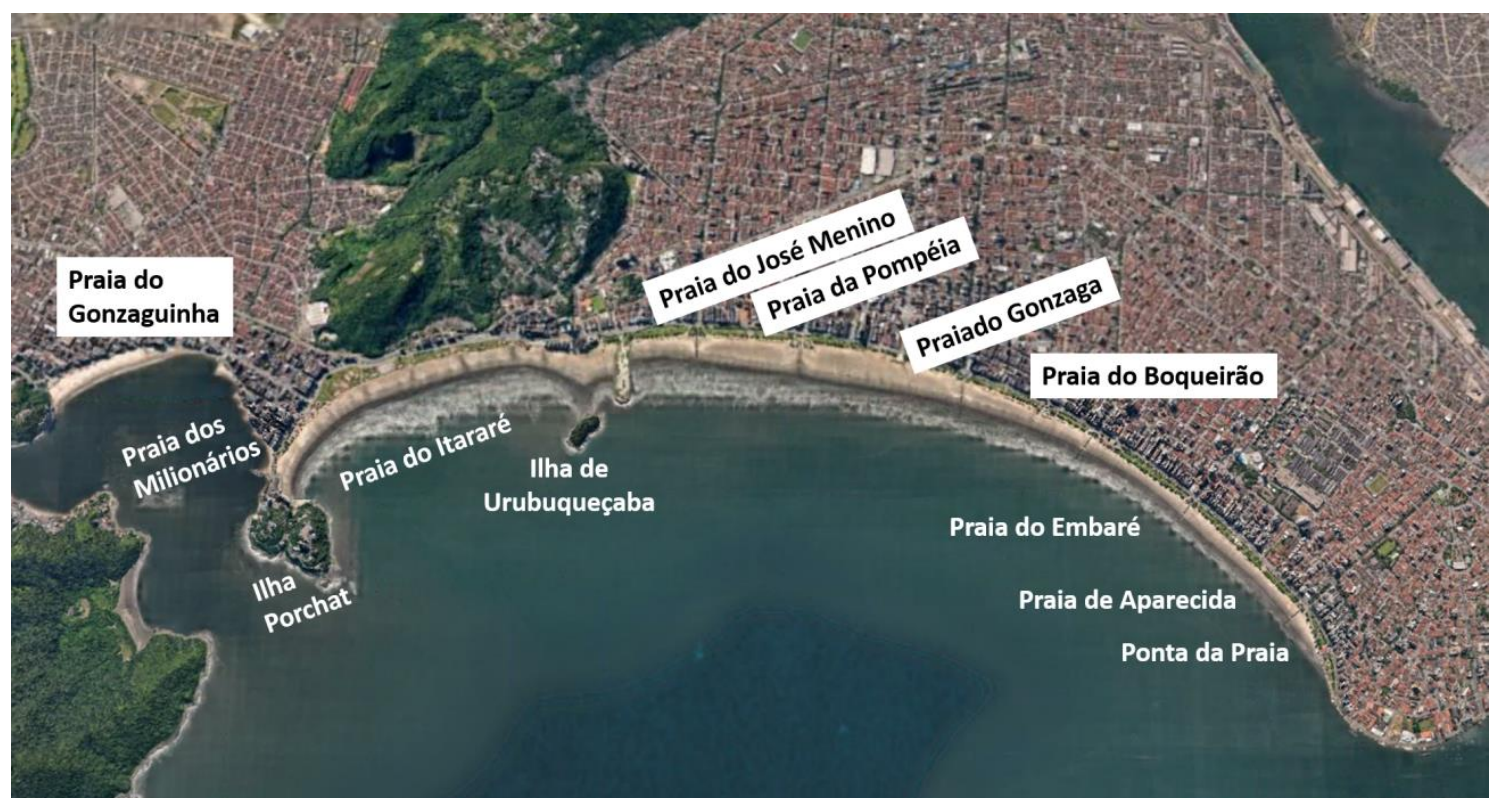

Figura 3 - Localização das Praias de Santos e São Vicente.

O desenvolvimento das feições de fundo da Baía encontra-se com o Canal de Navegação. Há um gradiente batimétrico de sul para norte e a porção oeste da baía encontra-se relativamente mais rasa que a porção leste. De modo geral, a baía é composta de sedimentos com fração de areia, e os sedimentos mais finos são encontrados em regiões específicas da baía (Rocha, 2003). Quanto às zonas deposicionais, Rocha (2003) observou uma zona ao sul da llha Porchat de sedimentos oriundos tanto do Canal do Porto quanto do Canal de São Vicente e outra na região centro-oeste da Baía de Santos. Quanto a principal região de transporte, a autora verificou que o sedimento ruma de Sul para Norte da baía pela porção leste. Além destas zonas, Fukumoto (2003) observou uma região propensa à deposição de sedimentos na região da desembocadura do Canal do Porto. Uma outra interpretação do transporte sedimentar foi apresentada em Ponçano (1985), nesta interpretação, segundo o autor, o sedimento da parte leste da baía é fornecido pelo estuário de Santos e carreado para a região oceânica enquanto que a oeste o sedimento é trazido da região oceânica até o estuário de São Vicente onde ruma leste nas regiões mais rasas. 


\section{Objetivos}

O objetivo geral deste trabalho consiste na representação da maré meteorológica na região de Santos - São Vicente, avaliando a sua influência na dinâmica sedimentar da área. Objetivos específicos são:

- Representar o empilhamento de água sobre a costa baseado em ventos fornecidos por modelos meteorológicos globais de reanálise.

- Detectar as frentes frias que melhor representam o cenários propostos para a avaliação do transporte sedimentar sobre o sistema praial.

- Validar o modelo numérico através de dados coletados em campo para garantir a qualidade da representação dos fenômenos estudados.

- Representar a interação entre a circulação estuarina e a passagem de sistemas frontais de forma a propiciar o transporte de sedimentos deste tipo de evento.

- Representar as condições do transporte de sedimento na região do embaiamento de Santos e nos Canais do Porto e de São Vicente e praias adjacentes.

- Inferir o destino do sedimento sobre efeitos de maré meteorológica para a região de Santos - São Vicente

- Determinar os setores de erosão e deposição em desequilíbrio

- Verificar os setores que não conseguem se recuperar os processos erosivos ou deposicionais em períodos inferiores a possível passagem de uma nova frente fria. 


\section{Metodologia}

Para a realização da análise de transporte sedimentar e resiliência morfodinâmica do estuário santista às passagens de frentes frias, o trabalho usa uma abordagem combinada entre a detecção de frentes frias e suas características, com três experimentos numéricos. As características das variáveis associadas a frentes frias (e.g. vento, ondas, nível do mar) formam as condições de contorno para os experimentos numéricos.

Os resultados dos são analisados de forma comparativa para estabelecer a condição típica do transporte de sedimento e qual a influência de eventos de frentes frias sobre o Complexo Estuarino de Santos

\subsection{Detecção das frentes frias}

Para o processo de detecção das frentes frias, foram utilizados dados atmosféricos e de nível do mar em relação ao geóide provenientes da base de dados do National Centers for Environmental Prediction (NCEP) Climate Forecast System Reanalysis (CFSR) versões 1 e 2. O CFSR é um produto de reanálise de terceira geração que acopla os sistemas oceano-atmosfera-terragelo, seus resultados são produzidos através da assimilação de dados de satélite, modelos interativos oceano-gelo e acoplamento entre modelos oceano-atmosfera. A resolução temporal é horária. Seus resultados possuem resolução horizontal de $0,5^{\circ}$ a $0,2^{\circ}$ temporal horária e resolução vertical de 64 níveis isobáricos (até $0.2 \mathrm{hPa}$ ) para a atmosfera, 40 níveis sigma para o oceano até $4737 \mathrm{~m}$ de profundidade, 4 níveis de solo para a terra e 3 para o gelo. $O$ modelo inclui as observações das variações de dióxido de carbono junto com outros aerossóis e variações solares. Juntos estes parâmetros incluem as mudanças ocorridas no sistema climático ao longo da série de dados do modelo. Os resultados da modelagem oceano-atmosfera do CFSR versão 1 contemplam uma série de dados, de 01 de janeiro de 1979 a 31 de dezembro de 2010, que apresenta resolução espacial de $0,5^{\circ}$, em alguns casos resolução de 0 ,3. Já a versão 2 contempla o período de 01 de janeiro de 2010 até 0 presente, e os dados de maior refinamento com resolução espacial de 0,2 $\varrho$ ambos com pontos de grade para todo o globo (Saha, et al., 2010; Saha, et al., 2014). 
A detecção de frentes frias está baseada na análise integrada de elementos atmosféricos característicos da física envolvida na passagem deste sistema. Para a região Sul e Sudeste do Brasil, Cavalcanti et al. (2016) propuseram a análise de variações bruscas na temperatura do ar, componente meridional do vento, a anomalia espacial da altura do geopotencial e a análise da pressão atmosférica. $\mathrm{Na}$ análise integrada apresentada, o autor sugere que seja verificado, ao longo de um período de 48 horas os seguintes parâmetros:

- Variações de mais de dois graus Celsius na temperatura do ar;

- Aumento da pressão;

- Diminuição da anomalia da altura do geopotencial;

- Intensidade do vento superior a $2 \mathrm{~m} / \mathrm{s}$,

- Inversão da direção da componente meridional do vento (que em condições normais é proveniente de norte e durante a passagem de um sistema frontal o vento torna-se mais intenso e oriundo de sul.);

Para a detecção das frentes frias, foram utilizados dados de temperatura do ar a $500 \mathrm{hPa}$, altura do geopotencial a $500 \mathrm{hPa}$, a componente meridional e zonal (usada para o cálculo da intensidade) do vento a 10 metros de altura e a pressão no nível do mar. Todos estes dados foram obtidos do CFSR versões 1 e 2 para a grade de resolução espacial de $0,5^{\circ}$ para todo 0 período de dados disponíveis (de 01 de janeiro de 1979 até 22 de novembro de 2015). O ponto de análise utilizado encontra-se na latitude de $24,25^{\circ} \mathrm{S}$ e longitude de $46,25^{\circ} \mathrm{W}$, sendo este um ponto representativo do clima no estuário Santista e com distância suficiente da costa para que os parâmetros meteorológicos resultados não sofram interação direta com o continente.

Primeiramente para o cálculo da anomalia espacial da altura do geopotencial, campos médios foram calculados (entre as coordenadas de $35,00^{\circ} \mathrm{S}$ a $-19,00^{\circ} \mathrm{S}$ e $-30^{\circ} \mathrm{W}$ a $-50^{\circ} \mathrm{W}$ ) para cada passo de tempo dos dados. Estes valores médios foram subtraídos do ponto de análise para o respectivo passo de tempo (uma hora).

Devido ao período de duração de uma frente fria, o sinal de fenômenos de maior frequência é por vezes detectado na série temporal. Portanto, buscouse remover o sinal destes fenômenos para que este não interferisse na análise 
mascarando sinais indicativos da passagem de frentes frias. A remoção destes sinais foi realizada através da aplicação de um filtro de janelas móveis do tipo Blackman (Stoica \& Moses, 1997) para todo conjunto de dados.

Este filtro é aplicado pelo método da convolução entre a série de dados e a janela para cada ponto. Isso significa que a aplicação do filtro em um ponto consiste no cálculo da média ponderada dos dados para o tamanho da janela. Ou seja, para um ponto $A_{n}$ selecionam-se os dados de $A_{n-w}$ e $A_{n+w}$ onde $n$ é o índice do dado ao longo da série e w corresponde a metade do tamanho da janela. Em seguida, calcula-se a média ponderada destes dados, sendo os pesos da média correspondentes aos valores da janela e o resultado é colocado no ponto $A_{n}$. Para evitar que a série reduzisse de tamanho na aplicação da convolução, buscou-se replicar a meia janela dos dados inicias e finais da série de forma espelhada nas bordas da série antes de aplicar o filtro. A equação que descreve o processo de filtros em janela é apresentada a seguir onde $g$ é a série do filtro, f é a função a ser filtrada e $k$ é o índice que varia de 0 a $2 n-2$ sendo $n$ o tamanho da série, $f$ e $h$ é a série resultante.

$$
(f * g)(k)=h(k)=\frac{\sum_{i=0}^{k} f(i) \cdot g(k-i)}{\sum_{j=0}^{i} f(i)}
$$

No caso do presente trabalho, a janela escolhida foi da família das cossenoidais, pois este tipo é o mais recomendado para a aplicação da convolução em séries com vários sinais e o tipo escolhido foi a janela Blackman pautada na maior priorização dos valores centrais em relação aos seus vizinhos quando comparada com outras janelas (Gaussiana, Tukey, Hanning e cosseno simples), este fato reduz a atenuação do sinal que ocorre durante o processo.

Para a detecção das frentes frias, o tamanho da janela foi de 48 horas (ou 48 passo de tempo) visto que frentes frias tendem a durar mais de dois dias (Farinnaccio, et al., 2009; Cavalcanti, et al., 2016).

Dos resultados da série, após o processo de filtragem, períodos de no mínimo dois dias foram selecionados, nos quais a componente meridional do vento encontrava com valores inferiores a zero (vento de sul) e a intensidade 
do vento superior a $2 \mathrm{~m} / \mathrm{s}$. Estas datas foram separadas e os gradientes e derivadas segundas da temperatura, componente meridional do vento, pressão e anomalia do geopotencial foram calculados. Do resultado destes cálculos considerou-se condição de frente fria onde havia um gradiente resultante descendente e a derivada segunda resultante positiva para:

- anomalia do geopotencial

- temperatura

- componente meridional do vento

e um gradiente resultante ascendente e a derivada segunda resultante negativa para:

- pressão reduzida ao nível do mar

Dentre os períodos encontrados escolheu-se o período de frente fria extrema (FFE) e de frente fria "média" (FFM). Para a data da condição de FFE os valores foram ordenados segundo a frente e o período que apresentou maior nível do mar médio e duração de aproximadamente 60 horas foi escolhido. Para a condição de FFM buscou-se o período de frente com valores de nível médio, nível máximo, vento médio e vento máximo mais próximos dos valores mais prováveis (mediana) de cada um destes parâmetros.

Por fim, para as séries de ondas, utilizou-se dados de reanálise do modelo global WaveWatchlll (WW3) também disponibilizados pelo NCEP (Tolman, 2014). O modelo WW3 é um modelo de ondas espectral de terceira geração utilizado inicialmente para a solução de ondas de gravidade em águas profundas, os resultados deste modelo são amplamente utilizados como inputs de modelos de com soluções de ondas de águas rasas ou soluções para quebra de ondas (Zijlema, et al., 2011). Atualmente o WW3 se propõe a resolver a propagação de ondas profundas até a quebra da onda, para tal o modelo inclui efeitos de swell, desenvolvimento do campo de ondas, refração, friç̧ão de fundo, dissipação, quebra da onda, interação da onda com o fundo. A discretização espectral do modelo considera todas as direções de propagação de onda e a discretização pela frequência é determinada por cálculos implícitos (Tolman, 2014).

Os dados disponíveis pelo NCEP são uma reanálise da aplicação do WW3 para todo o globo através de dados de vento, temperatura da água do 
mar e cobertura de gelo, gerados pelo próprio NCEP e aplicados em uma grade com resolução espacial de $0,5^{\circ} \times 0,5^{\circ}$ e temporal de uma hora. Esta rodada também realiza assimilação de dados de boias de ondas, o que mantém o modelo mais fidedigno a realidade, principalmente por tratar-se de rodadas de previsão para até uma semana.

Foram utilizados dados de altura significativa, período e direção de pico na latitude de $24,25^{\circ} \mathrm{S}$ e longitude de $46^{\circ} \mathrm{W}$ com passo de tempo de 3 horas. Destes dados, calculou-se uma situação de característica de onda média para o cenário SFF e obtiveram-se os dados de ondas que compreendessem os períodos de FFM e FFE.

\subsection{Modelagem numérica}

Para o presente trabalho, buscou-se escolher a abordagem da modelagem numérica para o entendimento do processo de transporte sedimentar. O modelo escolhido para o presente trabalho foi o XBeach versão King's Day (1.22).

O XBeach é um modelo numérico open-source desenvolvido originalmente para simular hidrodinâmicamente e morfodinamicamente processos e impactos de eventos de alta energia em costas arenosas com dimensão de quilômetros, validado principalmente na região de portos e estuários. Atualmente o modelo tem sido aplicado para outros tipos de costas e propósitos (Beevers, et al., 2016). O XBeach é um modelo essencialmente barotrópico e espectral que representa os processos de transformação de ondas curtas (ondas de gravidade) e longas (infragravidade) indução do setup de onda, relação entre correntes e ondas, inundação, quebra de ondas e sobrelavagem, bem como a indução de correntes por diferença do nível do mar e a transferência de energia entre os ventos e o corpo d'agua. Os processos morfodinâmicos incluem transporte de sedimento de fundo e em suspensão, avalanche, atualização topobatimétrica e rompimentos de feições. Além destes fenômenos efeitos de regiões vegetadas, navegação e estruturas rígidas podem ser aplicadas. O modelo apresenta modos 1D e 2DH e dois tipos de solução numérica uma hidrostática e outra não hidrostática o que depende do tempo computacional e grau de detalhamento da solução das ondas desejada. 
A seguir são apresentados mais detalhes sobre o modelo numérico.

\subsubsection{Grade numérica}

A elaboração da grade numérica do modelo XBeach pode ser curvilínea, irregular ou regular, sempre em valores métricos (ou coordenadas UTM). A configuração da grade determinará as regiões das bordas do modelo como apresentado na Figura 4. A borda de frente (front) representa a borda mais oceânica e a borda de trás (back) a borda mais costeira. Neste caso a inserção de dados batimétricos demanda cautela na disposição dos dados, pois é necessário que as regiões ao largo e costeira correspondam com as respectivas bordas do modelo.

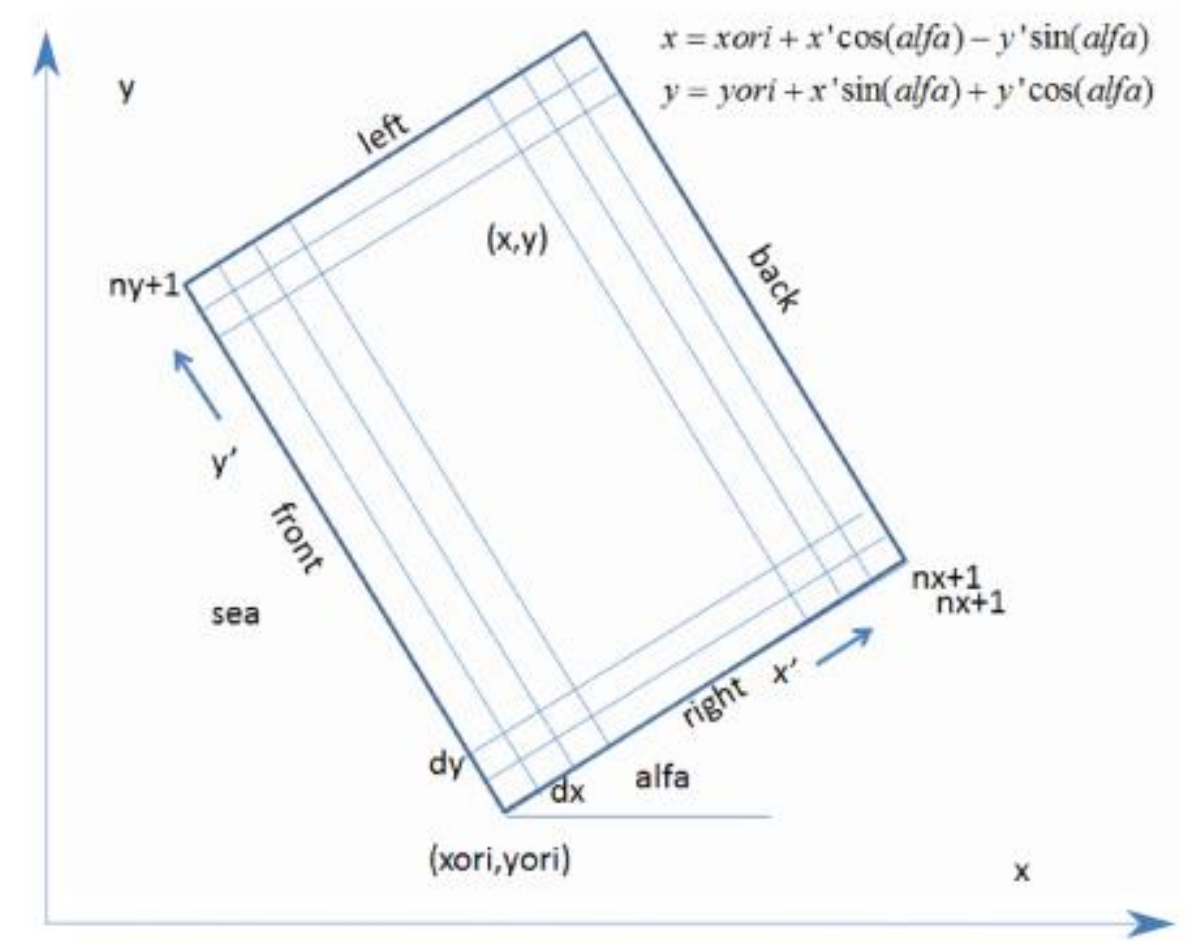

Figura 4 - Exemplo da disposição das bordas do modelo XBeach em função das coordenadas da grade numérica.

A grade numérica utilizada possui 259 células na direção x e 297 células na direção y, sua variabilidade espacial entre a célula de menor e maior resolução é de 2000 - 40 metros, sendo as regiões mais distantes da costa menos resolvidas (Figura 5) e as regiões dos canais e das praias as mais resolvidas (Figura 6). 


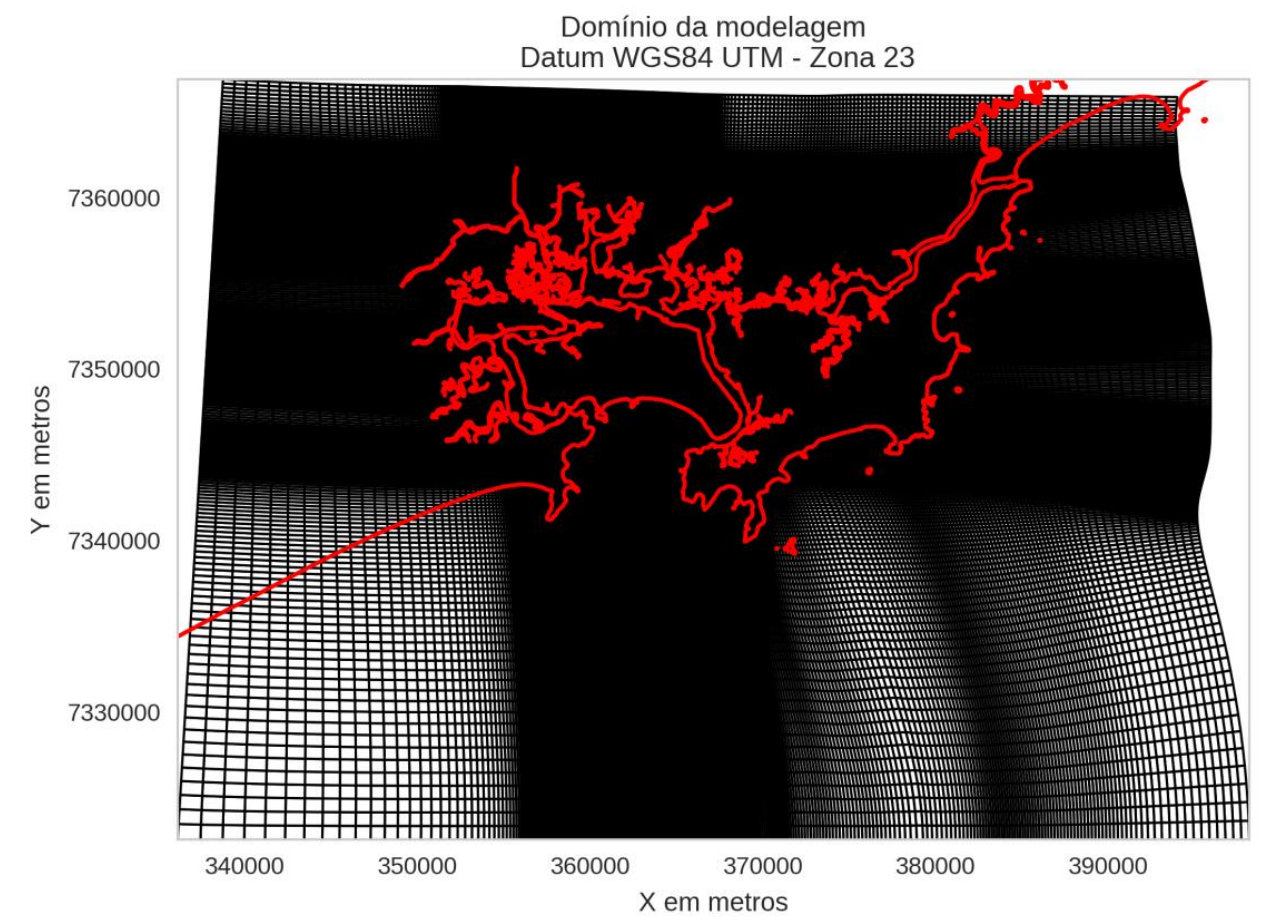

Figura 5 - Grade numérica utilizada na modelagem mostrando a totalidade do domínio. Em vermelho a representação da linha de costa utilizada para elaboração da grade - projeção UTM zona 23 datum WGS84.

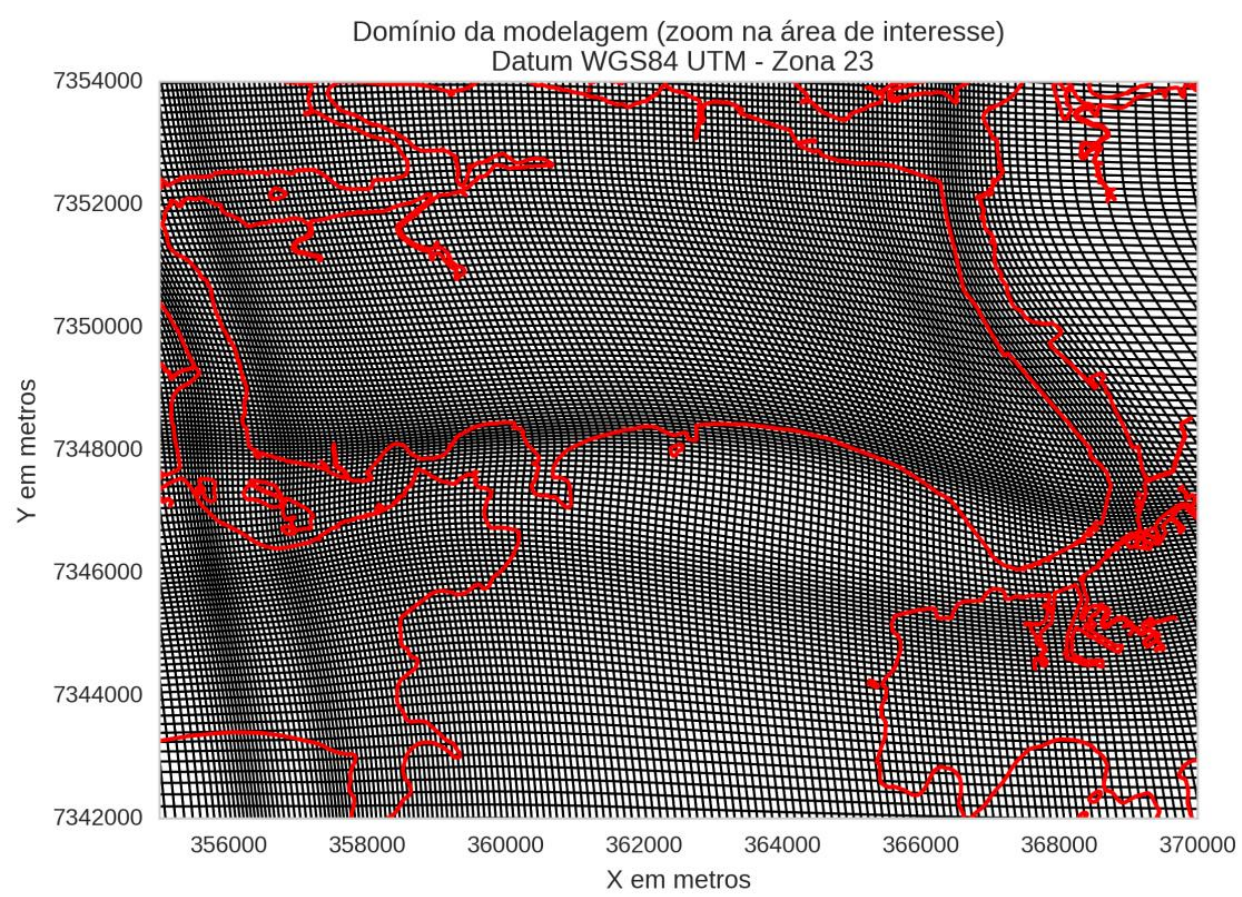

Figura 6 - Zoom na grade numérica utilizada na modelagem mostrando o adensamento nas regiões das praias e dos canais. Em vermelho a representação da linha de costa utilizada para elaboração da grade - projeção UTM zona 23 datum WGS84. 
A cota batimétrica utilizada consiste na interpolação linear entre dados de cartas náuticas, dados da base General Bathymetric Chart of the Oceans (GeBCo) e dados de levantamentos da Companhia de Docas do Estado de São Paulo (CODESP) já corrigidos. A interpolação dos dados para a grade numérica obedeceu a uma ordem de prioridade correspondente a resolução dos dados. Primeiramente, utilizou-se os dados da CODESP que correspondem a levantamentos batimétricos de alta resolução, em seguida preencheu-se as células vazias com informações de cartas náuticas que também correspondem a medidas, e posteriormente com informações do GeBCO que é um produto de interpolação topobatimétrica com resolução de aproximadamente $1 \mathrm{~km}$. Por fim, aplicou-se uma interpolação linear para 0 preenchimento das células que ainda permaneceram vazias. Deste modo buscou-se a representação mais realista possível da topografia de fundo. Para as regiões de manguezais, considerou-se uma topografia passível de alagamento parcial para equilibrar o prisma de maré da região. Por fim, os dados acima de $10 \mathrm{~m}$ do nível do mar foram transformados em $10 \mathrm{~m}$, de forma a representar as regiões não alagáveis. Dessa forma praias e manguezais puderam ser considerados regiões que são inundadas periodicamente de acordo com o nível da maré. Estas mesmas regiões de 10 metros acima do nível do mar foram consideradas não erosivas ao longo do processo de modelagem, todas as outras regiões foram consideradas com pacotes de 10 metros de sedimento. $O$ produto final deste processo de interpolação é apresentado na Figura 7 e Figura 8 


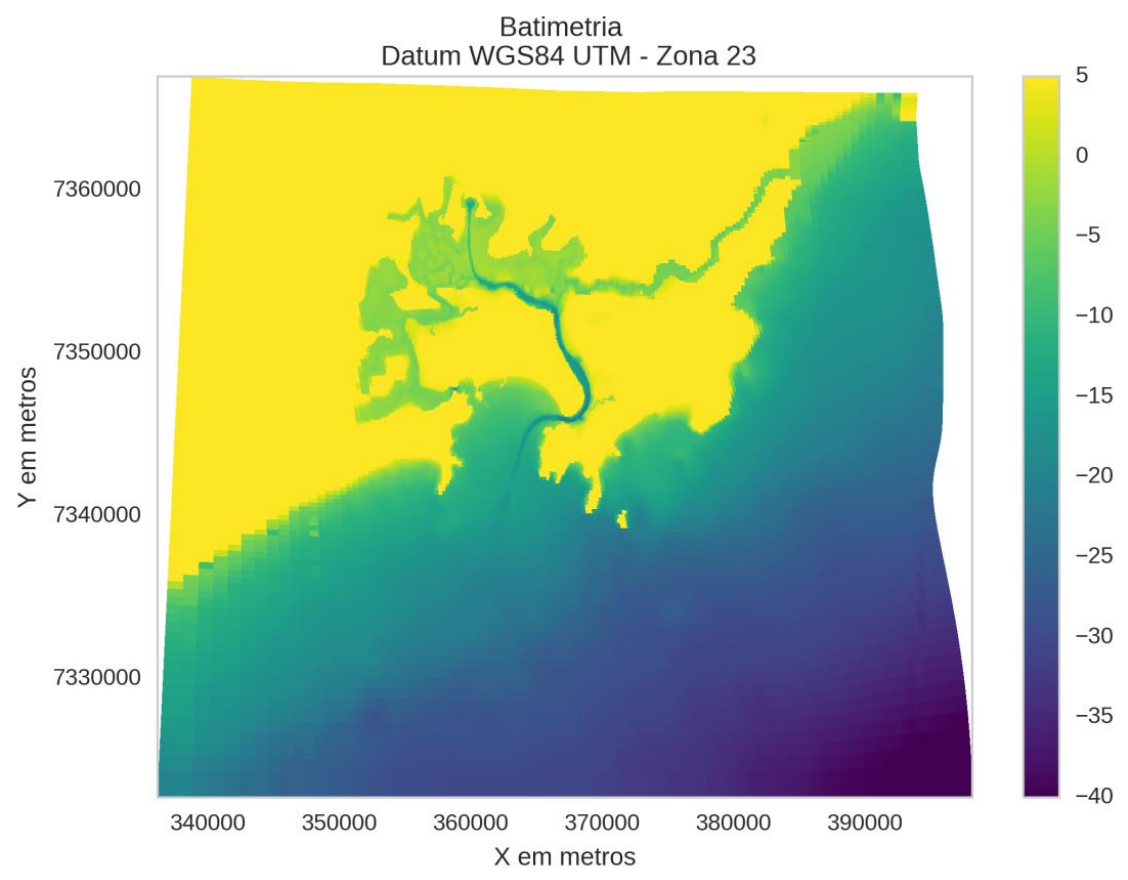

Figura 7 - Elevação de todo o domínio da modelagem, observa-se o canal de navegação aprofundado no processo de dragagem do porto de Santos ao longo do Canal do Porto, as ilhas de Santos e Guarujá, e as regiões de manguezais ao norte da ilha de Santos que foram criadas permitindo $o$ alagamento das mesmas - projeção UTM zona 23 datum WGS84. 


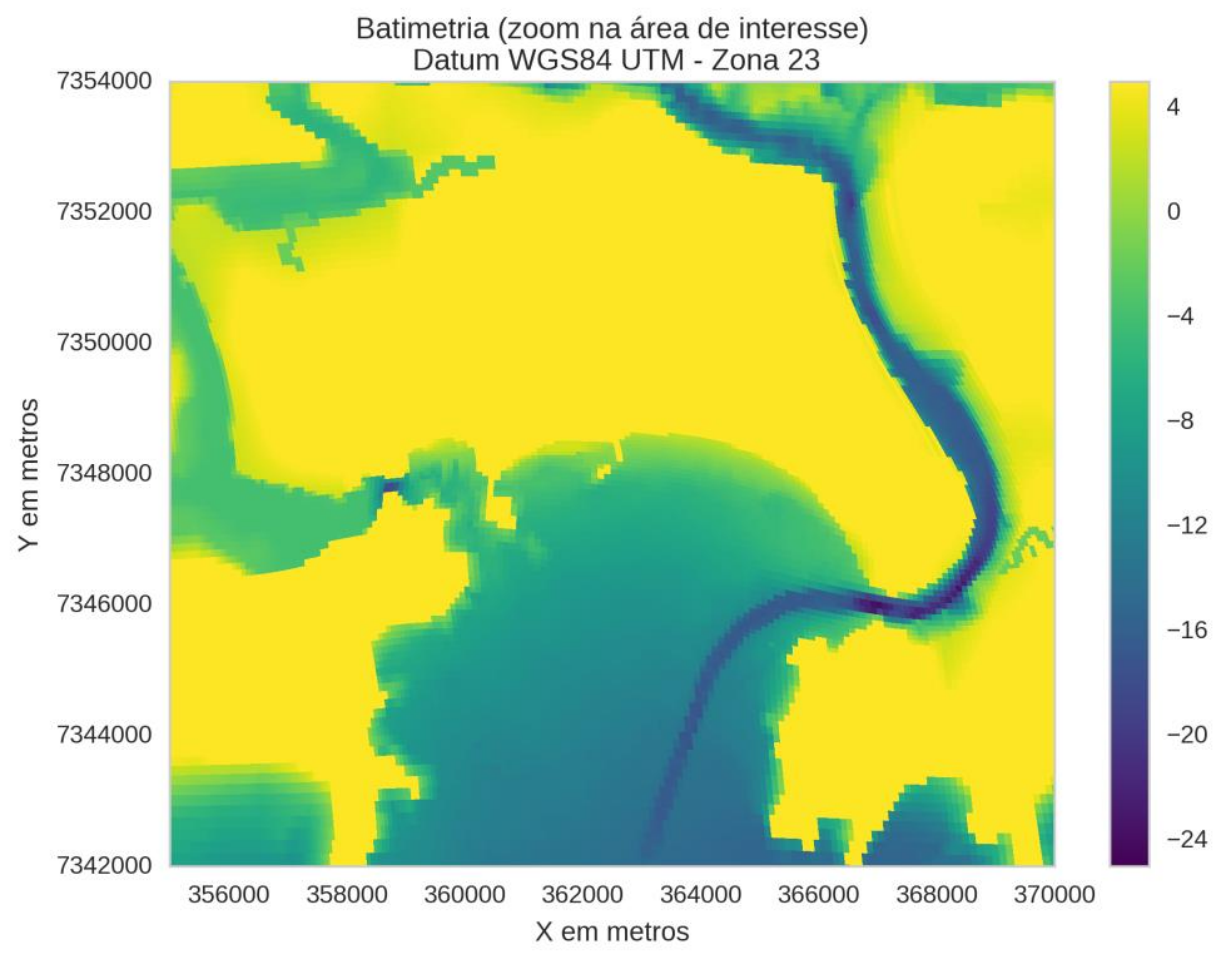

Figura 8 - Elevação do domínio da modelagem com zoom na região dos canais e praias de Santos e São Vicente, observa-seclaramente a representação do canal do porto da ilha de urubuqueçaba e de alguns rios, do quebramar e de uma área alagável na ilha do Guarujá ao norte - projeção UTM zona 23 datum WGS84.

Sendo o XBeach um modelo espectral de ondas, além da grade geográfica há também a necessidade de se elaborar uma grade espectral. Este conceito de grade descreve o espectro de ondas em um dado intervalo de tempo (passo de tempo) considerando a energia da passagem de diversas ondas em diversas direções com diversos períodos ou frequências (como em um ondógrado) em seguida o modelo integra este resultado calculado uma altura significativa, período e direção média e de pico. No caso do modelo implementado, a grade espectral compreende um círculo dividido em 36 direções uniformemente (espaçadas, embora o modelo tenha desconsiderado as direções entre noroeste e nordeste na borda visto a orientação da baía) com círculos concêntricos representando o período a cada 0.1 segundos dependendo do período médio observado. 


\subsubsection{Implementação do modelo numérico}

O modelo numérico implementado inclui os seguintes parâmetros e constantes:

\section{Processos físicos}

- Ondas curtas

- Fluxo

- Vento

- Advecção

- Trasporte de sedimento

- Variação Morfológica

\section{$\underline{\text { Constantes físicas }}$}

- $\mathrm{Rho}=1025$

- Gravidade $=9.81$

- Depthscale $=1$

\section{Ondas}

- Espectro JONSWAP

- $\mathrm{Nmax}=0.8$ (relação entre a celeridade de grupo de da onda que será aceita)

- Lateralwave=neumman

\section{Espectro da onda}

- $\mathrm{RT}=3600$ (duração do espectro)

- $\mathrm{Dtbc}=1$ (discretização temporal do espectro )

- Nspectrumloc=1(Espectro de ondas igual pra mesma borda, devido a resolução do WW3)

- Sprdthr = 0.8 (limiteda relação da energia máxima por bins que o espectro aceita)

\section{Quebra de onda}

- gamma $=.5500$ (coeficiente de dissipação)

- alpha $=1.0000$ (coeficiente de dissipação)

- $\mathrm{n}=10$ (intensidade do parametro de dissipação) 
- gammax =2 (maxima razão entre a altura de onda maxima e a profundidade)

- delta $=0.5$ (fração da onda adicionada ao níve)

- O coeficiete de fricção é aplicado em todo o domínio

- Modelo de delay de quebra de onda

- Modelo de rolamento ativado

Bordas hidrodinamico

- front =absorção-geração $2 \mathrm{~d}$

- $\quad$ left $=$ Neumann

- $\quad$ right $=$ Neumann

- back = terra

- Reflexão de onda

- Relação de transporte entre as partículas, ondas e correntes foi desativada e, portanto sempre ocorre sem valor definido

- Bordas com ondas longas e curtas

Interação onda-corrente

- $\quad$ hwci $=1$ (profundidade minima para a interação de onda corrente)

- cats =4.0000 (tempo para calculo da corrente media em períodos de onda)

Coeficientes de friçãao e viscosidade

- bedfriccoef $=55.0000$ (chezy)

- nuh $=0.1000$ (constante da viscosidade)

Vento

- Densidade do ar $=1.25 \mathrm{~kg} / \mathrm{m}^{3}$

- $\mathrm{Cd}=0.0020$ (atrito)

\section{Transporte de sedimento}

- Transporte turbulento por ondas curtas e longas

- Deslizamento

- O cálculo de sedimento suspenso foi baseado da velocidade de queda e não na concentração

- facsl $=1.6000$ (fator de deslizamento) 
- z0 =.0060 (espessura da camada nefelóide ainda não consolidada)

- tsfac $=0.1000$ (timestep do calculo de transporte de sedimento)

- facua $=0.1000$ (relação do fluxo onda assimetria e empinamento)

- facSk =0.1000 (Fator de fluxo durante o empinamento da onda)

- $\operatorname{facAs}=0.1000$ (Fator temporal entre a assimetria da onda e fluxo gerado)

- betad $=1.0000$ (fator de dissipação da onda longa)

- bed $=1$ (fator do transporte de fundo)

- $\operatorname{facDc}=1.0000$ (coeficiente de difusão)

Composição de fundo

- $\mathrm{ngd}=1$

- $\mathrm{nd}=1$

- porosidade $=0.4000$

- $\mathrm{D} 50=.0001$

- $\mathrm{D} 90=.0003$

- Densidade do grão $=2650.0000$

- $\mathrm{dzg}=.1000$ espessura da camada sedimentar

- Apenas uma camada de sedimento

- O sedimento é transportado pela velocidade crítica de transporte

\section{Morfologia}

- $\operatorname{morfac}=24$

- wetslp =.1500 (declividade de avalanche de na batimetria abaixo da agua)

- dryslp =1.0000 (declividade de avalanche de na batimetria fora da água)

- hswitch $=.1000$ (determinante de zonas secas e molhadas)

- Foram consideradas regiões de estruturas não erosivas

\subsubsection{Processos Hidrodinâmicos}

Dentre as soluções numéricas oferecidas pelo XBeach, para o presente estudo, a abordagem da grade foi no modo $2 \mathrm{DH}$ com solução numérica de 
ondas hidrostática, e com aceleração dos processos morfodinâmicos. Os processos físicos abordados na modelagem bem como as equações e justificativas para as escolhas são apresentados abaixo.

O XBeach possui 3 módulos para a solução hidrodinâmica, o estacionário, o hidrostático e o não-hidrostático. Dentre os módulos apresentados o módulo estacionário se mostrou inadequado, pois não permite processos de variação do espectro de ondas com o tempo, negligenciando efeitos da variação do campo de ondas entre fenômenos extremos e não extremos. Dos outros dois módulos restantes, o hidrostático e o nãohidrostático, ambos estão aptos para a resolução das praias santistas. Ambos são úteis para a solução de efeitos de alta energia em praias dissipativas, todavia a escolha foi pautada no tempo de processamento, que neste caso é menor na solução hidrostática reforçada pelo maior número de validações deste módulo.

Basicamente o módulo escolhido resolve movimentos de ondas curtas na escala de tempo dos grupos de onda. $\mathrm{O}$ armazenamento de momentum após a quebra de onda é representado através do modelo de dissipação que inclui o grupo de ondas e o modelo de rolamento. Essas variações permitem que as ondas de infragravidade exerçam força sobre a coluna d'água sendo computadas na formação das correstes resultantes dos gradientes de tensão radial. Portanto os movimentos sobre as zonas de praia induzidos por ondas de longo e curto período, vento local, correntes induzidas por ventos e movimentos de swash são incluídos neste módulo. Permitindo uma representação completa dos principais movimentos na zona costeira. Consequentemente este módulo se apresenta adequado para processos de transporte de sedimentos na zona costeira onde a quebra de ondas é induzida por gradientes topobatimétricos suaves como o caso da área de estudo do presente trabalho.

\section{Ação de ondas de áquas rasas}

O movimento das ondas de águas rasas é calculado pelo balanço entre a conservação de energia das ondas e a sua dissipação, denominado ação de ondas. A equação que rege este movimento é: 


$$
\frac{\partial A}{\partial t}+\frac{\partial c_{g y} A}{\partial y}+\frac{\partial c_{g x} A}{\partial x}+\frac{\partial c_{\theta} A}{\partial \theta}=\frac{D_{w}+D_{f}+D_{v}}{\sigma}
$$

Onde D representa os termos dissipativos de ondas (w), fricção de fundo (f) e vegetação (v); t, x,y, $\theta, \sigma$ descrevem a onda no tempo, direção zonal e meridional, direção e período do espectro respectivamente; e A representa a ação de ondas que é descrita por:

$$
A(x, y, t, \theta)=\frac{S_{w}(x, y, t, \theta)}{\sigma(x, y, t)}
$$

Onde $S_{w}$ representa a densidade espectral da energia de onda para cada direção. E a frequência $\sigma$ é descrita por :

$$
\sigma=\sqrt{g k \tanh (k h)}
$$

$E$ as velocidades de propagação do grupo de ondas $C$ para as dimensões horizontais e da direção espectral são descritas por:

$$
\begin{gathered}
C_{g x}(x, y, t, \theta)=C_{g} \cos (\theta) \\
C_{g y}(x, y, t, \theta)=C_{g} \sin (\theta) \\
C_{\theta}(x, y, t, \theta)=\frac{\sigma}{\sinh (2 k h)}\left(\frac{\partial h}{\partial x} \sin \theta-\frac{\partial h}{\partial y} \cos \theta\right)
\end{gathered}
$$

Onde $\mathrm{h}$ representa a profundidade local, $\mathrm{k}$ o numero de onda, e $\mathrm{g}$ a gravidade. O último termo da equação que descreve a velocidade de propagação da onda no espectro é referente aos efeitos de refração que a onda sofre ao longo da sua propagação.

\section{$\underline{\text { Interação onda-corrente }}$}

As interações entre corrente e ondas são baseadas na transferência de energia entre o fluxo e a onda, consequentemente, uma afeta o outra e vice 
versa. Sendo um fenômeno importante na descrição de processos de correntes de deriva litorânea e correntes de retorno. No modelo XBeach, este fenômeno faz a correção no número de ondas impactando a velocidade de propagação do grupo de ondas. O número de ondas é descrito espacialmente na direção perpendicular $\left(k_{x}\right)$ e paralela $\left(k_{y}\right)$ à costa. E o número de ondas é descrito como:

$$
\begin{aligned}
& \frac{d k_{x}}{d t}+\frac{\partial \omega}{\partial x}=0 \\
& \frac{d k_{y}}{d t}+\frac{\partial \omega}{\partial y}=0
\end{aligned}
$$

E o número de ondas é dado por :

$$
k=\sqrt{k_{x}^{2}+k_{y}^{2}}
$$

A frequência radial é calculada por :

$$
\omega=\sigma+k_{x} u^{L}+k_{y} v^{L}
$$

Onde $u^{L} e v^{L}$ são as velocidades lagrangianas médias para as direções perpendiculares e paralelas à costa. A velocidade de propagação da onda que é afetada pela tensão radial é escrita como:

$$
\begin{aligned}
& C_{x}(x, y, t, \theta)=C_{g} \cos (\theta)+u^{L} \\
& C_{y}(x, y, t, \theta)=C_{g} \sin (\theta)+v^{L}
\end{aligned}
$$

A velocidade de onda na dimensão direcional que é afetada pela tensão radial é descrita adicionando os dois termos de refração de correntes (dois últimos termos). 


$$
\begin{aligned}
C_{\theta}(x, y, t, \theta)= & \frac{\sigma}{\sinh (2 k h)}\left(\frac{\partial h}{\partial x} \sin \theta-\frac{\partial h}{\partial y} \cos \theta\right)+\cos \theta\left(\sin \theta \frac{\partial u}{\partial x}-\cos \theta \frac{\partial u}{\partial y}\right) \\
& +\sin \theta\left(\sin \theta \frac{\partial v}{\partial x}-\cos \theta \frac{\partial v}{\partial y}\right)
\end{aligned}
$$

\section{Dissipação}

Como apresentado anteriormente, 0 modelo divide 0 termos dissipativos em três compartimentos: quebra de onda, fricção de fundo e vegetação. No presente estudo o parâmetro dissipativo referente à vegetação foi desconsiderado.

A quebra de onda possui cinco formulações distintas para ser parametrizada. Dentre estas, duas delas são aplicadas para ondas estacionarias e três para movimentos não estacionários, portanto foram verificados apenas as parametrizações referentes ao módulo não estacionário. Os métodos são referentes aos artigos de (1) Roelvink (1993a) (2) Roelvink (1993b) e (3) (Daly, et al., 2011). Os métodos 1 e 2 consideram que há quebra de onda através da relação entre a altura máxima e a raiz quadrada média da altura de onda, distinguindo-se apenas por considerarem (2) ou não (1) a profundidade como um parâmetro que afeta a quebra de ondas, no terceiro caso, a quebra de ondas é restrita a relação entre a altura máxima e o parâmetro gamma, o que favorece quebra de ondas em praias reflectivas. Em vista das praias dissipativas que fazem parte da área de estudo, adotou-se a solução 2. As equações que regem esta solução numérica são descritas abaixo:

$$
\begin{gathered}
\overline{D_{w}}=2 \frac{a}{T_{r e p}} Q_{b} E_{w} \frac{H_{r m s}}{h} \\
\left.Q_{b}=1-e^{\left(-{ }^{H_{r m s}} / H_{\text {max }}\right.}\right) \\
H_{r m s}=\sqrt{\frac{8 E_{w}}{\rho g}} \\
H_{\text {max }}=\gamma\left(h+\delta H_{r m s}\right)
\end{gathered}
$$




$$
E_{w}(x, y, t)=\int_{0}^{2 \pi} S_{w}(x, y, t, \theta) d \theta
$$

Nestas equações busca-se uma abordagem referente a dissipação média das ondas é relativa a energia total do espectro de ondas $E_{w}$, fração de quebra de ondas $Q_{b}$ e período representativo do espectro $T_{\text {rep }}$ e a relação entre a raiz quadrada da altura média de onda $\mathrm{H}_{\mathrm{rms}}$ com a profundidade. $\mathrm{A}$ altura de onda máxima é determinada pelo parâmetro y e $\delta$. Portanto quando a altura máxima é muito próxima da altura média isso significa que parte da energia de onda foi dissipada pelo processo de quebra e convertida em outro processo.

A dissipação de energia por fricção de fundo afeta as velocidades orbitais das ondas, superfície de elevação, velocidade média da corrente. No modelo XBeach o cálculo deste parâmetro ocorre separadamente sobre a ação de ondas curtas, sendo modelado pela equação abaixo:

$$
D_{f}=\frac{2}{3 \pi} \rho f_{w}\left(\frac{\pi H_{r m s}}{T_{m 01} \sinh k h}\right)^{3}
$$

Onde fw é o coeficiente de friç̧ão de fundo de ondas curtas e Tm01 é o período do espectro de ondas. Para o caso do cálculo da dissipação média, substitui-se Tm01 pelo período de pico Tp.

\section{Tensão Radial}

A tensão radial é responsável pela formação das correntes através da ação das ondas sobre a costa. O modelo XBeach as descreve como:

$$
\begin{gathered}
S_{x x, w}(x, y, t)=\int\left(\frac{c_{g}}{c}\left(1+\cos ^{2} \theta\right)-\frac{1}{2}\right) S_{w} d \theta \\
S_{y y, w}(x, y, t)=\int\left(\frac{c_{g}}{c}\left(1+\sin ^{2} \theta\right)-\frac{1}{2}\right) S_{w} d \theta \\
S_{x y, w}(x, y, t)=S_{y x, w}(x, y, t)=\int \frac{c_{g}}{c} \sin \theta \cos \theta S_{w} d \theta
\end{gathered}
$$




\section{Fricção de Fundo}

A fricção de fundo $\left(\tau_{b}\right)$ é associada com as correntes médias e com as ondas longas, sendo calculado por :

$$
\begin{aligned}
& \tau_{b x}^{E}=c_{f} \rho u_{e} \sqrt{\left(1,16 u_{r m s}\right)^{2}+\left(u_{E}+v_{E}\right)^{2}} \\
& \tau_{b y}^{E}=c_{f} \rho v_{e} \sqrt{\left(1,16 u_{r m s}\right)^{2}+\left(u_{E}+v_{E}\right)^{2}}
\end{aligned}
$$

A solução numérica escolhida para o coeficiente de atrito foi a equação de Chezy. Primeiramente rejeitou-se, o calculo e White-Colebrook grain-size pois o modelo não apresenta variação granulométrica, já que a distribuição granulométrica é a mesma para todo o domínio espacial em virtude da falta de dados. Dentre as três outras opções, as equações de Manning e WhiteColebrook são dependentes da profundidade, e embora sejam recomendadas para modelagens com grandes variações de profundidade, como é o caso do domínio aqui aplicado. Porém o cálculo de atrito que usa qualquer uma destas soluções numéricas possuí o a profundidade no denomidador em função de uma raiz ou de uma função logarítimica o que impossibilita trabalhar com números muito pequenos (profundidades rasas) ou negativos (regiões emersas). Portanto, por exclusão, escolheu-se utilizar o cálculo do coeficiente de atrito através da formulação de Chezy que é apresentada abaixo:

$$
c_{f}=\frac{g}{C^{2}}
$$

\section{$\underline{\text { Vento }}$}

A transferência de energia entre o vento e o fluxo é representada pela tensão de cisalhamento do vento é calculada, baseado na densidade do ar, coeficiente de arrasto do vento, e na intensidade para cada uma das componentes Sendo descrito como:

$$
\begin{aligned}
\tau_{x x} & =\rho_{a} C_{d} W\left|W_{x}\right| \\
\tau_{y x} & =\rho_{a} C_{d} W\left|W_{y}\right|
\end{aligned}
$$




\section{Equações hidrodinâmicas de águas rasas}

O modelo XBeach representa os fluxos médios e das ondas de baixa frequência através da aproximação de águas rasas. Para levar em conta o fluxo de massa provocado pelas ondas o fluido é integrado na coluna d'água, sendo calculado pela generalização lagrangiana média. Ou seja, o fluxo é calculado através da equação do movimento lagrangiano $\left(u^{L}, v^{L}\right)$, que resulta da soma entre as velocidades eurelianas $\left(u^{E}, v^{E}\right)$ e a deriva de Strokes $\left(u^{S}, v^{S}\right)$.

$$
u^{L}=u^{S}+u^{E} ; \quad v^{L}=v^{S}+v^{E}
$$

A deriva de Strokes é calculada através das variações da energia do grupo de ondas curtas e a direção é calculada a partir do balanço da ação de ondas como apresentado abaixo.

$$
u^{S}=\frac{E_{w} \cos \theta}{\rho h c} ; v^{S}=\frac{E_{w} \sin \theta}{\rho h c}
$$

E a equação do movimento apresenta os efeitos do vento, da fricção de fundo das variações no nível do mar $(n)$ e dos movimentos induzidos pelas ondas $(F)$ e o movimento de Coriolis $(f)$ determinada por :

$$
\begin{gathered}
\frac{\partial u^{L}}{\partial t}+u^{L} \frac{\partial u^{L}}{\partial x}+v^{L} \frac{\partial u^{L}}{\partial y}-f v^{L}=\frac{\tau_{s x}}{\rho h}-\frac{\tau_{b x}^{E}}{\rho h}-g \frac{\partial n}{\partial x}+\frac{F_{x}}{\rho h}-\frac{F_{v, x}}{\rho h} \\
\frac{\partial v^{L}}{\partial t}+u^{L} \frac{\partial v}{\partial x}+v^{L} \frac{\partial v^{L}}{\partial y}-f u^{L}=\frac{\tau_{s y}}{\rho h}-\frac{\tau_{b y}^{E}}{\rho h}-g \frac{\partial n}{\partial x}+\frac{F_{y}}{\rho h}-\frac{F_{v, x}}{\rho h} \\
\frac{\partial n}{\partial t}+\frac{\partial h u^{L}}{\partial x}+\frac{\partial h v^{L}}{\partial y}=0
\end{gathered}
$$

\subsubsection{Processos de transporte sedimentar}

\section{Advecção e Difusão}

O sedimento é descrito na modelagem numérica pela sua concentração na célula, e os movimentos de difusão e advecção que são 
básicos no transporte de material em um modelo hidrodinâmico são representados por:

$$
\frac{\partial h C}{\partial t}+\frac{\partial h C u^{\varepsilon}}{\partial x}+\frac{\partial h C v^{\varepsilon}}{\partial y}+\frac{\partial}{\partial x}\left(D_{h} h \frac{\partial C}{\partial x}\right)+\frac{\partial}{\partial y}\left(D_{h} h \frac{\partial C}{\partial y}\right)=\frac{h C_{e q}-h C}{T_{S}}
$$

Onde $\mathrm{C}$ representa a concentração media na coluna d'água que varia com o grupo de ondas e com o coeficiente de difusão $D_{h}$ e com entranhamento $T_{s}$ na coluna de água, este último é descrito pela equação abaixo:

$$
T_{S}=\max \left(f_{T S} \frac{h}{w_{S}}, T_{S, \min }\right)
$$

Isto significa que o entranhamento ou velocidade de deposição é dado por um fator de calibração e a relação entre a velocidade de queda e a profundidade. $O$ processo deposicional de sedimentos é representado pela concentração de equilíbrio $\mathrm{C}_{\mathrm{eq}}$ em relação à concentração da célula.

Por sua vez esta concentração de equilíbrio que determina o potencial erosivo deposicional da célula do modelo para um dado instante de tempo depende basicamente da relação hidrodinâmica com o sedimento. Os parâmetros utilizados para calcular estes fenômenos são a magnitude da velocidade do fluxo ( $V_{\text {mag }}$ ), a velocidade orbital das ondas ( $\left.u_{r m s}\right)$, e a velocidade de queda da partícula. Esta última é calculada por:

$$
w_{s}=1,06 \tanh \left(0,016 A^{0,5} e^{-\frac{120}{A}}\right) \sqrt{\Delta g D_{50}}+0,055 \tanh \left(12 A^{0,59} e^{-0.0004 A}\right) \frac{\Delta g D_{50}}{v}
$$

\section{Equações de transporte}

O cálculo de transporte de sedimento é baseado na fração granulométrica dominante $\left(D_{50}\right)$ e na concentração de equilíbrio $\left(C_{\text {eq }}\right)$, no caso do modelo XBeach há duas equações de transporte de sedimentos, ambas distinguem o transporte de material em suspensão e o material de fundo. A primeira solução é a de Soulsby-Van Rijn, e a segunda, é a de Van ThielVanRijn. Para o presente trabalho optou-se pela segunda equação numérica, 
pois a velocidade crítica de transporte é calculada separadamente para ondas e correntes o que possibilita uma representação de maior detalhe nas situações em que o sedimento é transportado apenas por ondas.

Primeiramente a equação da concentração de equilíbrio de fundo $\left(\mathrm{C}_{\text {eq, }, \mathrm{f}}\right)$ e de suspensão $\left(\mathrm{C}_{\mathrm{eq}, \mathrm{s}}\right)$ é dada por:

$$
\begin{gathered}
C_{e q, f}=\frac{A_{s f}}{h}\left(\sqrt{v_{m a g}^{2}+0,64 u_{r m s, 2}^{2}}-U_{c r}\right)^{1,5} \\
C_{e q, s}=\frac{A_{s s}}{h}+\left(\sqrt{v_{m a g}^{2}+0,64 u_{r m s, 2}^{2}}-U_{c r}\right)^{2,4}
\end{gathered}
$$

E os coeficientes $\left(A_{s}\right)$ são calculados de acordo com a granulometria onde:

$$
A_{s f}=0,015 h \frac{\left(\frac{D_{50}}{h}\right)^{1,2}}{\left(\Delta g D_{50}\right)^{0,75}} ; A_{s s}=0,012 D_{50} \frac{\left(D^{*}\right)^{-0,6}}{\left(\Delta g D_{50}\right)^{1,2}}
$$

A velocidade crítica de transporte é calculada como a soma entre a velocidade crítica das ondas $\left(\mathrm{U}_{\mathrm{crw}}\right)$ e das correntes $\left(\mathrm{U}_{\mathrm{crc}}\right)$

$$
U_{c r}=\beta U_{c r c}+(1-\beta) U_{c r w}
$$

Onde :

$$
\beta=\frac{v_{\text {mag }}}{v_{\text {mag }}+u_{r m s}}
$$

E a velocidade crítica das correntes e das é determinada a partir da fração granolométrica onde:

$$
U_{c r c}=0,19 D_{50}^{0,1} \log _{10}\left(\frac{4 h}{D_{90}}\right) \text { para } D_{50} \leq 0,0005 m
$$




$$
\begin{aligned}
& U_{c r c}=8,5 D_{50}^{0,6} \log _{10}\left(\frac{4 h}{D_{90}}\right) \text { para } D_{50} \leq 0,0002 m \\
& U_{c r c}=1,3 \sqrt{\Delta \mathrm{gD}_{50}}\left(\frac{h}{D_{50}}\right)^{\frac{1}{6}} \text { para } D_{50} \geq 0,0005 m
\end{aligned}
$$

\section{Efeitos não lineares das ondas}

Efeitos de esbeltez e assimetria da onda (momento em que a onda começa a transportar massa) são considerados na equação de advecção e difusão como uma velocidade que depende da direção ( $\left.u_{a}\right)$ :

$$
\begin{gathered}
\frac{\partial h C}{\partial t}+\frac{\partial h C\left(u^{\varepsilon}-u_{a} \sin \theta\right)}{\partial x}+\frac{\partial h C\left(v^{\varepsilon}-v_{a} \cos \theta\right)}{\partial y}+\frac{\partial}{\partial x}\left(D_{h} h \frac{\partial C}{\partial x}\right)+\frac{\partial}{\partial y}\left(D_{h} h \frac{\partial C}{\partial y}\right) \\
=\frac{h C_{e q}-h C}{T_{s}}
\end{gathered}
$$

Onde esta velocidade é definida pela assimetria $\left(A_{s}\right)$ e esbeltez $\left(S_{k}\right)$ e dois fatores de calibração $\left(f_{S k}, f_{A s}\right)$ :

$$
u_{a}=\left(f_{S k} S_{k}-f_{A s} A_{s}\right) u_{r m s}
$$

\section{Efeito de declividade}

Os efeitos da declividade do terreno afeta diretamente o transporte de sedimento principalmente no que diz respeito ao fluxo junto ao fundo, as taxas e direções do transporte, e a energia necessária para impulsionar o movimento do material depositado. A descrição do transporte causado pela declividade é descrita como:

$$
\begin{aligned}
& q_{x, \text { slope }}=q_{x}-1,6 h C \sqrt{\left(u^{L}\right)^{2}+\left(v^{L}\right)^{2}} \frac{\partial z_{b}}{\partial x} \\
& q_{y, \text { slope }}=q_{y}-1,6 h C \sqrt{\left(u^{L}\right)^{2}+\left(v^{L}\right)^{2}} \frac{\partial z_{b}}{\partial y}
\end{aligned}
$$

Este método também pode ser aplicado sobre o transporte total de sedimento sendo: 


$$
q_{\text {slope }}=q\left(1-a \frac{\partial z_{b}}{\partial s}\right)
$$

O calculo de arrasto de fundo causado por escorregamento provocado pelo gradiente de declividade topobatimétrica é dado por:

$$
\begin{gathered}
\tan \left(a_{v, \text { new }}\right)=\frac{\sin \left(a_{\varphi}\right)-f(\theta) \frac{d z_{b}}{d y}}{\cos \left(a_{\varphi}\right)-f(\theta) \frac{d z_{b}}{d y}} \\
f(\theta)=\frac{1}{9 \theta^{0,5}\left(\frac{D_{50}}{h}\right)^{0,3}} \\
q_{b, x}=\left|q_{b}\right| \cos \left(a_{\varphi, \text { new }}\right) \\
q_{b, y}=\left|q_{b}\right| \sin \left(a_{\varphi, \text { new }}\right)
\end{gathered}
$$

Onde $a_{\varphi}$ é o ângulo entre o fluido e o eixo x e a inclinação que permite o movimento é determinada através da relação entre a velocidade orbital e do fluxo sendo descrito como:

$$
\theta_{c r}^{a j u s t}=\theta_{c r} \frac{\cos (\mu) \sin (\beta)+\sqrt{\cos ^{2}(\beta) \tan ^{2}\left(\sigma_{i}\right)-\sin ^{2}(\mu) \sin ^{2}(\beta)}}{\tan \left(\sigma_{i}\right)}
$$

Nesta equação, $\mu$ representa a diferença de ângulos entre o fluxo e o gradiente de declividade, $\beta$ a declividade e $\sigma$ o ângulo de repouso da declividade.

\section{Cálculo para a variação topobatimétrica}

A variação de profundidade causada pela mobilização de material não rígido que compõe o fundo dos corpos hídricos é dado calculado no modelo XBeach através da equação a baixo:

$$
\frac{\partial z_{b}}{\partial t}+\frac{f_{\text {mor }}}{(1-\rho)}\left(\frac{\partial q_{x}}{\partial x}+\frac{\partial q_{y}}{\partial y}\right)=0
$$


Onde o primeiro termo representa a variação de fundo com o tempo e o segundo termo representa as taxas espaciais de sedimento transportado multiplicadas pela relação entre um fator morfológico ( $f_{\text {mor }}$ ) e a não porosidade (1-p(porosidade)). O fator morfológico consiste no grau de aceleração do processo erosivo/deposicional que o modelo permite utilizar. Este recurso foi desenvolvido como um método de reduzir o esforço computacional no calculo de transporte de sedimento, porém mantendo a complexidade dos fenômenos físicos e numéricos representados. Este método é apresentado e bem discutido no trabalho de (Roelvink, 2006) consistindo em manter as forçantes hidrodinâmicas e extrapolar os processos de transporte durante o período simulado, isso permite que um cenário de 30 dias seja extrapolado para um ano sem que as forçantes hidrodinâmicas sofram qualquer alteração. Para o presente estudo aplicação deste método foi utilizada como forma de extrapolar os movimentos da dinâmica sedimentar na escala de seis meses para os cenários propostos.

\subsubsection{Avaliação do modelo numérico}

O processo de validação da modelagem numérica consiste na comparação entre dados medidos e o resultado da modelagem numérica. Os dados utilizados para validação do modelo correspondem a três medidas de correntes coletados por três Accostic Doppler current profile (ADCP) (Tabela 1).

Tabela 1 - Datas dos perfis de corrente coletados por ADCP

\begin{tabular}{|c|c|c|}
\hline ADCP & Data inicial da coleta & Data Final da coleta \\
\hline Bertioga & 08 de junho de 2014 12:00 & 03 de julho de 2014 13:00 \\
\hline Santos & 09 de junho de 2014 11:00 & 09 de julho de 2014 07:00 \\
\hline São Vicente & 09 de junho de 2014 14:00 & 03 de julho de 2014 09:00 \\
\hline
\end{tabular}

A descrição dos dados é apresentada no trabalho de Fielder (2015). Para mensurar a qualidade das representações numéricas entre o modelo e os dados, são calculados parâmetros estatísticos mensuram o erro associado ao resultado da modelagem. Todos os índices utilizados no presente trabalho são 
eficientes para avaliação das correntes. Os métodos de cálculo apresentados a seguir.

1. Erro Relativo Médio Absoluto (ERMA) - Este índice é utilizado para verificação das componentes zonal e meridional da velocidade e da magnitude da mesma. Sua equação é dada por:

$$
R M A E=\frac{\sum_{i=1}^{n} \mid d a d o_{i}-\text { modelo }_{i} \mid}{\sum_{i=1}^{n}\left|d a d o_{i}\right|}
$$

O valor ideal do ERMA é 0, Van Rijn e colaboradores (2003) apresentam uma tabela que qualifica o resultado da modelagem através do RMAE obtido. Esta classificação encontra-se abaixo apresentada na Tabela 2

Tabela 2 - Classificação do ERMA segundo (Van Rijn, et al., 2003).

\begin{tabular}{|c|c|}
\hline RMAE & Qualificação \\
\hline ERMA $<0.2$ & Excelente \\
\hline $0.2<$ ERMA $<0.4$ & Bom \\
\hline $0.4<$ ERMA $<0.6$ & Razoável \\
\hline $0.7<$ ERMA $<1$ & Ruim \\
\hline ERMA $>1$ & Péssimo \\
\hline
\end{tabular}

2. Erro Estatístico Absoluto Médio (Eabs). Este índice possibilita o entendimento do erro médio em magnitude da dimensão física do elemento analisado, portanto seu valor ideal é zero. O método de cálculo é apresentado abaixo baseado em

$$
E_{\text {abs }}=\frac{1}{n} \sum_{i=1}^{n} \mid \text { dado }_{i}-\text { modelo }_{i} \mid
$$

3. Skill parameter - este índice apresentado em Warner e colaboradores (2005) quantifica a capacidade do modelo de reproduzir o que é observado, o calculo é baseado na relação 
entre o erro e a variação do dado em relação a média. Seu valor ideal é 1 e o calculo é apresentado abaixo

$$
\text { Skill }=1-\frac{\sqrt{\frac{1}{n} \sum_{i=1}^{n}\left(\text { dado }_{i}-\text { modelo }_{i}\right)^{2}}}{\frac{2}{n} \sum_{i=1}^{n}\left|d a d o_{i}-\overline{\text { dado }}\right|}
$$

4. Índice de Concordância (IOC)- este índice busca comparar a variabilidade do dado e do modelo em relação à média do dado com o erro quadrático do dado e seu valor ideal é 1 (Fernandez, et al., 2006). O calculo do índice é dado pela equação abaixo :

$$
I O A=1-\left|\frac{\sum_{i=1}^{n}\left(\text { dado }_{i}-\text { modelo }_{i}\right)^{2}}{\sum_{i=1}^{n}\left(\mid \text { dado }_{i}-\overline{\text { dado }}|+| \text { modelo }_{i}-\overline{\text { dado }} \mid\right)}\right|
$$

5. Coeficiente de determinação $\left(R^{2}\right)$ - é o índice que indica a variância explicada pelo modelo, já que ele relaciona o erro total do modelo e a variância total do dado, seu valor ideal é 1 (du Bois \& Dumas, 2005), e a equação que o descreve é apresentada abaixo:

$$
R^{2}=1-\frac{\sum_{i=1}^{n}\left(\text { dado }_{i}-\text { modelo }_{i}\right)^{2}}{\sum_{i=1}^{n}\left(\text { dado }_{i}-\overline{\text { dado }}\right)^{2}}
$$




\section{Resultados e Discussão}

\subsection{Detecção de frentes frias}

O método para detecção de frentes frias encontrou 970 passagens de sistemas frontais entre o período de 01 de janeiro de 1979 a 31 de dezembro de 2015. A mediana anual é de 26 ocorrências de frentes por ano, com maior frequência nos meses de setembro e outubro (três sistemas frontais por mês), e menor nos meses de janeiro e fevereiro (uma frente por mês). Nos outros meses encontram-se aproximadamente duas frentes ao mês (Tabela 3). $\mathrm{O}$ ano com menor ocorrência foi o de 2001 com 15 frentes e o de maior ocorrência foi o de 2009 com 37 frentes (Tabela 4). Estes resultados diferem dos resultados observados por Rodrigues e colaboradores (2004) que encontraram 429 frentes que passaram por Santa Catarina para o período de 1990-1999, enquanto que o presente trabalho detectou 262 ocorrências de frentes frias para o mesmo período. Por outro lado tanto o método executado pelos autores quanto o método aqui descrito, encontrou uma maior ocorrência de frentes frias no período de setembro, outubro e novembro. As diferenças quantitativas entre os resultados podem estar associadas às (1) diferentes metodologias empregadas, já que os autores não consideram a anomalia do geopotencial e ou a pressão; (2) diferentes resoluções espaciais e temporais dos modelos analisados o que implica em diferentes discretizações dos fenômenos analisados; (3) a diferença de latitude e a distância da costa entre o ponto analisado neste trabalho e o dos autores visto que há uma relação inversa entre a latitude e a ocorrência e intensidade dos sistemas frontais, esta correlação foi observada e discutida por Castro e Lee (1995) em uma análise de dados meteorológicos e do nível do mar ao longo do litoral Sul-Sudeste do Brasil. Através dos resultados apresentados na Tabela 3, determinou-se que 0 período simulado seria de 15 dias basado no número médio de ocorrências de frentes por mês, e assumindo que as ocorrências destes sistemas são igualmente espaçadas no tempo. 
Tabela 3 - Mediana da ocorrência de frentes frias por mês para o período de 01 de janeiro de 1979 a 31 de dezembro de 2015.

\begin{tabular}{|c|c||c|c|}
\hline Mês & Ocorrência & Mês & Ocorrência \\
\hline \hline Janeiro & 1 & Julho & 2 \\
\hline Fevereiro & 1 & Agosto & 2 \\
\hline Março & 2 & Setembro & 3 \\
\hline Abril & 2 & Outubro & 3 \\
\hline Maio & 2 & Novembro & 2 \\
\hline Junho & 2 & Dezembro & 2 \\
\hline
\end{tabular}

Tabela 4 - Ocorrência de frentes frias por ano para o período de 01 de janeiro de 1979 a 31 de dezembro de 2015.

\begin{tabular}{|c|c||c|c||c|c|}
\hline Ano & Ocorrência & Ano & Ocorrência & Ano & Ocorrência \\
\hline \hline 1979 & 28 & 1992 & 28 & 2005 & 25 \\
\hline 1980 & 21 & 1993 & 24 & 2006 & 21 \\
\hline 1981 & 21 & 1994 & 26 & 2007 & 26 \\
\hline 1982 & 31 & 1995 & 23 & 2008 & 30 \\
\hline 1983 & 27 & 1996 & 26 & 2009 & 37 \\
\hline 1984 & 25 & 1997 & 26 & 2010 & 24 \\
\hline 1985 & 24 & 1998 & 29 & 2011 & 24 \\
\hline 1986 & 26 & 1999 & 30 & 2012 & 26 \\
\hline 1987 & 23 & 2000 & 31 & 2013 & 32 \\
\hline 1988 & 34 & 2001 & 15 & 2014 & 31 \\
\hline 1989 & 27 & 2002 & 22 & 2015 & 25 \\
\hline 1990 & 26 & 2003 & 30 & & \\
\hline 1991 & 24 & 2004 & 22 & Total & 970 \\
\hline
\end{tabular}

Dentre os resultados obtidos, a Tabela 5 apresenta uma descrição estatística dos dados com os valores de média, mediana, desvio padrão, primeiro e terceiro quartil para todos os parâmetros analisados na metodologia de detecção de frentes frias. O resultado obtido caracteriza uma frente fria típica como um evento que dura aproximadamente 64 horas com ventos médios de aproximadamente $5,71 \mathrm{~m} / \mathrm{s}$ e a elevação do nível do mar médio (descontado a maré astronômica) de $16 \mathrm{~cm}$. 
Tabela 5 - Parâmetros estatísticos dos ventos, duração e nível do mar para as frentes frias encontradas no período de 01 de janeiro de 1979 a 31 de dezembro de 2015.

\begin{tabular}{|c||c|c|c|c|c|}
\hline Parâmetro & $\begin{array}{c}\text { Vento Med. } \\
\mathbf{( m / s})\end{array}$ & $\begin{array}{c}\text { Vento max. } \\
\mathbf{( m / s})\end{array}$ & Duração & $\begin{array}{c}\text { Nível Méd. } \\
\mathbf{( m})\end{array}$ & $\begin{array}{c}\text { NívelMax. } \\
\mathbf{( m )}\end{array}$ \\
\hline \hline Média & 3,26 & 5,87 & 75 h45min & 0,19 & 0,34 \\
\hline Desvio Padrão & 1,03 & 1,88 & $40 \mathrm{~h} 30 \mathrm{~min}$ & 0,13 & 0,17 \\
\hline Mínimo & 1,16 & 2,83 & $25 \mathrm{~h}$ & $-0,14$ & 0,00 \\
\hline $\mathbf{1}^{\mathbf{o}}$ quartil & 2,45 & 4,37 & $48 \mathrm{~h}$ & 0,09 & 0,21 \\
\hline Mediana & 3,15 & 5,71 & $64 \mathrm{~h}$ & 0,16 & 0,31 \\
\hline Terceiro Quartil & 3,96 & 7,12 & $91 \mathrm{~h}$ & 0,26 & 0,44 \\
\hline Máximo & 6,83 & 11,95 & $167 \mathrm{~h}$ & 0,65 & 0,95 \\
\hline
\end{tabular}

A partir dos resultados obtidos, selecionou-se 0 momento representativo da condição de FFM e FFE. A escolha das datas corresponde aos períodos com valores mais próximos de vento médio e máximo e nível médio e máximo das condições típicas e extremas encontradas na Tabela 5. Os intervalos de tempo selecionados para serem utilizados na modelagem numérica como FFM e FFE iniciam-se em 31 de maio de 1998 as 2 horas e 21 de julho de 1996 a 0 horas respectivamente. As características de vento e nível do mar que correspondente estão apresentadas na Tabela 6, e as séries temporais dos dados filtrados com o comportamento das frentes escolhidas encontram-se representados na Figura 9 e Figura 11 onde:

- A linha azul representa o nível do mar em relação ao geoide (descontado a maré) em metros;

- A linha vermelha a componente meridional do vento em $\mathrm{m} / \mathrm{s}$;

- A linha lilás a temperatura em kelvin;

- A linha verde a anomalia da pressão atmosférica em milibares;

- A linha preta a anomalia do geopotencial em metros;

- A linha sólida representa o período onde foi detectada a frente;

- A linha pontilhada outro período 
Tabela 6 - Períodos de frentes frias selecionados para a modelagem, o primeiro período representa a frente fria típica e o segundo período a frente fria extrema.

\begin{tabular}{|c||c|c|c|c|}
\hline Data inicial & $\begin{array}{c}\text { Vento Med. } \\
(\mathbf{m} / \mathbf{s})\end{array}$ & $\begin{array}{c}\text { Vento max } \\
(\mathbf{m} / \mathbf{s})\end{array}$ & $\begin{array}{c}\text { Nível Méd. } \\
(\mathbf{m})\end{array}$ & $\begin{array}{c}\text { Nível } \\
\text { Max.(m) }\end{array}$ \\
\hline \hline $\mathbf{3 1 / 0 5 / 1 9 9 8 ~ 0 2 : 0 0}$ & 3.02 & 4.74 & 0.16 & 0.33 \\
\hline $\mathbf{2 1 / 0 7 / 1 9 9 6 ~ 0 0 : 0 0}$ & 4.88 & 7.95 & 0.60 & 0.82 \\
\hline
\end{tabular}

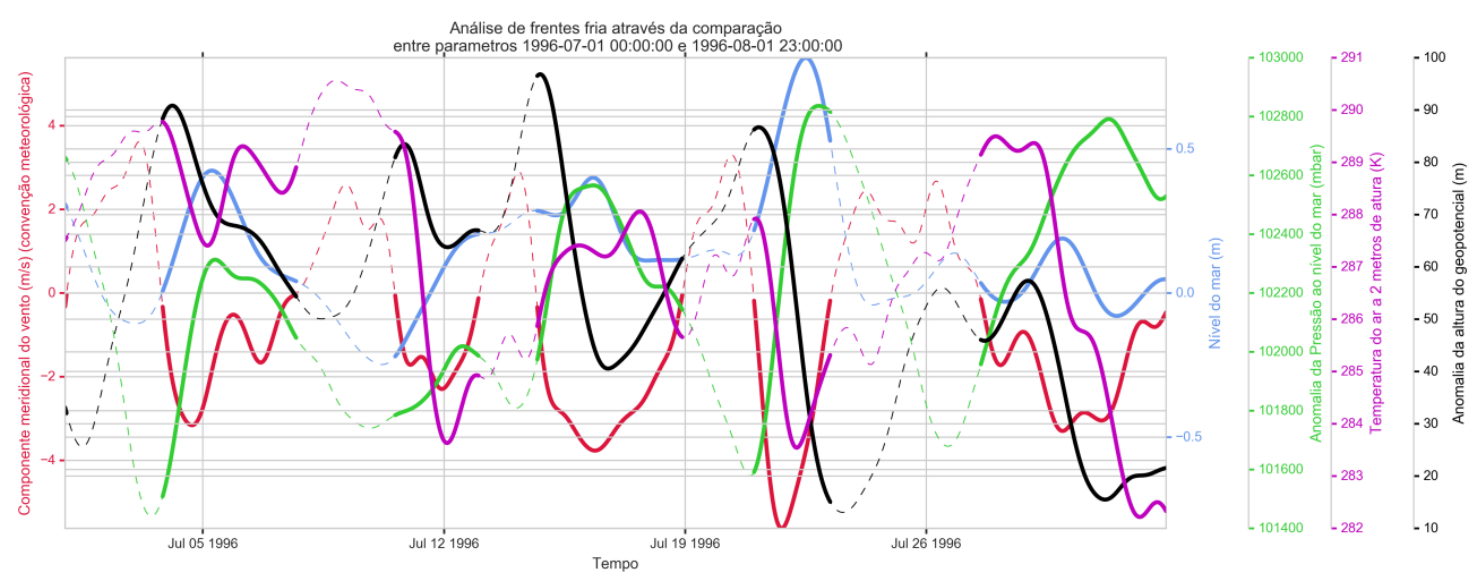

Figura 9 - Série temporal dos dados filtrados do período representativo de frente fria extrema. As linhas sólidas representam os períodos onde foi detectado frente. A linha azul representa o nível do mar em relação ao geoide (descontado a maré) em metros, a linha vermelha a componente meridional do vento em $\mathrm{m} / \mathrm{s}$, a linha lilás a temperatura em kelvin, a linha verde a anomalia da pressão atmosférica em milibares, a linha preta a anomalia do geopotencial em metros. O período representado na série corresponde ao dia primeiro de julho de 1996 a primeiro de agosto de 1996, o período da frente fria extrema encontra-se entre 19 a 24 de julho de 1996.

Na série correspondente ao período representativo da FFE (Figura 9), o intervalo entre 19 e 25 de julho de 1998 apresenta as maiores variações em todos os parâmetros meteorológicos e do nível do mar quando comparados às outras frentes encontradas neste intervalo de tempo, destacando-se os valores de vento e nível do mar. No período correspondente a FFE a subida do nível do mar ocorre de forma rápida, partindo de valores de $10 \mathrm{~cm}$ a $82 \mathrm{~cm}$ em apenas 2 dias, esta mudança ocorre durante o aumento da pressão atmosférica em aproximadamente 12000 milibares e a diminuição em aproximadamente $80 \mathrm{~m}$ 
da anomalia da altura do geopotencial (que é inversamente proporcional a pressão atmosférica) e intensificação dos ventos de sul que variaram mais de 8 $\mathrm{m} / \mathrm{s}$ na componente meridional. Estas condições evidenciam a passagem de um sistema de alta pressão que impulsiona uma massa de ar fria (queda da temperatura superficial em $4 \mathrm{~K}$ ) proveniente de sul (componente meridional do vento com valores negativos o que é indicativo de ventos de sul), em seguida a pressão aumenta. Esta frente fria é representada espacialmente na Figura 10 por um campo de vetores de vento sobrepostos à isolinhas de pressão atmosférica para às $00 \mathrm{~h}$ do dia 23 de junho de 1996, onde há um centro de alta pressão sobre a região sul do Brasil e ventos intensos de leste perpendiculares à costa provavelmente impulsionando a coluna d'água contra o continente. Destacam-se também os ventos de sul entre as longitudes de $45^{\circ} \mathrm{W}$ e $40^{\circ} \mathrm{W}$, principalmente ao norte de Cabo Frio, já mais próximos ao centro de baixa pressão. 


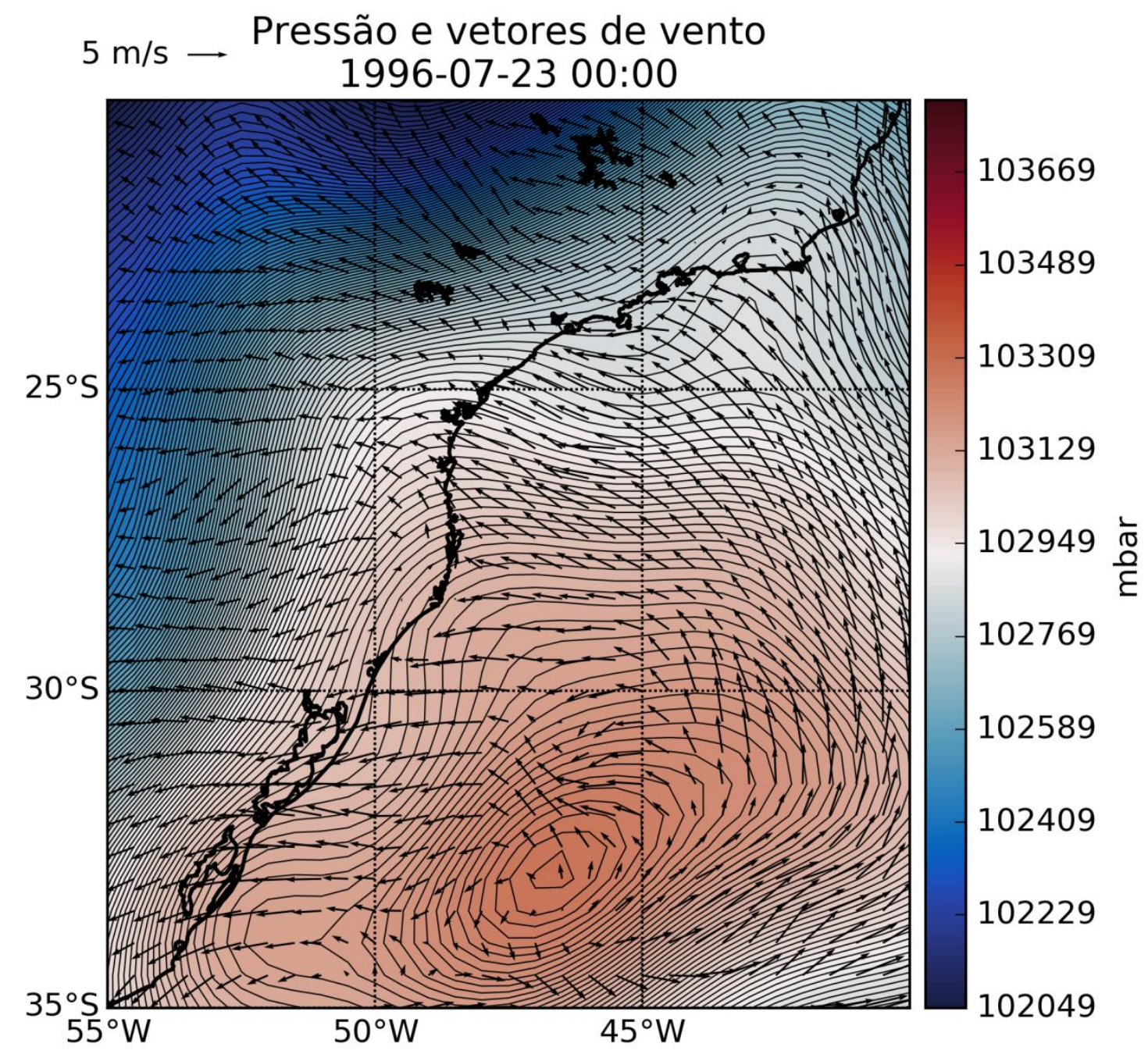

Figura 10 - Campo instantâneo com vetores de vento sobrepostos as isolinhas de pressão em milibar para as 00 horas do dia 23 de julho de 1996 projeção Mercator datum WGS84. 


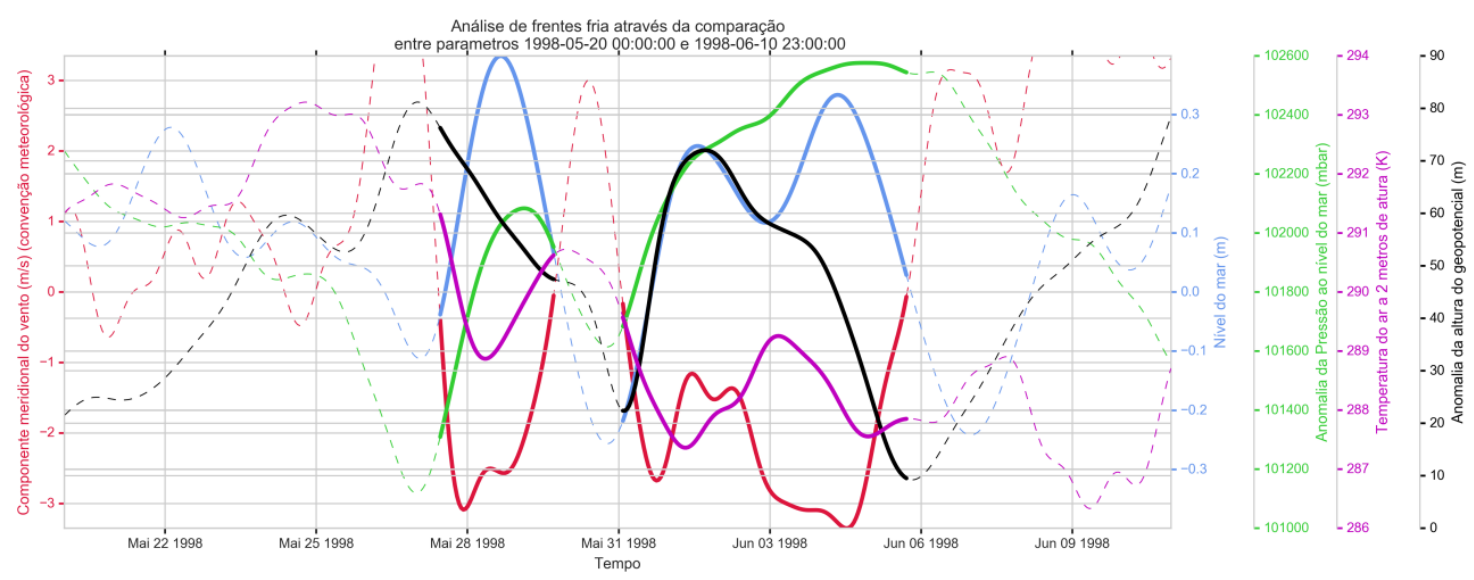

Figura 11 - Série temporal dos dados filtrados do período representativo de frente fria média. As linhas sólidas representam os períodos onde foi detectado frente. A linha azul representa o nível do mar em relação ao geoide (descontado a maré) em metros, a linha vermelha a componente meridional do vento em $\mathrm{m} / \mathrm{s}$, a linha lilás a temperatura em kelvin, a linha verde a anomalia da pressão atmosférica em milibares, a linha preta a anomalia do geopotencial em metros. O período representado na série corresponde ao dia 20 de maio de 1998 a 20 de junho de 1998, o período da frente fria média encontra-se entre 31 de maio a 03 e junho de 1998.

No caso da série de dados de FFM (Figura 11), os sistemas frontais encontrados no período de 20 de maio de 1998 a 10 de junho de 1998 apresentam intervalos curtos entre si. Destaca-se o período de 31 a 6 de junho que apresenta dois sinais de frentes frias intervaladas em um dia onde a frente menor apresenta altura do nível do mar de $16 \mathrm{~cm}$ a variação da componente meridional do vento em $5 \mathrm{~m} / \mathrm{s}$ e o aumento do gradiente de pressão em 8000 mbar em seguida há uma segunda subida do nível do mar para $30 \mathrm{~cm}$. 0 intervalo entre as duas subidas foi detectado pela metodologia como uma única frente fria de longa duração. Para o entendimento do fenômeno que justificasse as duas subidas do nível do mar, elaboraram-se campos de vetores de vento sobre isolinhas de pressão para as 18 horas dos dias 2 e 4 de junho de 1998. No primeiro campo (Figura 12) observa-se ventos de sul associados a um centro de alta pressão entre as latitudes de $25^{\circ} \mathrm{S}$ a $30^{\circ} \mathrm{S}$ que ruma para norte em direção à um centro de baixa. Ao sul do campo, observa-se outro centro de baixa pressão onde os ventos de oeste tornam-se mais intensos conforme se 
afastam da costa. Dois dias depois, representado pela Figura 13 observa-se 0 núcleo do centro de baixa pressão sobre a divisa entre os estados de São Paulo e Paraná, tanto o litoral paulista e carioca quanto o litoral uruguaio e gaúcho sofrem ação de ventos intensos de perpendiculares à costa que provavelmente estão impulsionando a coluna d'água em direção ao continente. Ao sul do campo, observa-se a chegada de um centro de alta pressão possivelmente relacionado a um sistema de frontogênese. Esta situação é indicativa de que houve a passagem de duas frentes frias intervaladas por um dia, sinalizadas principalmente pelo sinal de elevação do nível do mar.

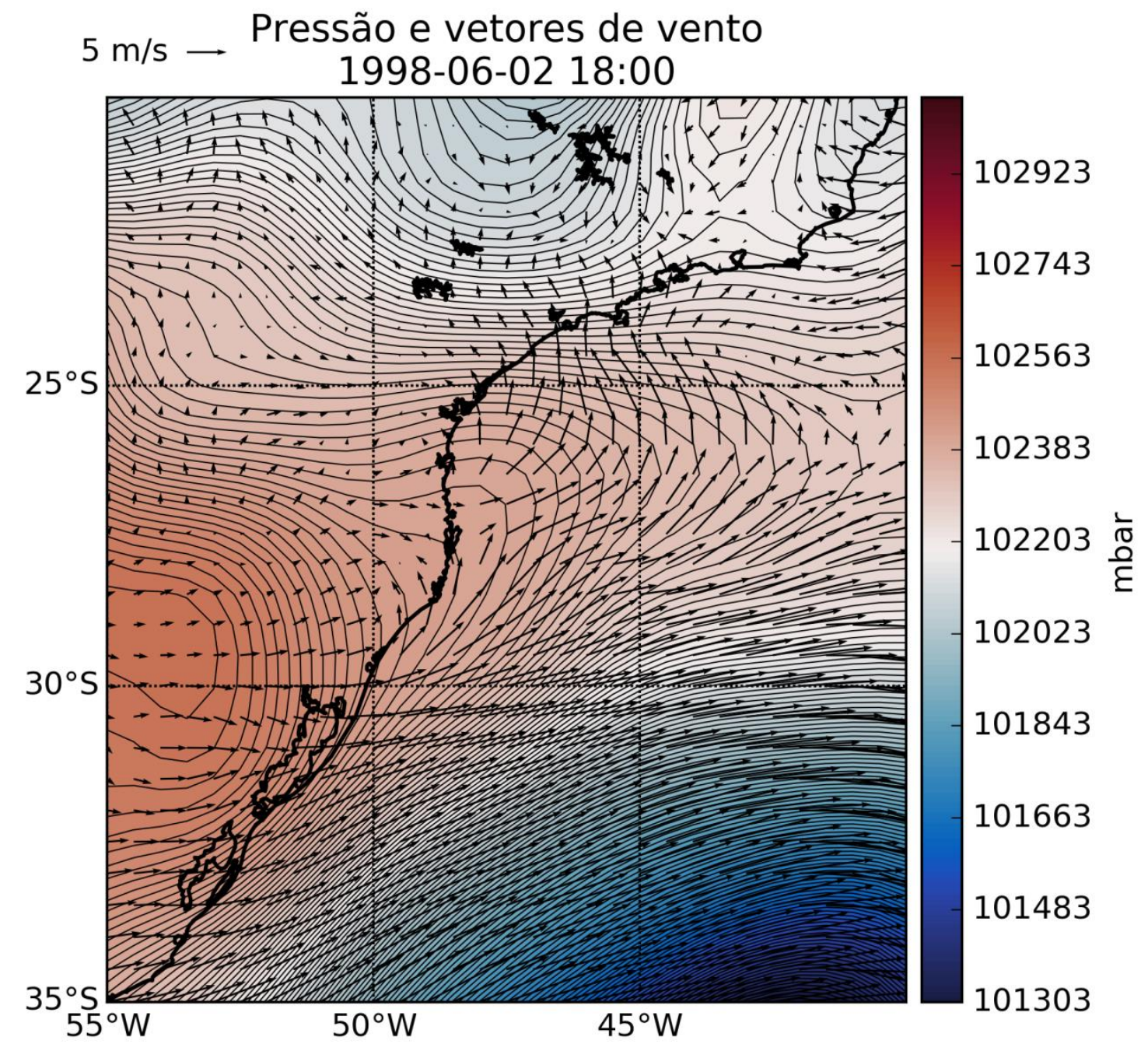

Figura 12 - Campo instantâneo com vetores de vento sobrepostos as isolinhas de pressão em milibar para as 18 horas do dia 02 de junho de 1998 projeção Mercator datum WGS84. 


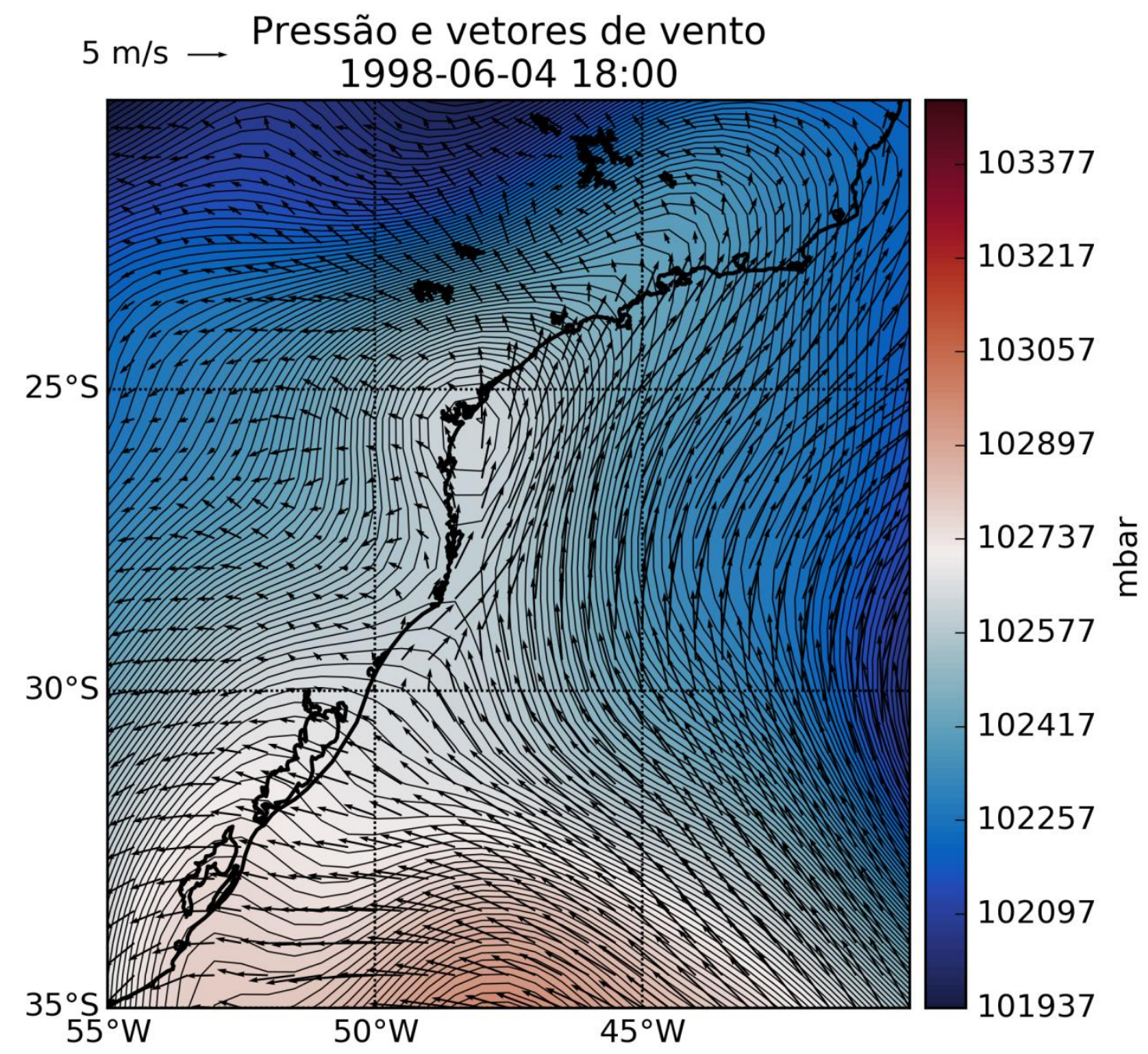

Figura 13 - Campo instantâneo com vetores de vento sobrepostos as isolinhas de pressão em milibar para as 18 horas do dia 04 de junho de 1998 projeção Mercator, Datum WGS84.

A passagem de frentes frias seguidas por um intervalo tão curto de tempo não puderam ser identificadas pela metodologia aplicada. Mesmo com esta limitação, a caracterização das frentes frias não é comprometedora no que diz respeito aos cenários extremos e médios escolhidos, já que os períodos representativos de FFM e FFE dependem também dos valores máximos de ventos e nível e a maioria das frentes apresenta duração de menos de 100 horas segundo a metodologia aplicada.

\subsection{Validação do modelo numérico}

Para a validação foi realizada uma simulação de 01 de junho de 2014 a 
01 de julho de 2014, desta simulação extraíram-se os pontos mais próximos possíveis das coordenadas dos dados medidos como demonstrado na Tabela 7, os índices estatísticos calculados são apresentados na Tabela 8.

Tabela 7 - Pontos de coleta dos dados de ADCP e pontos do modelo utilizados para comparação. Zona UTM 23, datum WGS84, o período de comparação corresponde a data de início da coleta a 01 de julho de 2014.

\begin{tabular}{|c|c|c|c|c|}
\hline \multirow{2}{*}{ Nome do ADCP } & \multicolumn{2}{|c|}{ Coordenadas do dado } & \multicolumn{2}{c|}{ Coordenadas do modelo } \\
\cline { 2 - 5 } & Longitude & Latitude & Longitude & Latitude \\
\hline \hline São Vicente & $358068,35 \mathrm{E}$ & $7347146,92 \mathrm{~S}$ & $358042,35 \mathrm{E}$ & $7347134,60 \mathrm{~S}$ \\
\hline Santos & $368860,75 \mathrm{E}$ & $7346618,77 \mathrm{~S}$ & $368870,42 \mathrm{E}$ & $734660749 \mathrm{~S}$ \\
\hline Bertioga & $382974,82 \mathrm{E}$ & $7360629,60 \mathrm{~S}$ & $382922.55 \mathrm{E}$ & $7360629,12 \mathrm{~S}$ \\
\hline
\end{tabular}

Tabela 8 - Tabela com os parâmetros estatísticos de avaliação do modelo numérico implementado.

\begin{tabular}{|c|c|c|c|c|c|c|}
\hline \multirow{2}{*}{ Parâmetro } & \multicolumn{2}{|c|}{ São Vicente } & \multicolumn{2}{c|}{ Santos } & \multicolumn{2}{c|}{ Bertioga } \\
\cline { 2 - 7 } & $\mathbf{u}$ & $\mathbf{V}$ & $\mathbf{U}$ & $\mathbf{V}$ & $\mathbf{U}$ & $\mathbf{v}$ \\
\hline \hline ERMA (\%) & $60,76 \%$ & $62.74 \%$ & $64,28 \%$ & $64,25 \%$ & $53,38 \%$ & $67,45 \%$ \\
\hline Eabs (m/s) & 0,12 & 0.06 & 0.07 & 0,9 & 0,12 & 0.08 \\
\hline Skill (\%) & $61,21 \%$ & $51,38 \%$ & $40,70 \%$ & $47,87 \%$ & $66,40 \%$ & $56,24 \%$ \\
\hline IOC (\%) & $93,04 \%$ & $96,25 \%$ & $94,87 \%$ & $94,12 \%$ & $94,77 \%$ & $95,87 \%$ \\
\hline $\mathbf{R}^{\mathbf{2}}(\%)$ & $66,94 \%$ & $51,04 \%$ & $26,81 \%$ & $45,73 \%$ & $71,12 \%$ & $51,86 \%$ \\
\hline
\end{tabular}

Os parâmetros estatísticos, principalmente os índices de Skill e IOC demonstram que o modelo representa satisfatoriamente os fenômenos mais importantes da região encontrados no período de dados avaliados. Sendo a melhor representação hidrodinâmica encontrada nos canais de São Vicente (skill=61,21\% e IOC=93,01\% para a componente u e skill $=51,04 \%$ e IOC $=96,25 \%$ para a componente v) e Bertioga (skill $=66,40 \%$ e $10 C=94,77 \%$ para a componente u e skill $=56,24 \%$ e $10 \mathrm{C}=95,87 \%$ para a componente $\mathrm{v}$ ). Para o ADCP de Santos, os resultados para Skill são menores do que 50\%, porém os valores de IOC apresentaram bons resultados $(94,87 \%$ para componente u e $94,12 \%$ para componente v) o que indica que a variabilidade do modelo e a do dado são próximas.

No que diz respeito à comparação entre os resultados do modelo e a camada superficial do $A D C P$, os resultados para o ponto mais próximo do 
ADCP de Santos são apresentados na Figura 14 para a componente zonal e na Figura 15 para a componente meridional:

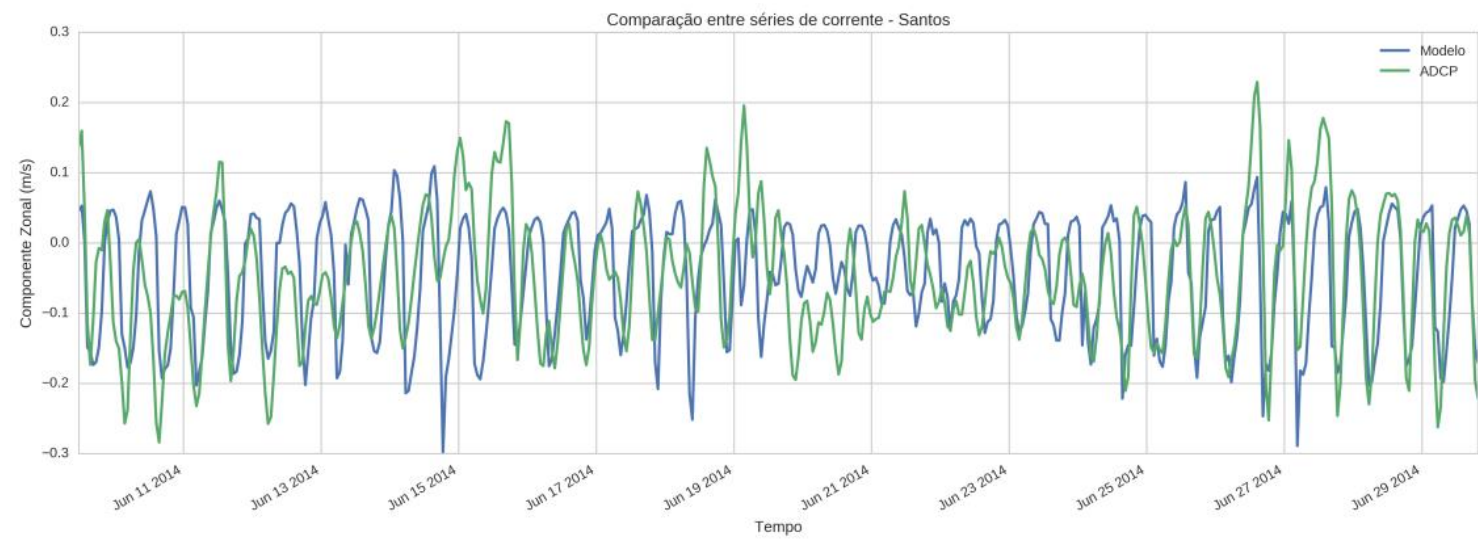

Figura 14 - Comparação entre a série temporal da componente zonal para os dados de corrente de superfície de Santos coletado com o ADCP e o ponto mais próximo do modelo numérico para o período de 09 de junho a 01 de julho de 2014.

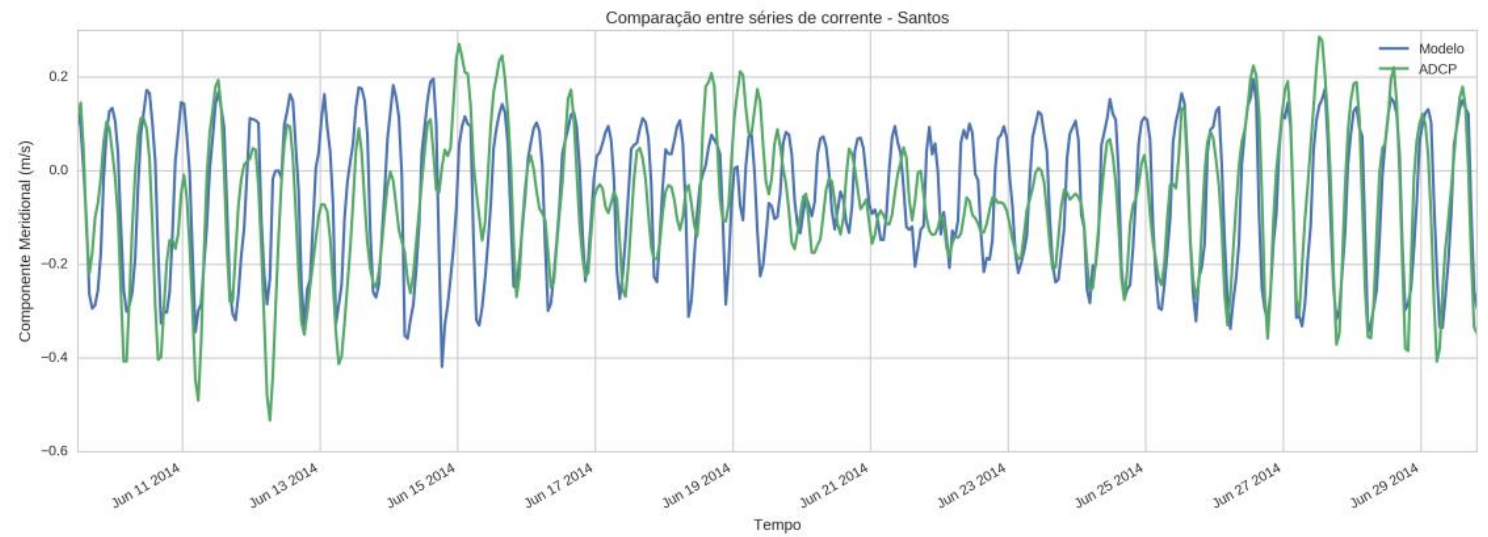

Figura 15 - Comparação entre a série temporal da componente meridional para os dados de corrente de superfície de Santos coletado com o $A D C P$ e o ponto mais próximo do modelo numérico para o período de 09 de junho a 01 de julho de 2014.

Observa-se que na relação de sobreposição de sinais, as componentes meridional e zonal do modelo apresentam-se em fase com os dados medidos. Isso significa que as ondas observadas nos sinais apresentam mesma fase, o que significa que a maré e outros fenômenos tem sua periodicidadee escala de tempo representada no modelo. Observa-se também que as correntes medidas 
pelo ADCP e as correntes geradas pelo modelo tem intensidades aproximadas, principalmente no final da série, portanto o modelo e o dado apresentam comportamento físico satisfatório para a representação das principais forçantes de correntes neste ponto.

Para a comparação entre os dados do ADCP de São Vicente com os dados do modelo a Figura 16 apresenta a comparação entre as séries da componente zonal enquanto que a Figura 17 compara as séries da componente meridional.

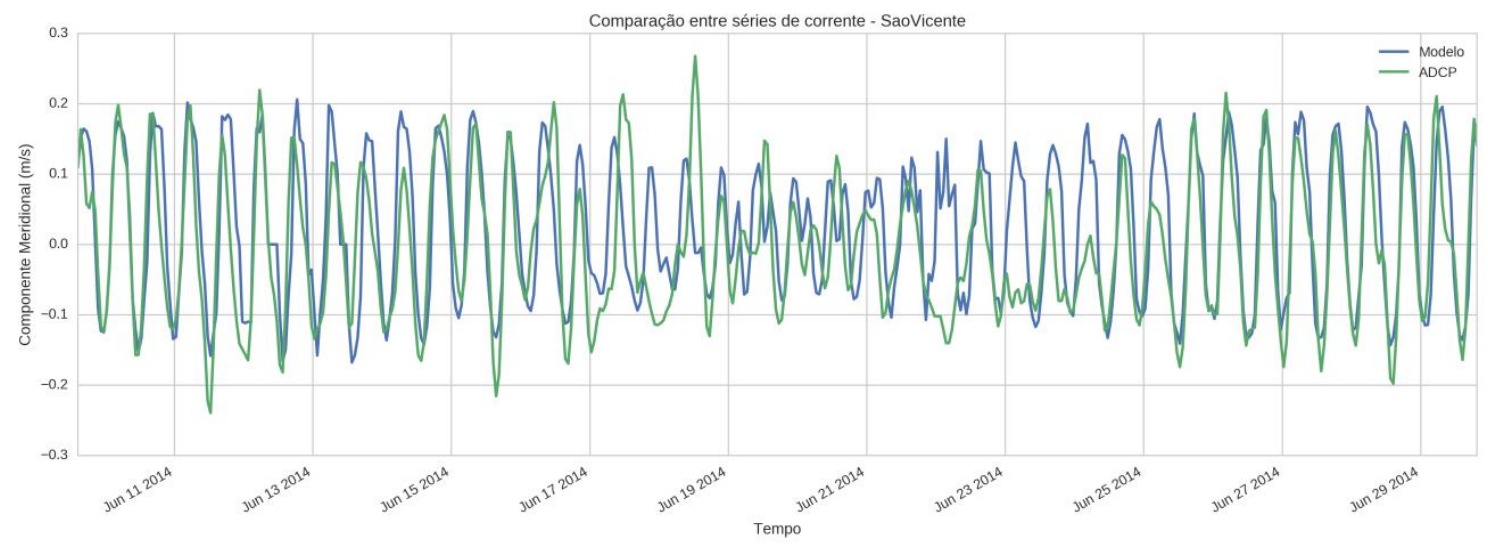

Figura 16 - Comparação entre a série temporal da componente zonal para os dados de corrente de superfície de São Vicente coletado com o ADCP e o ponto mais próximo do modelo numérico para o período de 08 de junho a 01 de julho de 2014.

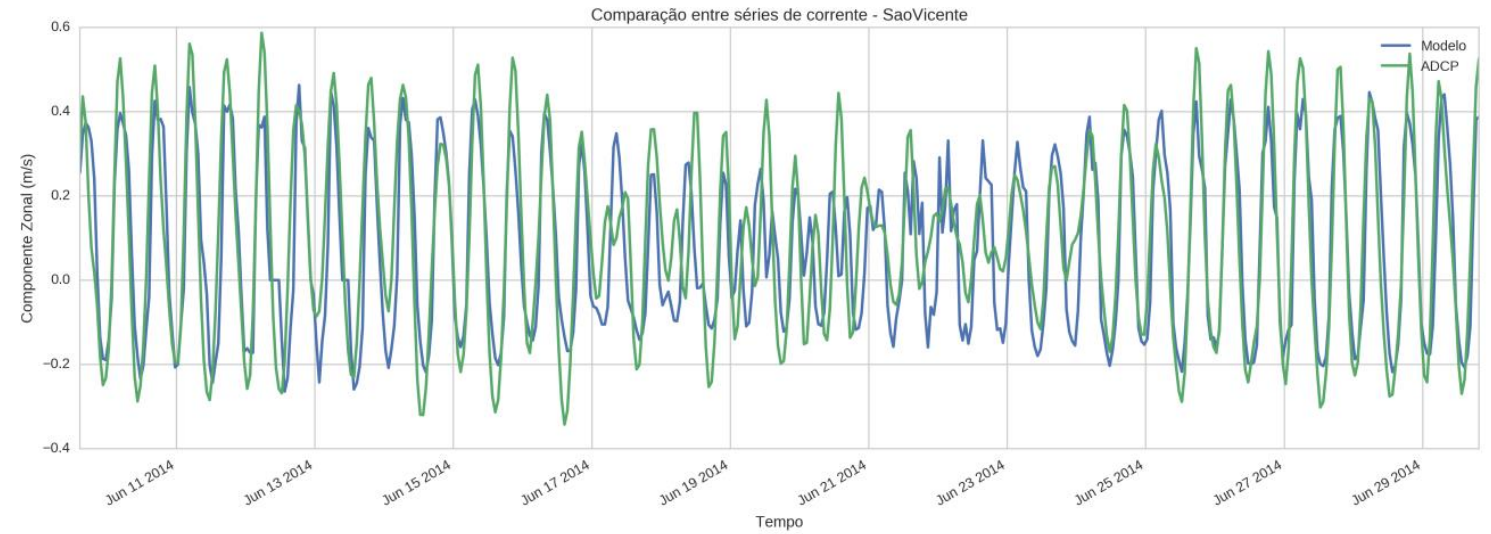

Figura 17 - Comparação entre a série temporal da componente meridional para os dados de corrente de superfície de São Vicente coletado com o ADCP e o ponto mais próximo do modelo numérico para o período de 08 de junho a 01 de julho de 2014. 
$\mathrm{Na}$ comparação entre as séries os resultados da modelagem numérica também estão em fase. De modo geral as intensidades das componentes zonal e meridional estão bem representadas, embora os valores dos picos e cavas das ondas sejam menores no modelo do que no dado. Em ambos os casos o modelo representou os principais fenômenos para esta região.

Por fim a análise do ADCP de Bertioga para a validação dos resultados é apresentada na Figura 18 e Figura 19 para as componentes zonal e meridional

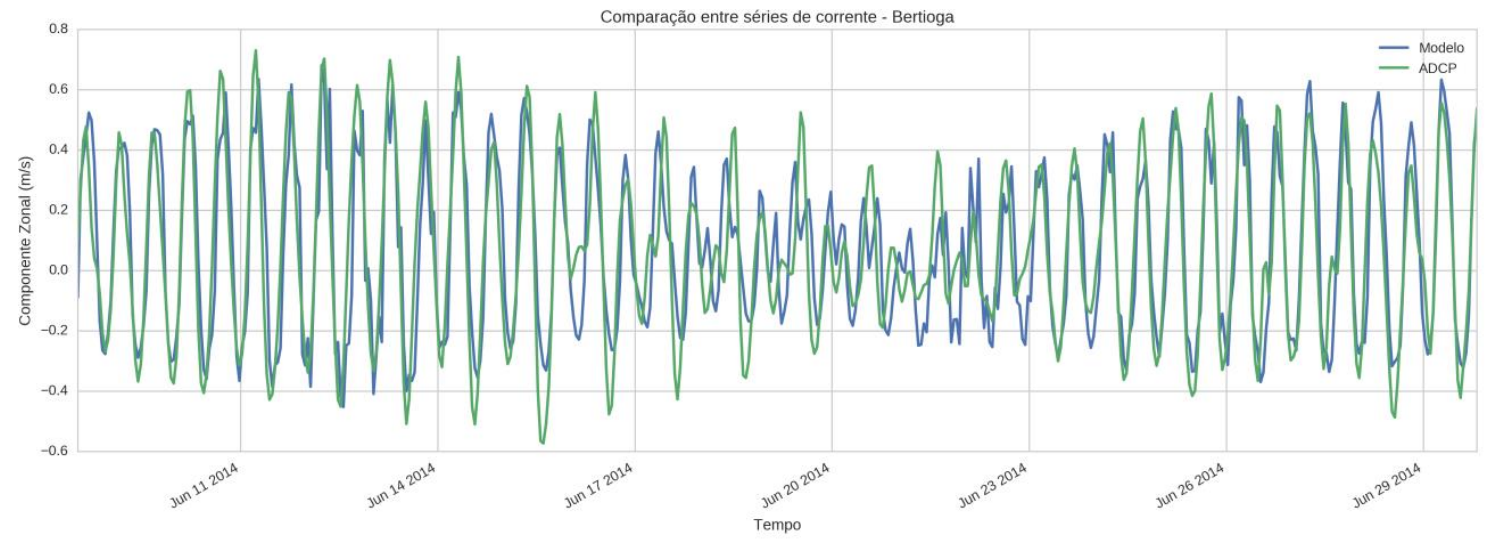

Figura 18 - Comparação entre a série temporal da componente zonal para os dados de corrente de superfície de Bertioga coletado com o ADCP e o ponto mais próximo do modelo numérico para o período de 09 de junho a 01 de julho de 2014.

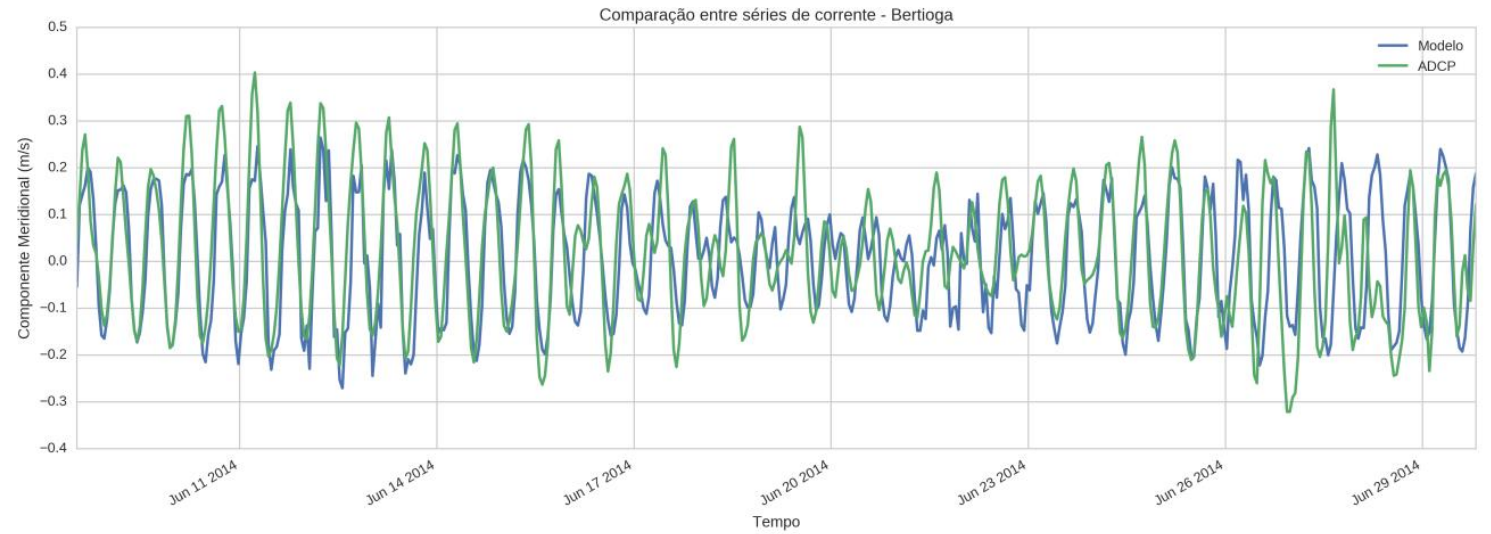

Figura 19- Comparação entre a série temporal da componente meridional para os dados de corrente de superfície de Bertioga coletado com o $A D C P$ e o ponto mais próximo do modelo numérico para o período de 09 de junho a 01 de julho de 2014. 
Assim como nas outras duas comparações, o modelo também se encontra em fase quando comparado com o dado medido. Diferentemente dos resultados do ponto de São Vicente, o ponto de Bertioga apresenta a componente meridional como a menos intensa e a zonal como a mais intensa.

De modo geral, há um expressivo sinal de maré astronômica tanto nas medidas do ADCP quanto nos resultados do modelo, este sinal foi constatado nas análises de espectro de séries temporais realizadas por Fielder 2015 para este conjunto de dados. Embora haja diferenças de intensidade a variação da corrente em função da maré astronômica está em fase para todo o modelo e, de modo geral, com intensidades próximas. As diferenças entre as medidas de ADCP e o modelo podem estar relacionadas a não representação da drenagem continental tanto em relação ao volume de água inserido no sistema quanto em relação às variações baroclínicas causadas pela entrada de água doce em um sistema de água salobra. Outra razão para a não representação destes fenômenos de menor energia observados no ADCP é em função do método numérico do modelo XBeach, que para este estudo é 2DH o que implica na não discretização das camadas verticais, embora os elementos de transporte sejam representados.

Embora com limitações, tendo em vista que o sistema é regido majoritariamente pela circulação relacionada à movimentos barotrópicos, infere-se que o modelo representará corretamente o transporte de sedimento ao longo do estuário santista já que este é regido pela forçante de maior intensidade.

\subsection{Elaboração dos cenários}

A comparação do efeito do transporte de sedimentos sobre as condições de FFM e FFE demandaram a elaboração de três cenários sendo todos eles baseados em uma série de maré astronômica com ondas e ventos médios, diferenciados pela inserção de uma condição de frente fria por 120 horas após o período de aquecimento do modelo. Portanto, serão apresentados os três cenários de 15 dias, sendo um deles sem frente, um com a condição de FFM por 120 horas interpolada na série e o último análogo ao segundo cenário porém com condição de FFE. 


\subsubsection{Cenário sem a presença de frente fria}

O cenário sem a presença de frente fria foi baseado na maré astronômica modelada pela ferramenta OpenEarthTools para os dados do modelo de constantes harmônicas de maré TOPEX/POSSEIDON 7.2 (Egbert \& Erofeeva, 2002). Os dados foram corrigidos para a zona GMT 3 para o período de 01 de junho de 2014 a 01 de julho de 2014. Os pontos onde os dados de maré foram extraídos estão apresentados na Tabela 9 e representam os cantos direito e esquerdo da borda oceânica do domínio. A série obtida é apresentada na Figura 20, observa-se que a amplitude de maré do canto esquerdo é ligeiramente maior do que a do direito. Esse desnível barotrópico favorece a circulação para leste na região de fora da Baía de Santos (Gregório, 2009; Roversi, 2012).

Tabela 9 - Coordenadas dos cantos das bordas onde foram extraídas as constantes de maré do modelo TOPEX/POSSEIDON, Zona UTM 23 DATUM - WGS84.

\begin{tabular}{|c|c|c|}
\hline Canto da borda Offshore & Longitude & Latitude \\
\hline Direito & 336151,2721 & 7322696,3 \\
\hline Esquerdo & 398152,5461 & 7322696,3 \\
\hline
\end{tabular}

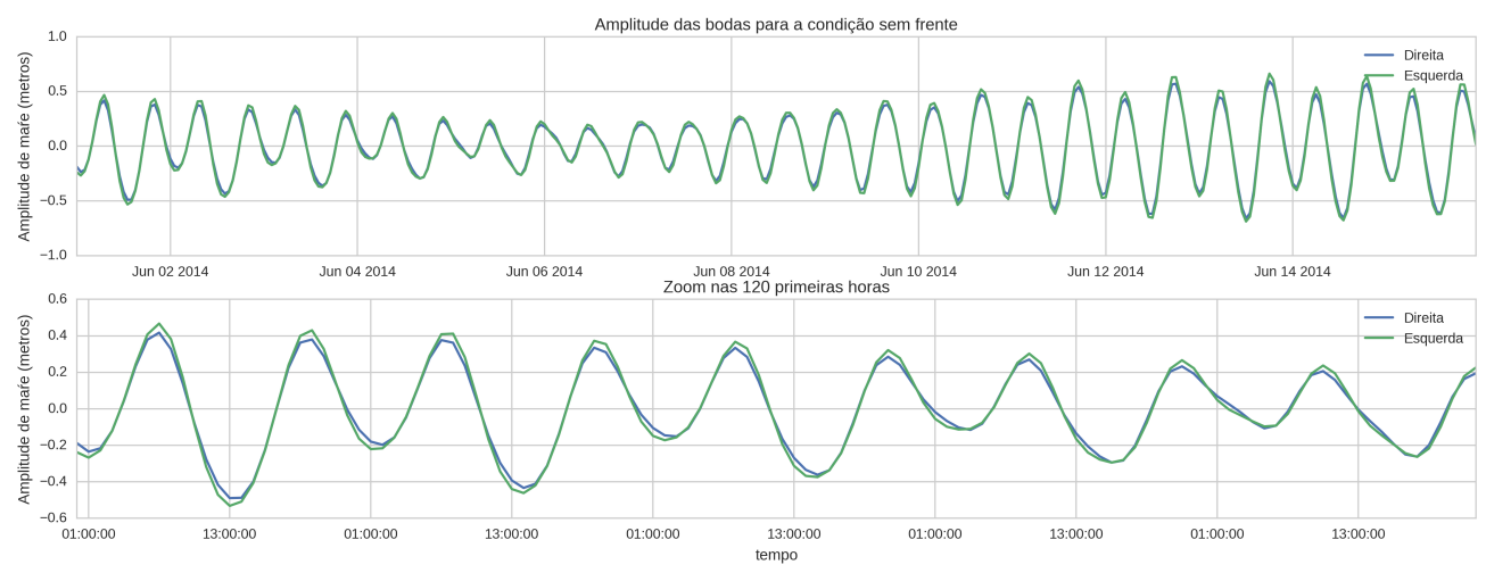

Figura 20 - Série de maré astronômica proveniente do modelo TOPEX/POSSEIDON 7.2 para o período de 01 de junho a 15 de junho de 2014 para os cantos direito e esquerdo da borda offshore do domínio de modelagem. A figura abaixo representa o zoom nas primeiras 120 horas da modelagem para ambas as bordas. 
As condições de ventos e ondas foram baseadas na análise de ocorrência conjunta de intensidade e direção. Nesta análise são apresentados histogramas direcionais cumulativos discretizados em 16 direções para a intensidade do vento, altura significativa e período de pico. Para os dados de onda foi utilizada a direção de pico e, em ambos os casos, é utilizada a convenção de direção meteorológica. As tabelas de ocorrência conjunta apresentam classes de intensidade para cada uma das 16 direções, os valores de médios e máximos para cada uma das direções também é apresentado bem como o número de ocorrências por classe de intensidade. Para os dados de intensidade e direção do vento apresentado na Figura 21 e Tabela 11, observase que os ventos ocorrem em todas as direções, com maior frequência nas octantes E e ENE (11,5\% e 11,4\% respectivamente), e as intensidades mais frequentes estão entre $2-6 \mathrm{~m} / \mathrm{s}$ com $71,6 \%$ das ocorrências. Os ventos mais intensos são geralmente oriundos de E-ENE e SSW-S, com intensidades médias de 4,9-4,8 e 4,3-4,5 e máximas de 12,5 -13,4 e 16,6-17,6. Os ventos desta região são principalmente de leste nordeste relacionado com a circulação da Zona de Convergência Intertropical (Cavalcanti, et al., 2016).

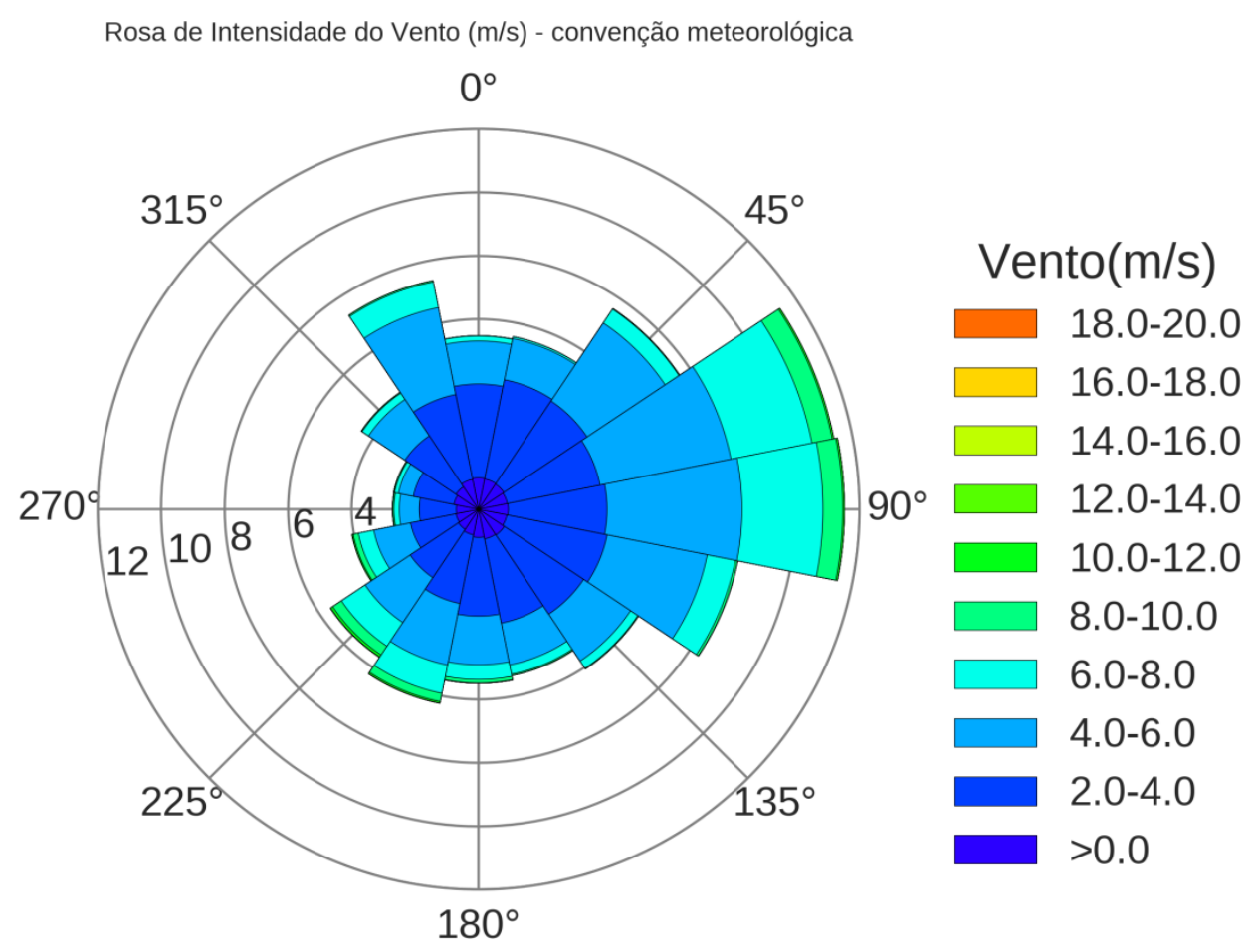

Figura 21 - Histograma direcional da intensidade dos ventos para o período de 1979 a 2015, convenção meteorológica. 
Tabela 10 - Tabela de ocorrência conjunta de direção e intensidade dos dados de vento para o período de 1979 a 2015.

\begin{tabular}{|c|c|c|c|c|c|c|c|c|c|c|c|c|c|c|c|c|c|}
\hline Vento(m/s) & $\mathbf{N}$ & NNE & NE & ENE & E & ESE & SE & SSE & $\mathbf{S}$ & ssw & sw & WSW & W & WNW & NW & NNW & (\%) \\
\hline $0,0-2,0$ & 3216 & 3164 & 3103 & 2987 & 3038 & 2942 & 3156 & 3086 & 2872 & 2666 & 2475 & 2353 & 2283 & 2572 & 2778 & 3126 & 14.1 \\
\hline $2,0-4,0$ & 9605 & 10356 & 10226 & 9667 & 10092 & 10450 & 9749 & 8785 & 8062 & 7157 & 5932 & 4739 & 3782 & 4227 & 6272 & 8850 & 39.5 \\
\hline $4,0-6,0$ & 4400 & 4301 & 9597 & 13635 & 13790 & 10424 & 5767 & 4365 & 4980 & 6419 & 5528 & 3822 & 2039 & 1547 & 4472 & 9070 & 32.1 \\
\hline $6,0-8,0$ & 514 & 192 & 1700 & 8444 & 8267 & 2930 & 894 & 977 & 1512 & 2963 & 2912 & 1605 & 544 & 404 & 787 & 2677 & 11.5 \\
\hline $8,0-10,0$ & 21 & 5 & 73 & 2106 & 2022 & 239 & 82 & 127 & 356 & 856 & 1072 & 536 & 130 & 93 & 85 & 138 & 2.4 \\
\hline $10,0-12,0$ & 2 & 0 & 2 & 166 & 168 & 18 & 1 & 20 & 45 & 164 & 258 & 121 & 29 & 15 & 9 & 9 & 0.3 \\
\hline $12,0-14,0$ & 1 & 1 & 0 & 7 & 6 & 4 & 0 & 1 & 3 & 24 & 32 & 21 & 5 & 0 & 4 & 0 & 0.0 \\
\hline $14,0-16,0$ & 0 & 1 & 0 & 0 & 0 & 0 & 0 & 0 & 1 & 5 & 3 & 0 & 0 & 0 & 0 & 0 & 0.0 \\
\hline $16,0-18,0$ & 0 & 0 & 0 & 0 & 0 & 0 & 0 & 0 & 0 & 1 & 1 & 0 & 0 & 0 & 0 & 0 & 0.0 \\
\hline (\%) & 5.5 & 5.6 & 7.6 & 11.4 & 11.5 & 8.3 & 6.1 & 5.4 & 5.5 & 6.2 & 5.6 & 4.1 & 2.7 & 2.7 & 4.4 & 7.4 & \\
\hline Media & 3.3 & 3.2 & 3.8 & 4.9 & 4.8 & 4.0 & 3.5 & 3.4 & 3.7 & 4.3 & 4.5 & 4.0 & 3.3 & 3.0 & 3.5 & 4.0 & \\
\hline Max. & 12.6 & 15.4 & 10.9 & 13.4 & 12.5 & 13.1 & 10.1 & 12.4 & 14.1 & 16.6 & 17.6 & 13.7 & 12.5 & 11.1 & 12.4 & 11.6 & \\
\hline
\end{tabular}

Para os dados de período de pico, altura significativa e direção de pico da onda apresentados na Figura 22, Tabela 11 e Tabela 12, observa-se que as ondas são de E a SSW com predomínio de S (32\% das ocorrências). Os períodos de pico de maior ocorrência estão entre 6 e 12 s (83,2\% das ocorrências). Os maiores valores são encontrados para as direções SSE S e SSW, onde as médias são 10,10,8 e 10 s e as máximas são 20,2 19,3 e 18,5 s, respectivamente. Já as principais alturas de onda ocorrem entre 1-2 m (59,4\%) sendo as maiores alturas médias de sul com destaque para SW com a altura média de onda de 2,2 $\mathrm{m}$ e alturas máximas de até 5,7 m para ondas de SE.

Estas características indicam que as principais ondas de swell vêm de sul, provavelmente associados a ventos de sul somados a efeitos de refração que direciona os trens de onda paralelamente a plataforma de acordo com a orientação isobatimétrica em frente ao estuário santista. As ondas mais energéticas (altas e de maior período) estão associadas a ondas de frentes frias de sul oriundas da Zona de Convergência do Atlântico Sul, onde a pista de vento é maior e mais distante da costa, além do vento apresentar-se mais intenso e com direção constante (Farinnaccio, et al., 2009; Cavalcanti, et al., 2016). 

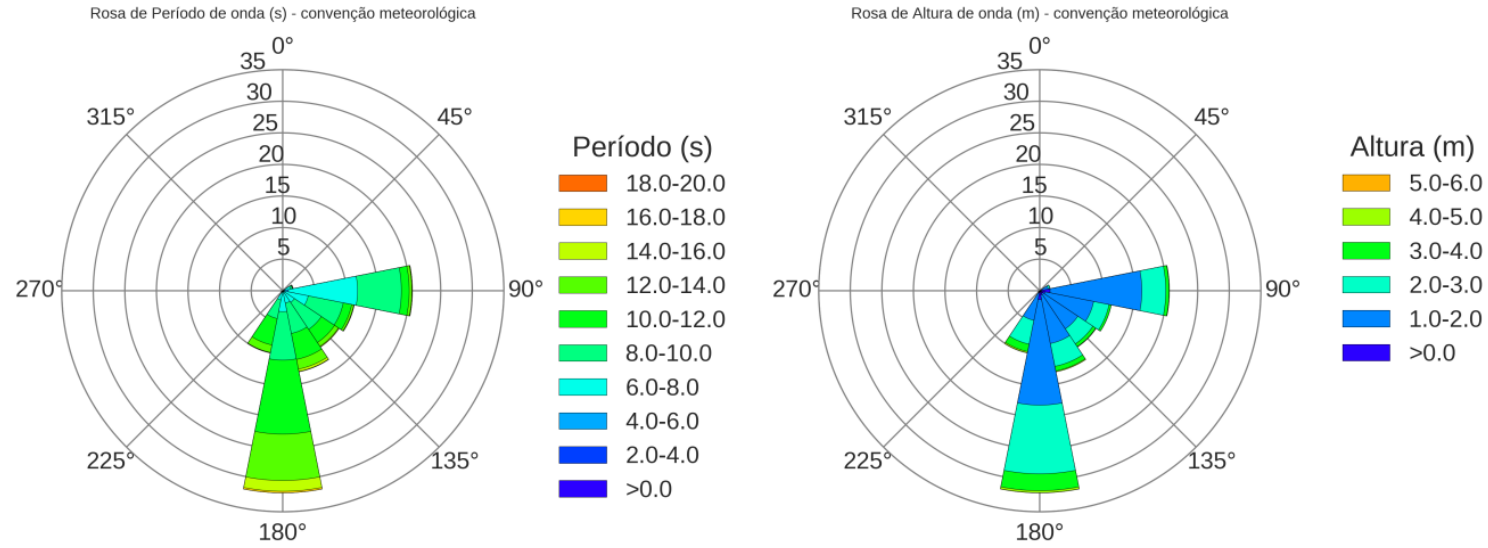

Figura 22 - Histogramas direcionais de onda para o período de 1979 a 2015, a esquerda apresentado o período de pico e a direita é apresentado a altura significativa, convenção meteorológica.

Tabela 11 -Tabela de ocorrência conjunta de direção e período de pico de onda para o período de 1979 a 2015.

\begin{tabular}{cccccccccccccccccc} 
Período (s) & N & NNE & NE & ENE & E & ESE & SE & SSE & S & SSW & SW & WSW & W & WNW & NW & NNW & $(\%)$ \\
\hline $\mathbf{0 , 0 - 2 , 0}$ & 0 & 0 & 1 & 0 & 0 & 0 & 0 & 0 & 0 & 0 & 0 & 0 & 0 & 0 & 0 & 1 & 0.0 \\
$\mathbf{2 , 0 - 4 , 0}$ & 0 & 0 & 0 & 5 & 4 & 2 & 3 & 0 & 6 & 2 & 3 & 5 & 4 & 1 & 1 & 3 & 0.0 \\
$\mathbf{4 , 0 - 6 , 0}$ & 0 & 0 & 0 & 308 & 926 & 189 & 147 & 154 & 308 & 189 & 90 & 56 & 17 & 4 & 1 & 0 & 2.3 \\
$\mathbf{6 , 0 - 8 , 0}$ & 0 & 1 & 0 & 1012 & 11483 & 4111 & 2176 & 1934 & 3158 & 1369 & 155 & 9 & 2 & 0 & 0 & 0 & 24.2 \\
$\mathbf{8 , 0 - 1 0 , 0}$ & 0 & 0 & 0 & 274 & 7281 & 5936 & 5380 & 5140 & 8051 & 3142 & 53 & 10 & 3 & 2 & 0 & 0 & 33.6 \\
$\mathbf{1 0 , 0 - 1 2 , 0}$ & 0 & 0 & 0 & 92 & 1294 & 1424 & 2636 & 4394 & 12283 & 4478 & 18 & 10 & 1 & 0 & 0 & 0 & 25.4 \\
$\mathbf{1 2 , 0 - 1 4 , 0}$ & 0 & 0 & 0 & 55 & 426 & 349 & 764 & 1646 & 7706 & 1271 & 7 & 0 & 0 & 0 & 1 & 0 & 11.7 \\
$\mathbf{1 4 , 0 - 1 6 , 0}$ & 0 & 0 & 0 & 6 & 83 & 65 & 123 & 402 & 1786 & 46 & 1 & 1 & 0 & 0 & 0 & 0 & 2.4 \\
$\mathbf{1 6 , 0 - 1 8 , 0}$ & 0 & 0 & 0 & 1 & 20 & 17 & 17 & 40 & 261 & 7 & 0 & 0 & 0 & 0 & 0 & 0 & 0.3 \\
$\mathbf{1 8 , 0 - 2 0 , 0}$ & 0 & 0 & 0 & 0 & 3 & 1 & 0 & 18 & 9 & 1 & 0 & 0 & 0 & 0 & 0 & 0 & 0.0 \\
$\mathbf{( \% )}$ & 0.0 & 0.0 & 0.0 & 1.7 & 20.5 & 11.5 & 10.7 & 13.1 & 32.0 & 10.0 & 0.3 & 0.1 & 0.0 & 0.0 & 0.0 & 0.0 & \\
Media & 0.0 & 6.7 & 1.1 & 7.4 & 8.0 & 8.7 & 9.4 & 10.0 & 10.8 & 10.0 & 7.0 & 6.2 & 5.7 & 6.1 & 6.9 & 2.8 & \\
Max. & 0.0 & 6.7 & 1.1 & 16.2 & 18.9 & 18.0 & 17.7 & 20.2 & 19.3 & 18.5 & 14.2 & 14.3 & 10.0 & 9.9 & 12.8 & 3.5 \\
\hline
\end{tabular}

Tabela 12 - Tabela de ocorrência conjunta de direção de pico e altura significativa de onda para o período de 1979 a 2015.

\begin{tabular}{cccccccccccccccccc}
\hline Altura $(\mathbf{m})$ & $\mathbf{N}$ & NNE & NE & ENE & E & ESE & SE & SSE & S & SSW & SW & WSW & W & WNW & NW & NNW & $(\%)$ \\
\hline $\mathbf{0 , 0 - 1 , 0}$ & 0 & 0 & 1 & 264 & 1708 & 883 & 520 & 751 & 1462 & 361 & 8 & 6 & 4 & 2 & 2 & 4 & 5.7 \\
$\mathbf{1 , 0 - 2 , 0}$ & 0 & 0 & 0 & 1161 & 15238 & 8231 & 7086 & 8182 & 17532 & 4638 & 136 & 67 & 17 & 4 & 1 & 0 & 59.4 \\
$\mathbf{2 , 0 - 3 , 0}$ & 0 & 1 & 0 & 288 & 3975 & 2604 & 3003 & 3868 & 11411 & 4040 & 141 & 18 & 6 & 1 & 0 & 0 & 28.0 \\
$\mathbf{3 , 0 - 4 , 0}$ & 0 & 0 & 0 & 38 & 536 & 364 & 568 & 784 & 2794 & 1253 & 37 & 0 & 0 & 0 & 0 & 0 & 6.1 \\
$\mathbf{4 , 0 - 5 , 0}$ & 0 & 0 & 0 & 2 & 59 & 9 & 54 & 140 & 343 & 208 & 5 & 0 & 0 & 0 & 0 & 0 & 0.8 \\
$\mathbf{5 , 0 - 6 , 0}$ & 0 & 0 & 0 & 0 & 4 & 3 & 15 & 4 & 26 & 5 & 0 & 0 & 0 & 0 & 0 & 0 & 0.1 \\
$(\%)$ & 0.0 & 0.0 & 0.0 & 1.7 & 20.5 & 11.5 & 10.7 & 13.1 & 32.0 & 10.0 & 0.3 & 0.1 & 0.0 & 0.0 & 0.0 & 0.0 & \\
Media & 0.0 & 2.4 & 0.1 & 1.6 & 1.6 & 1.7 & 1.8 & 1.9 & 2.0 & 2.1 & 2.2 & 1.7 & 1.6 & 1.4 & 1.0 & 0.5 & \\
Max. & 0.0 & 2.4 & 0.1 & 4.2 & 5.4 & 5.2 & 5.7 & 5.2 & 5.6 & 5.4 & 4.3 & 2.8 & 2.4 & 2.2 & 1.7 & 0.7 \\
\hline
\end{tabular}

Após a caracterização das ondas e dos ventos incidentes na região, foram escolhidos os valores médios para as direções de maior ocorrência na 
área de estudo, e estas condições serão as consideradas na modelagem do cenário sem frentes frias (Tabela 13).

Tabela 13 - Valores de onda e vento para o cenários sem frentes frias.

\begin{tabular}{|c|c|}
\hline Parâmetro & Valor \\
\hline \hline Intensidade do vento $(\mathrm{m} / \mathrm{s})$ & 4,8 \\
\hline Direção do vento $\left(^{\circ}\right)$ & 88 \\
\hline Altura significativa $(\mathrm{m})$ & 2 \\
\hline Período de pico $(\mathrm{s})$ & 10.8 \\
\hline Direção de pico $\left(^{\circ}\right)$ & 180 \\
\hline
\end{tabular}

\subsubsection{Cenários com presença de frente fria}

Os cenários de FFM e FFE consistem na inserção do sinal meteooceanográfico de frente fria nos cinco primeiros dias de simulação da condição sem frente. Isso significa que temos um sinal de frente fria por 120 horas e 0 restante da simulação corresponde novamente a condição típica.. A série de nível do mar é apresentada na Figura 23 para a condição de FFM e na Figura 24 para FFE em cada um dos cantos, podendo-se observar uma que na condição de FFM o nível amplificou a maré em até $0,63 \mathrm{~m}$ enquanto que na condição de FFE o nível foi amplificado para 1,3m. Considerando estes resultados e que o regime do estuário santista é de micromaré (Harari \& Camargo, 1998), constata-se que o sinal de maré apresentará uma forte assimetria reduzindo a amplitude de vazante e aumentando a de enchente afetando diretamente a circulação do estuário (Dronkers, 1986)

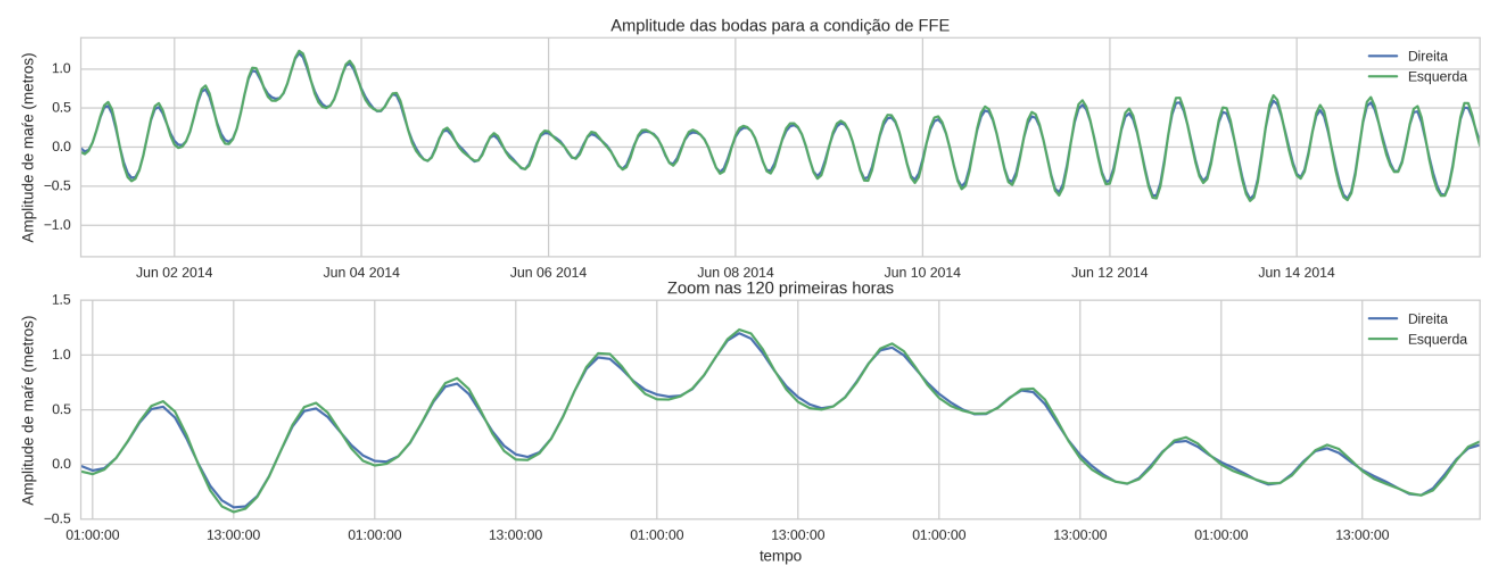

Figura 23 - Série temporal do nível do mar para a condição de FFM. Zoom nas primeiras 120 horas para demonstração da frente inserida (período de 01 de junho de 2014 00:00 a 06 de junho de 2014 00:00) . 


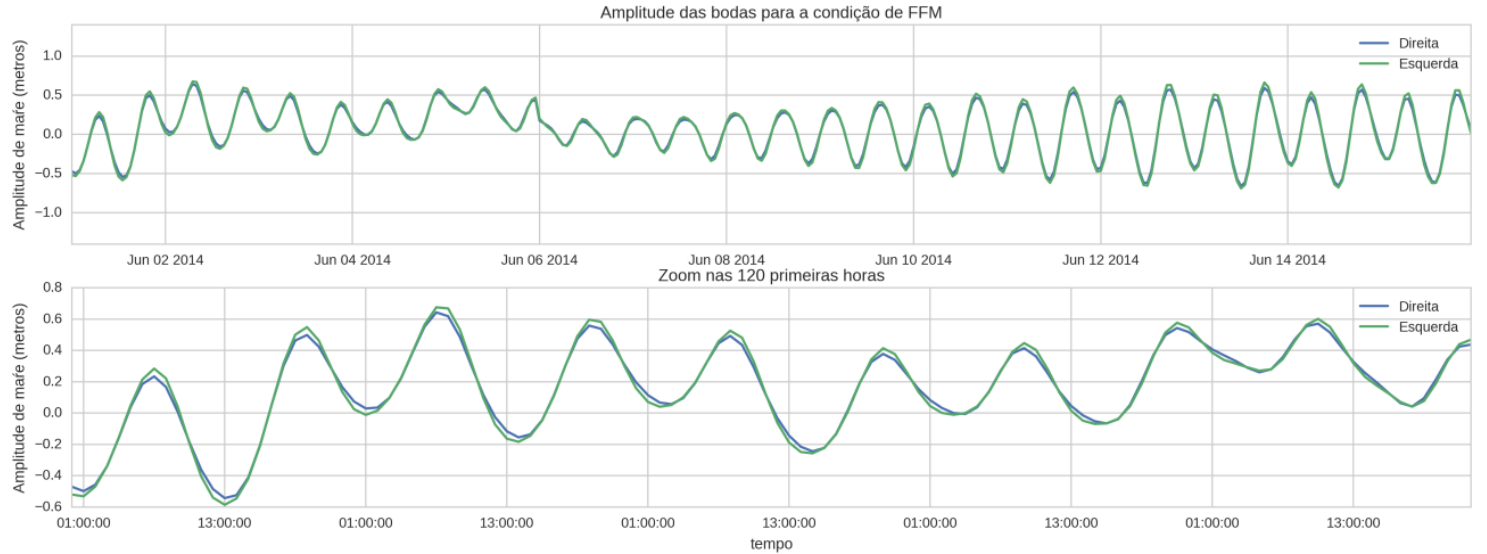

Figura 24 - Série temporal do nível do mar para a condição de FFE. Zoom nas primeiras 120 horas para demonstração da frente inserida período de 01 de junho de 2014 00:00 a 06 de junho de 2014 00:00).

No que diz respeito às ondas, os dados de frentes que foram inseridos como condição de contorno são apresentados nas Figura 25 e Figura 26, para as condições de FFE e FFM respectivamente. As setas indicam a direção geográfica na convenção meteorológica, e as cores de fundo indicam a intensidade e a linha pontilhada em vermelho indica o período em segundos. Nota-se uma maior continuidade e duração na FFE do que na FFM nas condições de ondas, demonstrando que a condição extrema permanece por mais tempo que a média. Observa-se que as ondas possuem períodos e alturas muito maiores na condição de FFE do que de FFM e que para ambos os casos a direção de onda é sempre de sul. Na condição de FFM o sinal de duas frentes é observado nas ondas, observa-se um aumento, diminuição e novo aumento das ondas na condição média, o mesmo sinal de nível do mar e vento de sul encontrado na Figura 11. 


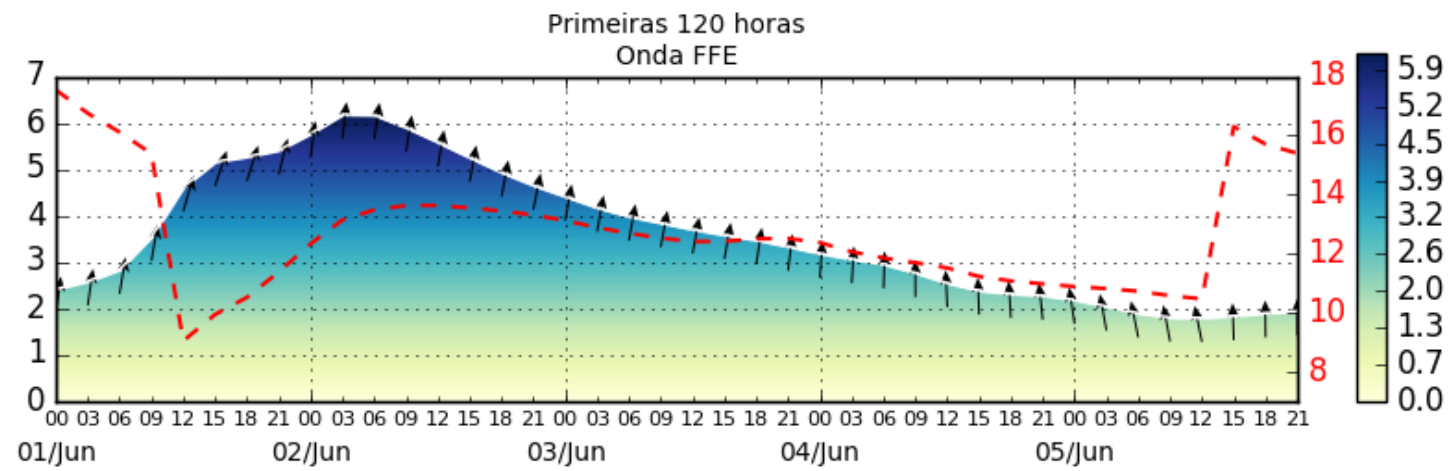

Figura 25 - Série de ondas para as 120 primeiras horas de modelagem para o cenário de FFE, período de 01 a 06 de junho de 2014.

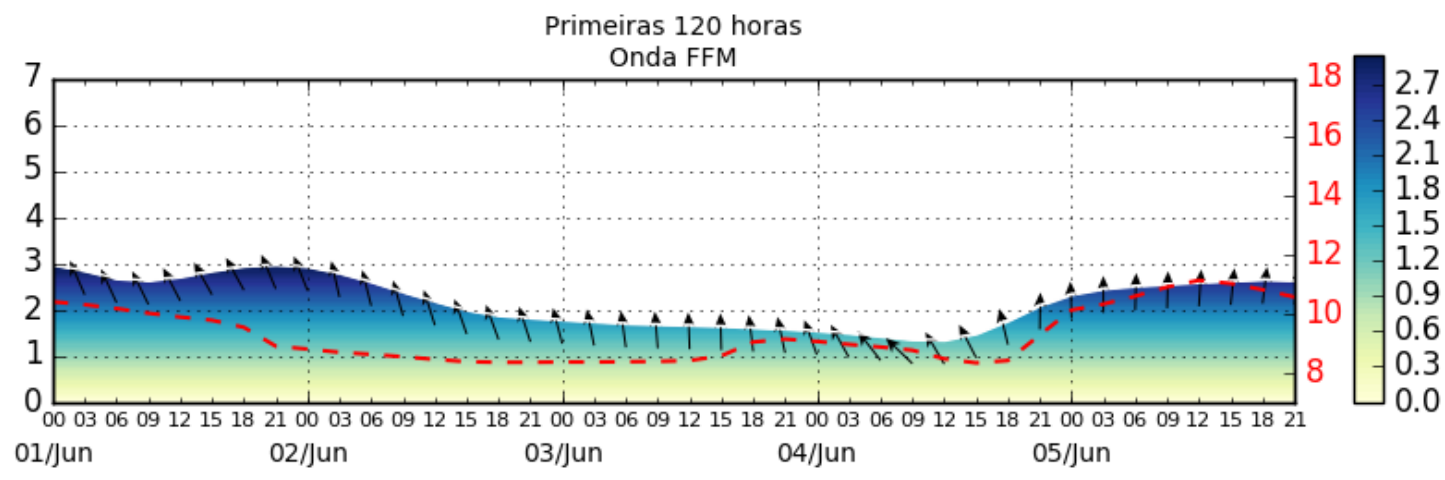

Figura 26 - Série de ondas para as 120 primeiras horas de modelagem para o cenário de FFM, período de 01 a 06 de junho de 2014.

\subsection{Resultados da modelagem numérica}

Os resultados da modelagem são todos apresentados em campos espaciais de erosão e deposição do final de um período da simulação, ou da mesma como um todo. Nestes campos, a cor vermelha e azul indica as regiões de erosão e deposição (em metros), respectivamente. As isolinhas pretas indicam a costa e as cotas batimétricas de 20,15,10,5 0 e -2 metros, e os vetores de mesmo tamanho indicam apenas a direção residual do transporte de sedimento para o período de simulação analisado. Uma breve descrição da dinâmica sedimentar das condições sem frentes frias é apresentada a seguir. Posteriormente, os resultados das outras condições de frentes frias serão apresentados, como critério comparativo.

\subsubsection{Descrição da dinâmica sedimentar do cenário sem frentes frias}

A seguir são apresentados os campos de transporte de sedimento 
resultantes dos cenários onde não há ocorrência de maré meteorológica, e, portanto, a subida e descida do nível do mar é regida apenas pela maré astronômica, adicionalmente, os ventos e ondas provêm de uma única direção com uma intensidade média. O período simulado corresponde foi de 15 dias apresentando um sinal de sizígia e outro de quadratura, portanto, pode-se dizer que os resultados finais também são influenciados pela maré astronômica nas duas condições principais, visto o domínio das componentes semidiurnas (Harari \& Camargo, 2006).

Primeiramente, ao olharmos a Baía de Santos (Figura 27), observa-se que o sedimento é trazido pelos canais é transportado para fora da baía como observado no mapa de transporte de sedimentos residual de Rocha (2003) e nos resultados numéricos da corrente residual de Magini e colaboradores (2007). As desembocaduras dos canais do Porto e de São Vicente são regiões deposicionais conforme constatado em Fukamoto, (2003). As setas, que indicam a direção média do transporte de fundo, demonstram diferenças na direção entre a região com profundidades maiores que a isóbata de $15 \mathrm{~m}$ (funda) em relação à região de profundidades menores que $15 \mathrm{~m}$ (rasa). $\mathrm{Na}$ região rasa observa-se uma rotação do transporte que é inicialmente de oeste para leste, e que se altera para SSE com o aumento da profundidade local. Portanto pode-se inferir que esta configuração direcional do transporte sedimentar determina a diferença de orientação isobatimétrica da baía nas porções leste e oeste. O gradiente deposicional da baía é inverso ao transporte de sedimentos da região mais rasa, portanto, embora o sedimento seja transportado de oeste para leste, há maior deposição na baía na parte oeste do que na parte leste. Esta característica da Baía de Santos tem relação com o gradiente deposicional, que possui direção inversa ao transporte na região rasa provavelmente associado ao sedimento trazido do Estuário de São Vicente e pelo sedimento oceânico. Este padrão é distinto do encontrado nos modelos de transporte e circulação encontrados em Rocha (2003). Em uma análise das forçantes dos dois modelos de circulação, o Canal de Navegação na Baía de Santos é resentado no modelo numérico deste trabalho, o que não ocorre no trabalho da autora, isto provavelmente é a principal divergência entre os resultados encontrados. Além disso, o modelo de transporte residual de 
sedimentos aplicado por Rocha (2003) considera a parcela coesiva do material o que não é representado nesta aplicação do XBeach. Todavia o resultado encontrado corrobora com o modelo de transporte de sedimentos sugerido por Ponçano (1985) onde o sedimento chega no estuário pela porção oeste até a região próxima a costa e é transportado em seguida para leste em direção ao Estuário do Canal do Porto de Santos. Ressalta-se que os vetores correspondem ao transporte residual, o que significa que após o efeito bidirecional das correntes de maré sobre o sedimento o predomínio das correntes mais intensas sobre uma determinada área determinarão 0 transportefinal do material.

O transporte em frente à Praia de Itararé indicado pelos vetores mostra que esta região exporta parte do sedimento diretamente para fora da baía, sem que o mesmo seja levado para as outras praias. Isto ocorre em função da restrição da circulação costeira forçada pelo Emissário Submarino junto a llha de Urubuqueçaba (Magini, et al., 2007). Já na região das praias do município de Santos, observa-se uma divergência longitudinal, do transporte aproximadamente sobre a isóbata de $5 \mathrm{~m}$, isso significa que parte do sedimento é depositado na praia, e parte é exportada ao longo da deriva litorânea até um aumento abrupto de declividade em função do Canal de Navegação, onde a direção muda completamente, por vezes invertendo completamente o sentido indicando uma área deposicional.

Os vetores de direção do transporte de sedimentos de fundo na parte leste do canal indicam que o sedimento trazido pelo Canal do Porto é transportado para o fundo do Canal de Navegação da Baía de Santos. Consequentemente as correntes de vazante do Canal do Porto não transportaram sedimento ao longo da região rasa da Baía já que o Canal de Navegação na Baía atua como uma armadilha de sedimentos restringindo principalmente o material proveniente do Estuário do Canal do Porto de Santos. $\mathrm{Na}$ porção oeste da baía, em frente à llha Porchat, encontra-se a área deposicional mais expressiva da área de estudo. A formação desta feição deposicional em frente à desembocadura do Canal de São Vicente é a somatória do encontro das correntes de oeste para leste na situação de maré vazante que confluem próximas a llha Porchat (Harari \& Camargo, 1998; 
Magini, et al., 2007; Gregório, 2009; Roversi, 2012), ao comportamento interno da circulação do Estuário de São Vicente que se comporta como delta de maré vazante e com as correntes oceânicas que entram na baía pela borda oeste. É a soma destes três fenômenos que permite a intensificação da deposição na desembocadura do estuário sendo as correntes de vazante as principais responsáveis por mobilizar este material da frente da desembocadura do canal em direção ao centro da baía.

Quanto ao gradiente deposicional, este corresponde ao sedimento transportado das praias para a região de influência da corrente de maré vazante do Canal do Porto, onde esta corrente é mais próxima a desembocadura (intensa) ela tende a transportar o sedimento mais rapidamente para o fundo do que em regiões mais distantes (fraca). Ao observarmos as regiões mais profundas, percebemos o sedimento não tende a deposição no fundo da baía sendo exportado para regiões mais ao largo, em direção a plataforma continental. Quanto a região do canal de navegação, há um perfil deposicional e no interior do canal e erosivo apenas no lado leste, este perfil é relacionado ao processo de deslizamento pelo gradiente batimétrico. Para esta região ele ocorre apenas de um lado do canal por conta do excesso de sedimento depositado do lado oeste, proveniente da dinâmica de região mais rasa anteriormente mencionada. 


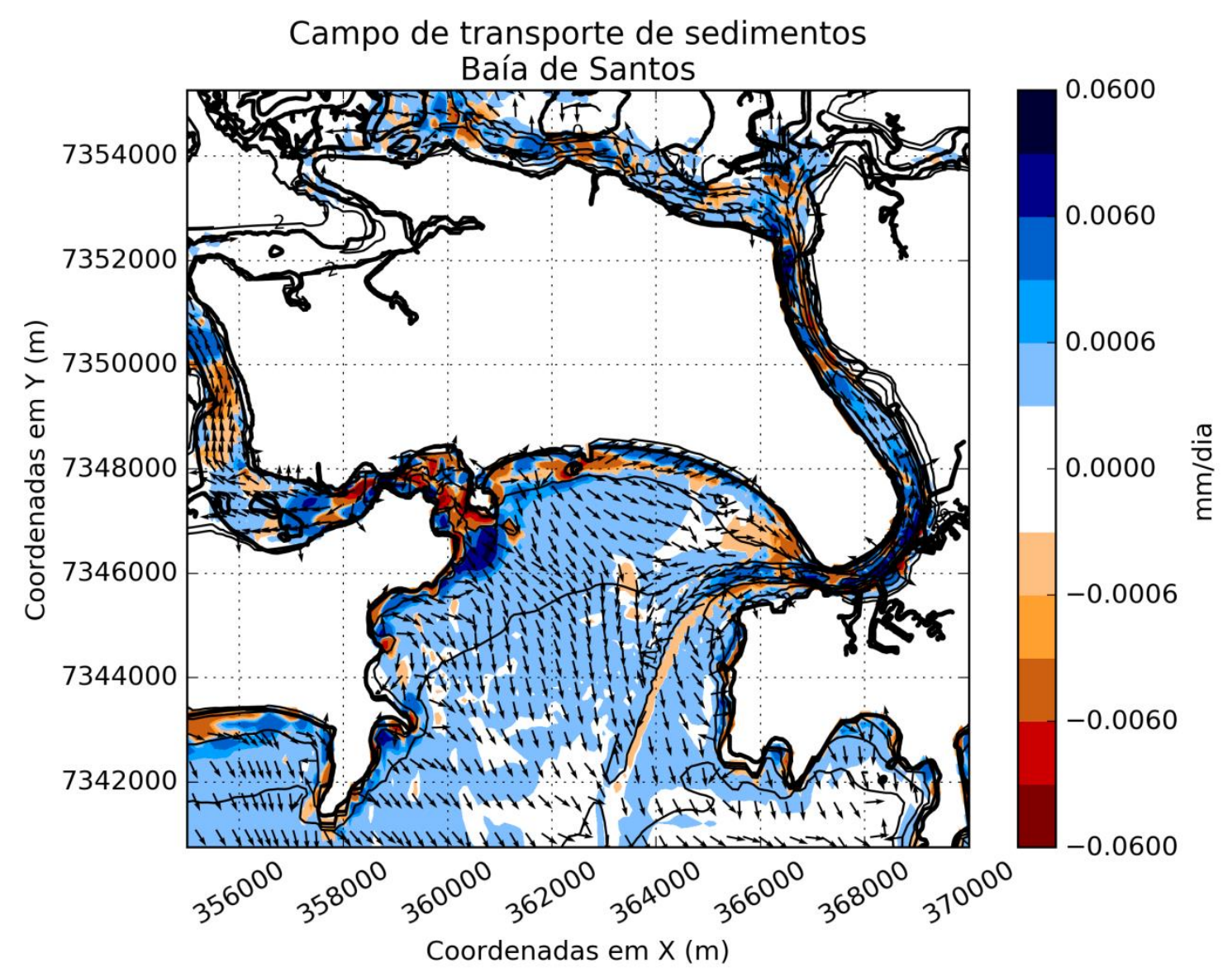

Figura 27 - Campos das regiões de deposição e erosão da Baía de Santos para o final da simulação, as cores azul e vermelhas representam os valores em metros, as setas verdes as direções residuais do transporte as linhas pretas representam as cotas batimétricas de 20,15,10,0 e -2 metros projeção UTM zona 23 datum WGS84..

Além da região da Baía de Santos, outra região tema deste trabalho refere-se à praia da desembocadura do Canal de Bertioga (Figura 28), constata-se uma região de baixa dinâmica sedimentar quando comparado a Baía de Santos. Primeiramente vale mencionar que esta região apresenta células menos resolvidas do que as da baía, e a discretização meridional é muito maior do que a zonal. A direção do transporte apresenta um ponto de divergência na região centro-oeste da praia de Bertioga onde a dinâmica sedimentar parece ser mais intensa. A partir deste ponto de divergência há uma corrente de deriva mais longa rumando para nordeste e outra curta em direção sudoeste. A caracterização da deriva litorânea é também apreciada na 
forma difusa que os vetores de transporte são encontrados, sendo o processo de deriva bem definido pelos vetores das regiões imediatamente emersas que apontam para nordete ou sudoeste. Outro ponto de maior dinâmica sedimentar é observado na porção leste da praia, onde um promontório permite uma zona de mais abrigada da energia de ondas proporcionando uma zona de maior deposição.

De um modo geral, as regiões de erosão e deposição ao longo da praia não apresentam padrão bem definido, indicando que a dinâmica praial possivelmente mantém o balanço sedimentar sem grandes alterações. Na zona submersa um pouco distante da linha de costa observa-se uma faixa erosiva que acompanha a linha de costa, seguida de outra deposicional ainda mais distante. Estas feições são indícios de que a dinâmica incidente média busca suavizar o perfil da praia em relação à batimetria. 


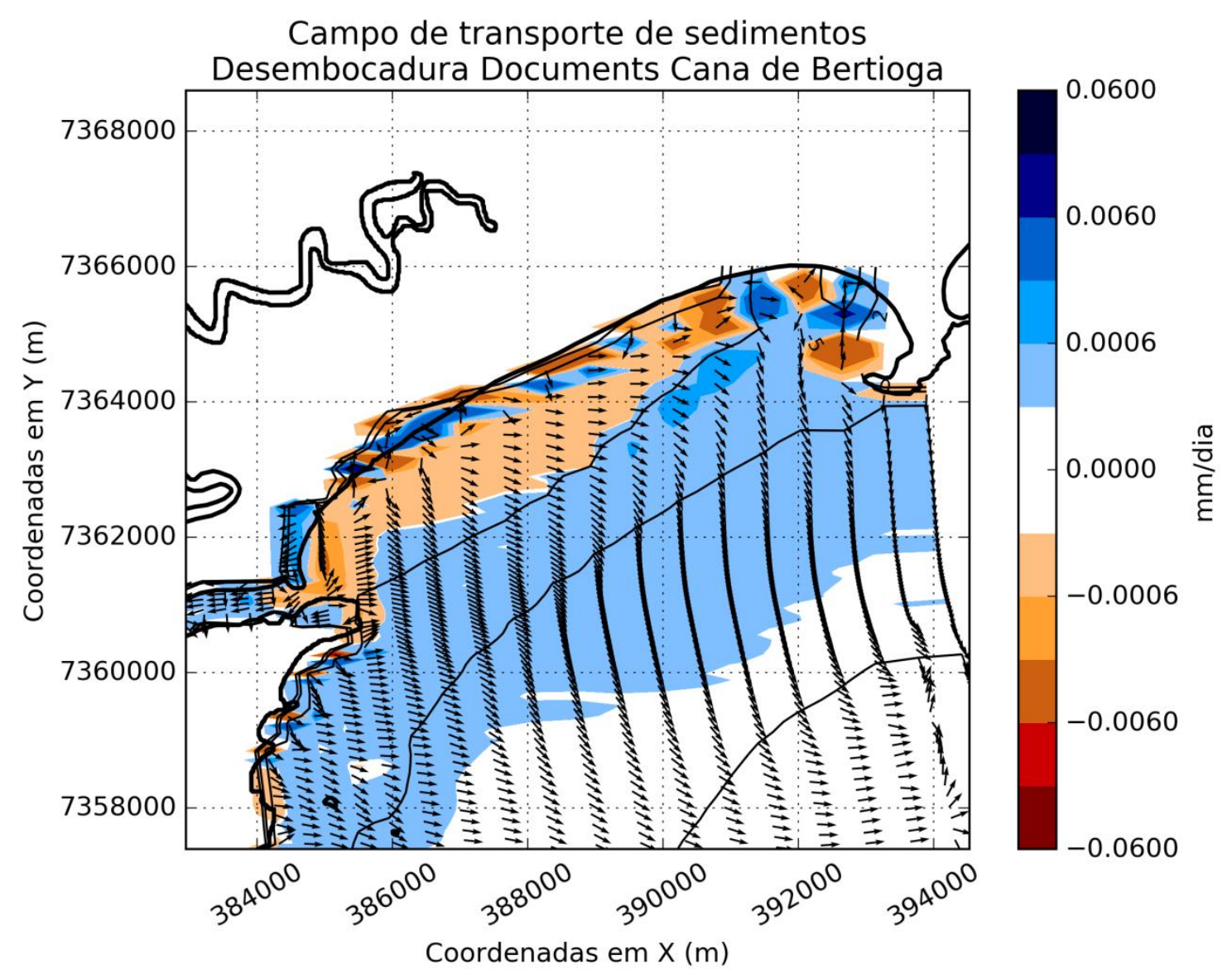

Figura 28 - Campos das regiões de deposição e erosão da desembocadura do Canal de Bertioga para o final da simulação, as cores azul e vermelhas representam os valores em metros, as setas verdes as direções residuais do transporte as linhas pretas representam as cotas batimétricas de 20,15,10,0 e -2 metros - projeção UTM zona 23 datum WGS84. .

Do outro lado do Canal de Bertioga, na porção norte do Canal do Porto (Figura 29), o transporte de sedimentos tende a rumar em direção a baía com expressivas taxas de deposição e erosão. As regiões erosivas e deposicionais estão localizadas principalmente ao longo do canal de navegação, onde os gradientes batimétricos propiciam deslizamentos de sedimentos. Estes deslizamentos removem sedimentos das bordas do canal em direção ao centro do mesmo, como observado no sinal convergente dos vetores que representam a direção do transporte. Este comportamento justifica as características deposicionais das regiões mais profundas, e erosivas nas imediações. Em virtude da dragagem de manutenção do canal do porto para que o mesmo 
mantenha suas cotas batimétricas.

Como mencionado anteriormente, as correntes de vazante são mais intensas do que as de enchente, e o transporte de sedimento no Canal do Porto move material do Canal de Piaçaguera até a Baía de Santos. Além do fluxo intenso, a impermeabilização das margens de quase todo o canal impossibilita a formação de zonas deposicionais, salvo o interior do canal de navegação, fazendo com que o sedimento seja carregado ao longo do canal em direção a sua desembocadura sem a possibilidade de uma possível alteração na sua configuração geomorfológica.

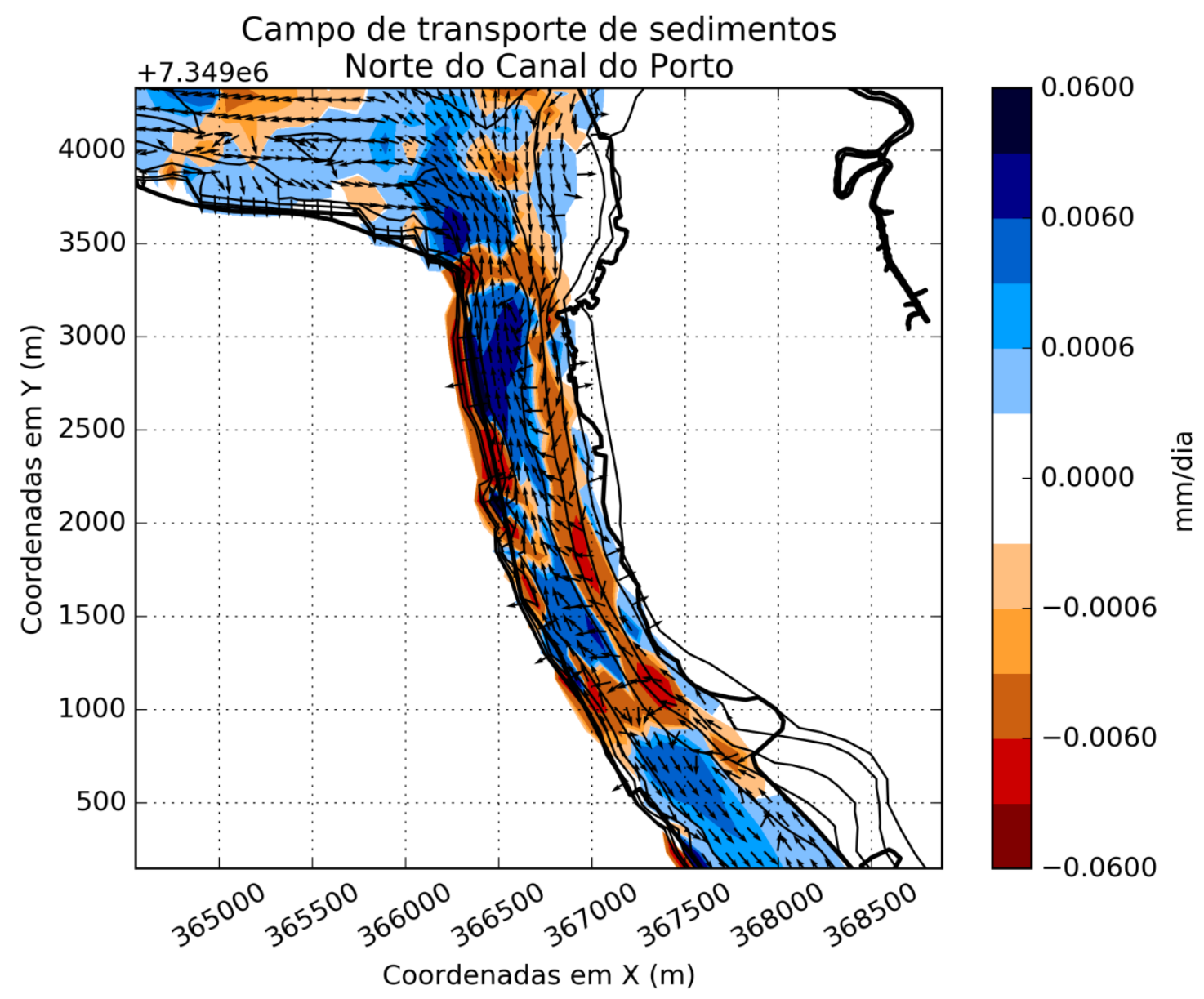

Figura 29 - Campos das regiões de deposição e erosão da região norte do Canal do Porto para o final da simulação, as cores azul e vermelhas representam os valores em metros, as setas verdes as direções residuais do transporte as linhas pretas representam as cotas batimétricas de 20,15,10,0 e 2 metros - projeção UTM zona 23 datum WGS84. 
O mesmo comportamento encontrado na parte norte do Canal do Porto é constatado na parte sul (Figura 30), tanto no que diz respeito ao destino do sedimento quanto nas características erosivas/deposicionais do Canal de Navegação. Uma das situações de destaque é que nas praias de Santos encontra-se uma região de divergência na deriva litorânea ao sul da Praia de Aparecida. Na porção norte o sedimento encontra-se em movimentação de deriva para noroeste, com tendência de acumulação e erosão aproximadamente em balanço em função da proximidade das células de erosão e deposição semelhantes às encontradas na Figura 28.

No caso do ramo sudeste da corrente de deriva litorânea, parte sul da Praia de Aparecida e a Ponta da Praia, a região apresenta comportamento completamente erosivo como constatado no trabalho de Farinnacio e colaboradores (2009) e Italiani (2015), sendo o sedimento transportado para o fundo do Canal do Porto.

No que diz respeito a rotação praial encontrada por Souza (2015), os resultados do transporte de sedimento na região impossibilitam a constatação deste fenômeno ou de qualquer outro sobre a Praia do Góes, visto que o modelo não apresenta células suficientemente resolvidas para descrever os processos desta região. 


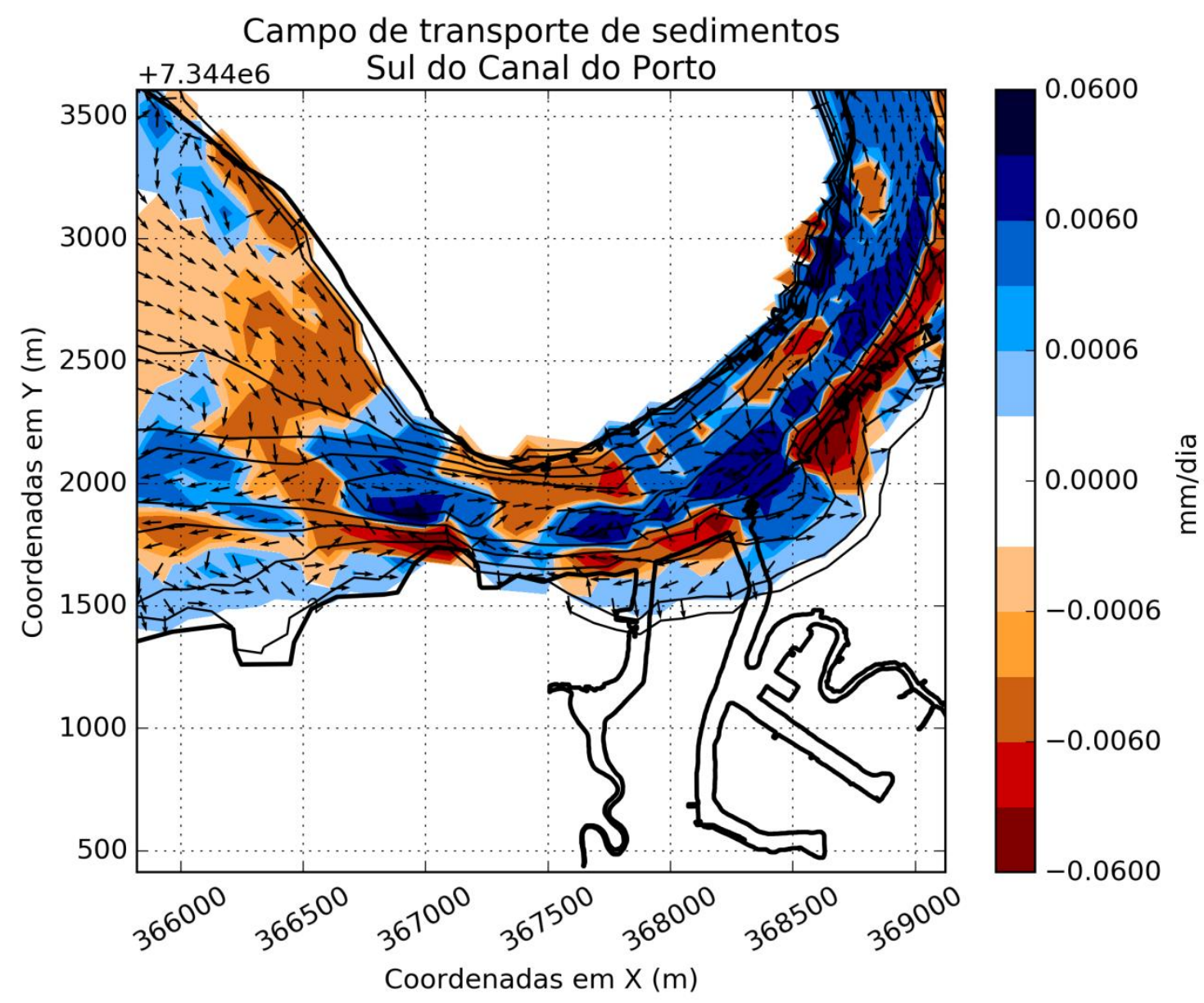

Figura 30 - Campos das regiões de deposição e erosão da região norte do Canal do Porto para o final da simulação, as cores azul e vermelhas representam os valores em metros, as setas verdes as direções residuais do transporte as linhas pretas representam as cotas batimétricas de 20,15,10,0 e 2 metros - projeção UTM zona 23 datum WGS84..

As regiões das praias de Santos e São Vicente apresentam características distintas como mencionado anteriormente (Figura 31). A Praia de Itararé, em São Vicente e José Menino em Santos, possuem duas regiões de elevada deposição. A primeira encontra-se entre a ilha de Urubuqueçaba e o continente onde por vezes forma-se um tômbolo já que esta ilha atua como uma protetora das ondas (Rocha, 2003). A outra região deposicional encontrase na parte oeste da praia, ao lado da llha Porchat (Farinnaccio, et al., 2009). No centro da praia, os vetores de transporte indicam um movimento de convecção, com divergência nas zonas imediatamente vizinhas. A 
movimentação da zona de surf em direção as praias é representada por uma faixa erosiva leve no centro da praia de itararé, que exporta sedimentos para a região adjacente mais profunda, conforme descrito anteriormente. Sobre a deriva, há um sinal de transporte para sudeste que transporta o sedimento depositado em regiões mais profundas, como observado na Figura 27.

$\mathrm{Na}$ região das praias de Santos, o transporte tende para leste em função da dinâmica de ondas simulada, principalmente em relação aoprocesso de refração da isóbata de 10 para a de $5 \mathrm{~m}$ onde as ondas mais a oeste rotacionam menos do que as ondas mais a leste. Ao longo de quase todas as praias observa-se uma leve erosão na zona submersa e a deposição na zona parcialmente emersa, correspondendo à dinâmica da zona de surf que transporta sedimentos das regiões profundas para a região emersa adjacente, em condições menos energéticas. Este transporte é mais pronunciado na parte oeste das praias e perde intensidade no sinal conforme se aproxima do Canal do Porto.

A leste, observa-se uma região onde a deriva litorânea converge com a corrente de deriva litorânea da Praia da Aparecida, exatamente na região onde a deposição/erosão nula, e a direção do transporte move o sedimento em partes para sul e para o fundo do canal de navegação. 


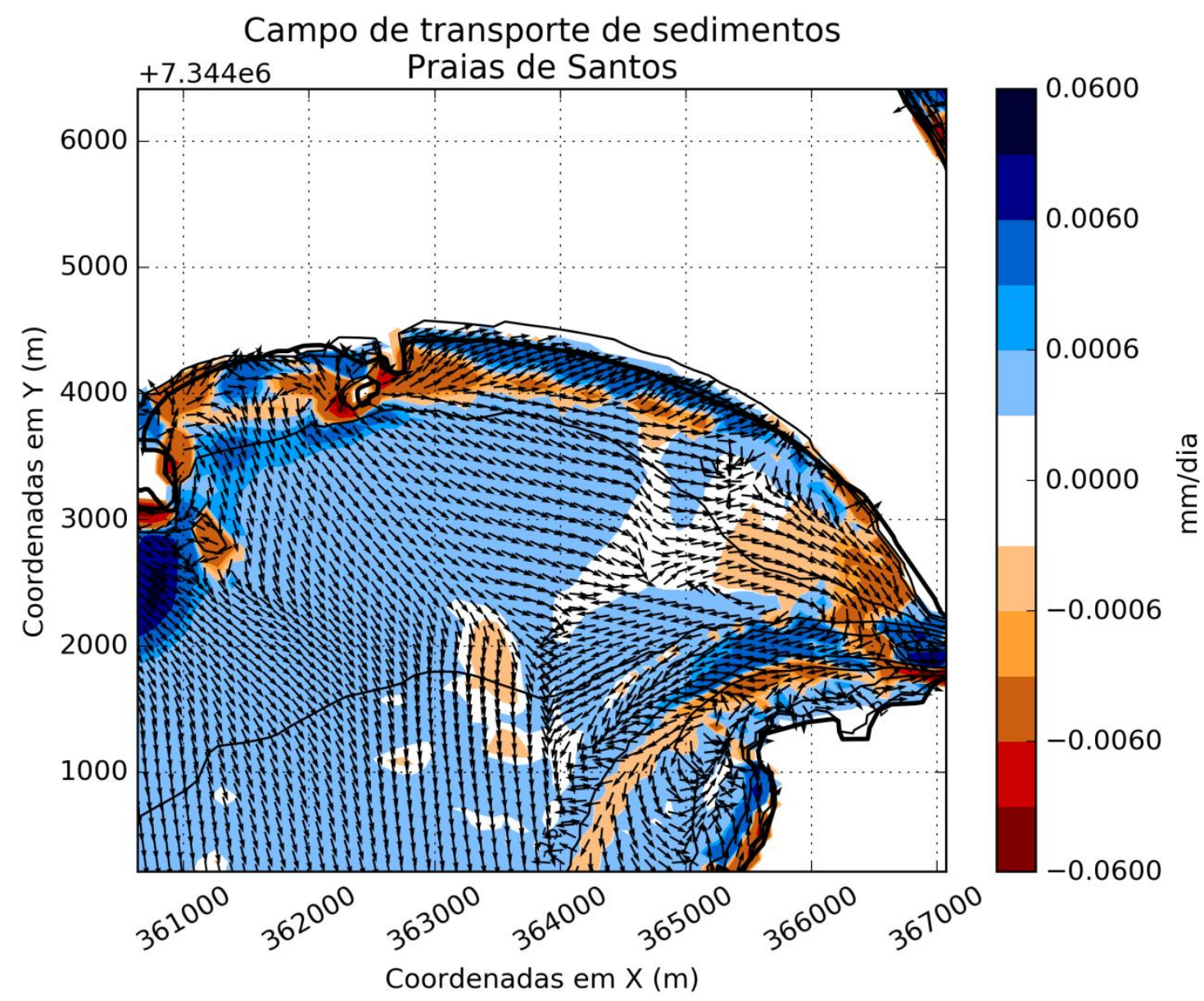

Figura 31 - Campos das regiões de deposição e erosão da região das praias deSantos para o final da simulação, as cores azul e vermelhas representam os valores em metros, as setas verdes as direções residuais do transporte as linhas pretas representam as cotas batimétricas de 20,15,10,0 e 2 metros - projeção UTM zona 23 datum WGS84.

A desembocadura do canal de São Vicente (Figura 32) recebe sedimentos preferencialmente pelas laterais, associado a um caráter erosivo tanto nos arredores da llha Porchat, quanto ao longo do continente. Este material, ao se encontrar com o fluxo do canal, é levado para fora ou depositando na baía de São Vicente ou na desembocadura do canal, dependendo da fase da maré. Pela feição deposicional encontrada na desembocadura e precedida por uma feição erosiva, acredita-se que o Canal de São Vicente apresenta um comportamento característico de maré vazante como observado em outros lugares do mundo. (Dronkers, 1986; Anthony \& 
Héquette, 2007)

Ao longo do tômbolo da llha Porchat encontra-se uma feição erosiva correspondente à região da praia dos Milionários, praia que praticamente desapareceu em função da interrupção da deriva litorânea causado pela construção da ligação da llha Porchat ao continente (Farinnaccio, et al., 2009). Já na região interna ao canal, o sedimento é transportado das regiões adjacentes para as feições mais profundas como na parte do canal onde há um estreitamento e no centro da Baía de São Vicente com uma depressão imediatamente em frente à praia dos Milionários. Ao norte da Baia de São Vicente, na Praia do Gonzaguinha, encontra-se uma região aproximadamente estável, ao menos para as condições sem frente, possivelmente esta característica é relacionada a herança geológica que permitiu a formação de uma praia bem protegida da ação de ondas nesta região. Ainda sobre esta praia observa-se uma região deposicional na parte oeste e leste, e ao que os vetores indicam, que o sedimento é carregado do fundo da baía ou da região que deveria ser a Praia dos Milionários. 


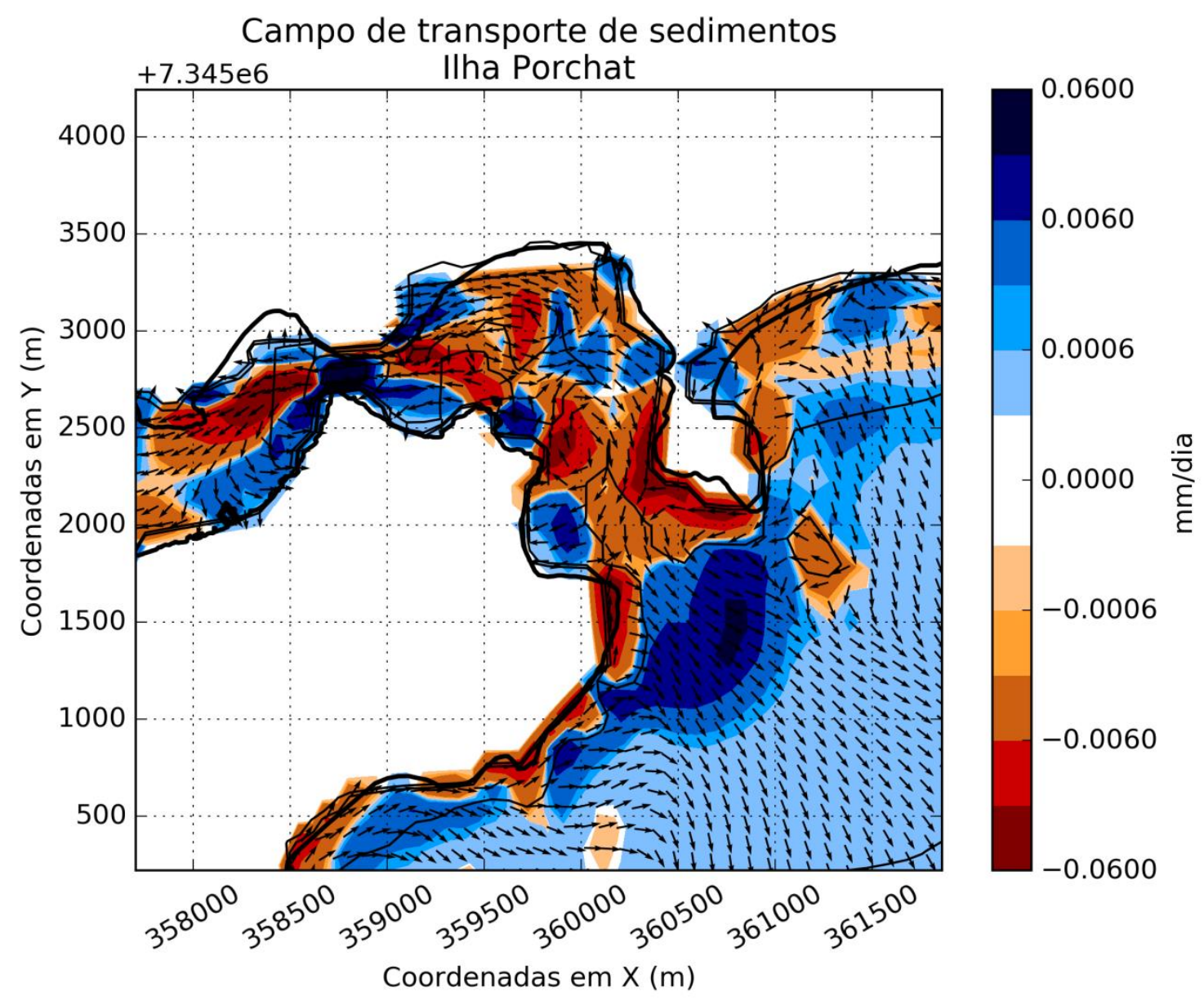

Figura 32 - Campos das regiões de deposição e erosão da região dos arredores da liha Porchat para o final da simulação, as cores azul e vermelhas representam os valores em metros, as setas verdes as direções residuais do transporte as linhas pretas representam as cotas batimétricas de 20,15,10,0 e 2 metros - projeção UTM zona 23 datum WGS84.

\subsubsection{Análise do efeito das frentes frias médias}

Para inferir a resiliência do sistema, utilizou-se a taxa de sedimentação em milímetros por dia das primeiras 120 horas de simulação comparada com a mesma taxa após a passagem da frente. Desta forma pode-se avaliar se as regiões anteriormente apresentadas possuem ou não resiliência a passagem das frentes e se, após a passagem da frente, é possível que o sistema volte a uma configuração geomorfológica aproximadamente semelhante a da condição sem frentes frias.

Primeiramente, com uma perspectiva geral da Baía de Santos, nota-se 
alterações na direção do transporte do centro da baía, uma maior erosão na Praia de Itararé e José Menino e de uma intensificação na alteração da zona de deposição em frente à llha Porchat que se encontra mais a montante do canal em uma situação de FFM (Figura 33).

A alteração da direção do transporte sedimentar nas áreas de profundidades acima de $15 \mathrm{~m}$ da Baia de Santos na parte mais sudoeste demonstram que os sedimentos deixam de ser transportados leste-oeste para serem transportados na direção do gradiente batimétrico, indicando a convecção de correntes de vazante com o empilhamento de água na costa, caracterizando uma maior influência de correntes de maré na dinâmica sedimentar pós frente. 

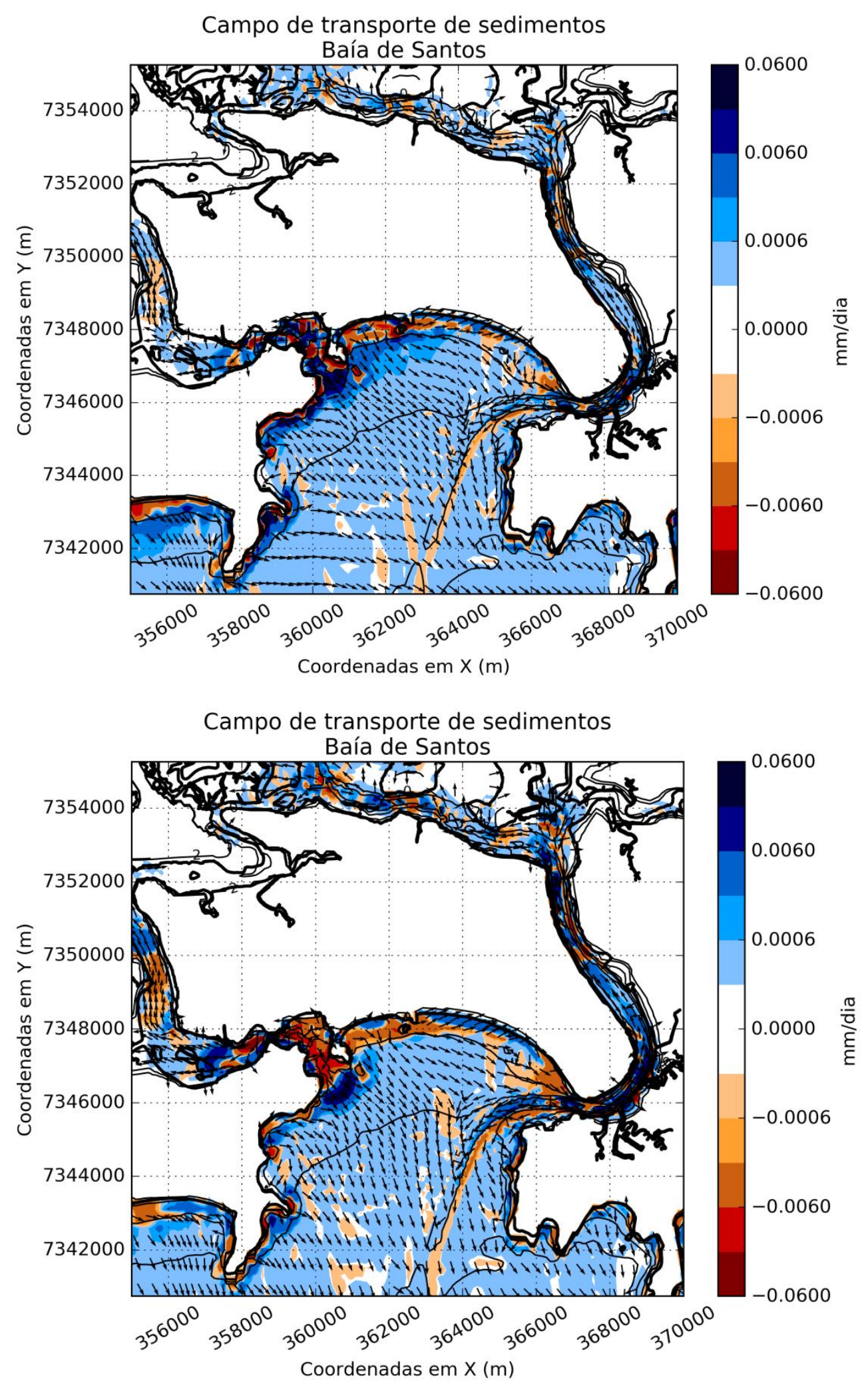

Figura 33 - Taxa de sedimentação em milímetros por dia para a Baía de Santos nas 120 primeiras horas de simulação (figura superior) e das 240 últimas horas (figura inferior) para a condição de frente fria média - projeção UTM zona 23 datum WGS84 
Para o Canal de Bertioga durante a passagem de frente fria contatouse maior intensidade nas zonas deposicionais e erosivas exceto para a região próxima ao promontório. Observando a direção de transporte, a região de divergência na parte centro-oeste da praia é mantida e a inclinação dos vetores de transporte demonstra uma maior tendência ao transporte de sedimento para uma região oceânica enquanto que no período sem frentes o transporte se encontra paralelo à costa em regiões mais profundas. Observa-se também que para o caso aqui apresentado há um sinal de redistribuição sedimentar nas área mais emersas, visto que o sinal de erosão/deposição difuso encontrado na situação de frentes frias na região de praia (emersa/submersa) se atenua para um sinal deposicional uniforme (Figura 34 ). $\mathrm{Na}$ região do promontório $\mathrm{O}$ aumento do sinal deposicional erosivo pode ser um indicativo de que um maior volume de sedimento chega nesta região pela deriva litorânea.

No caso do Canal do Porto, embora qualitativamente as regiões erosivas e deposicionais sejam as mesmas observadas antes e depois da passagem de frentes frias, as taxas são menores na situação com frente do que a na situação sem frente em virtude da intensificação das correntes de cheia. No balanço final, a corrente residual do canal ainda de vazante, tende a ser menos intensa no período de frentes frias do que pós-frente em contrapartida ao empilhamento de água que impulsiona o colume estuário acima. O resultado deste "contrafluxo" é percebido nas taxas de transporte de sedimentos. 

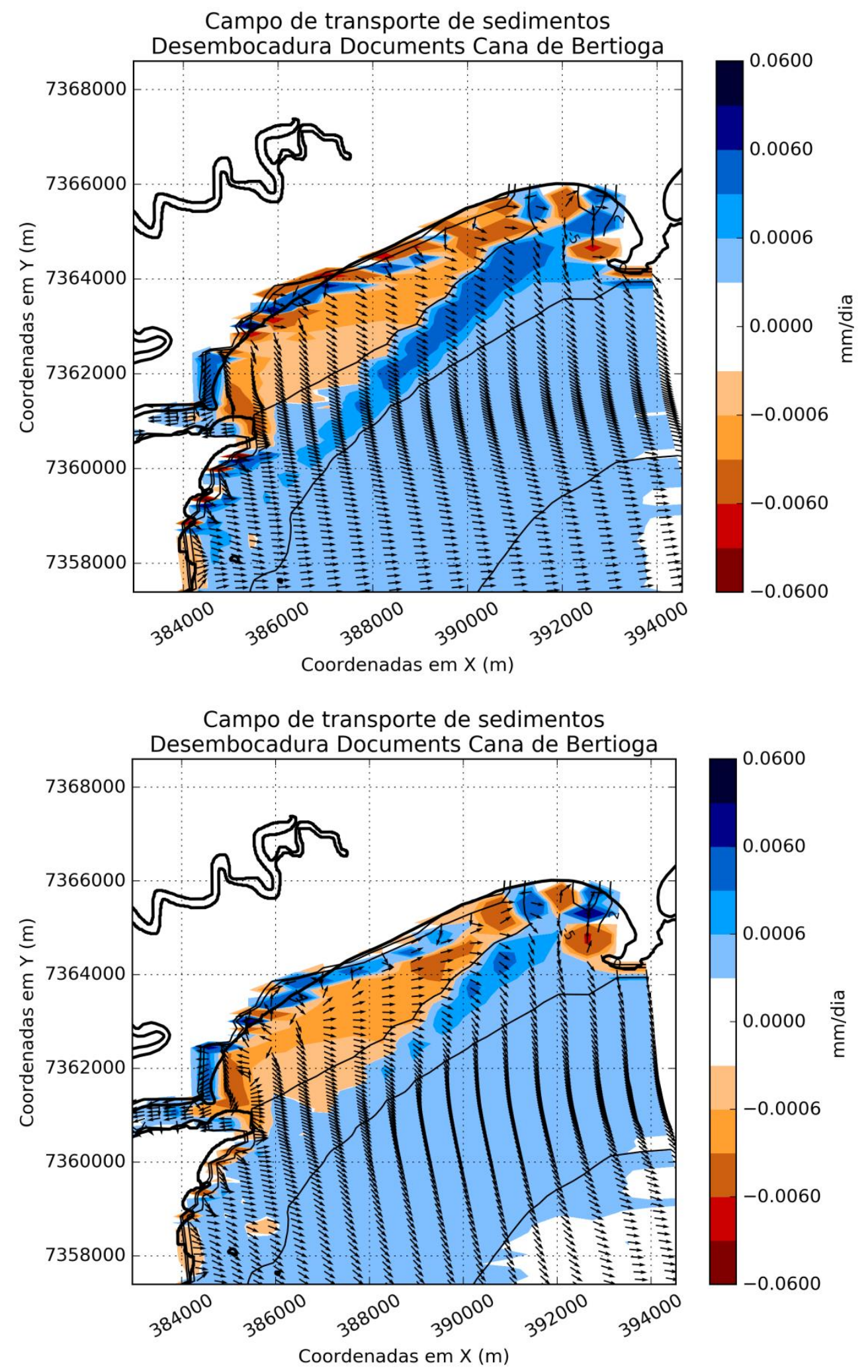

Figura 34 - Taxa de sedimentação em milímetros por dia para a Praia de Bertioga nas 120 primeiras horas de simulação (figura superior) e das 240 últimas horas (figura inferior) para a condição de frente fria média - projeção UTM zona 23 datum WGS84. 

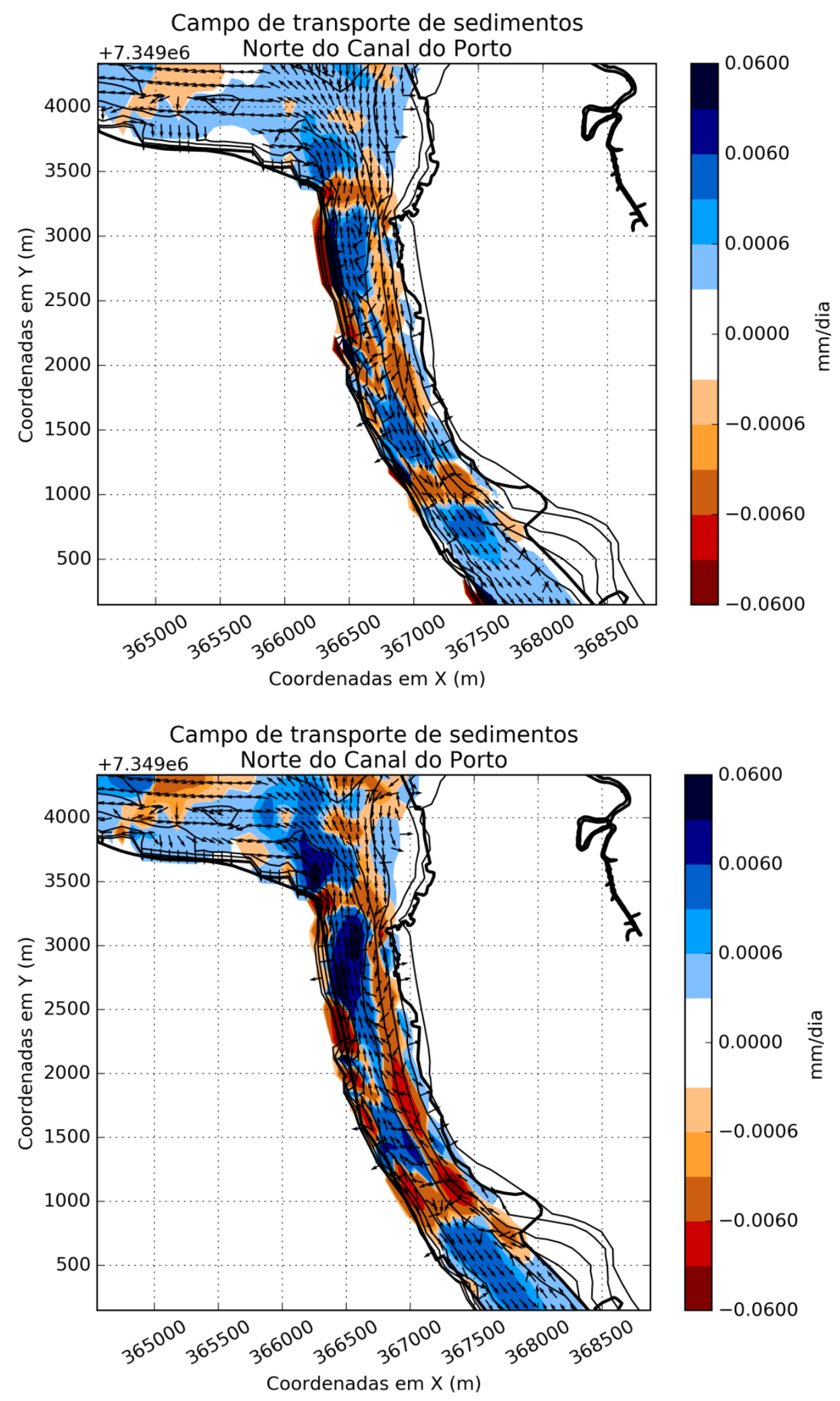

Figura 35 - Taxa de sedimentação em milímetros por dia para a região norte do Canal do Porto nas 120 primeiras horas de simulação (figura superior) e das 240 últimas horas (figura inferior) para a condição de frente fria média projeção UTM zona 23 datum WGS84. 
A mesma constatação sobre as taxas sedimentares e regiões de erosão e deposição são encontradas na parte sul do canal (Figura 36), ou seja, as frentes frias apresentam menores taxas de erosão e deposição do que quando comparadas às taxas pós-frentes frias. No que diz respeito às praias, a passagem da FFM e o período pós-frente apresentaram taxas similares de erosão para a Ponta da Praia. No caso de Praia de Aparecida a FFM teve um caráter deposicional, possivelmente trazendo sedimentos do fundo do canal para a praia, enquanto que condição pós-frente um caráter erosivo com taxas semelhantes as deposicionais. Estes resultados são indicativos de balanço sedimentar próximo de zero, ora tendo seu sedimento removido e ora depositado.

Nas praias de Santos e de São Vicente (Figura 37) é possível observar que a situação de frente fria comum tem caráter erosivo. Nas praias de Itararé e José Menino, a configuração da dinâmica é a mesma observada no cenário sem frente fria. Após o retorno a uma condição mais branda, as taxas erosivas e deposicionais são quase inversas, apesar de manter a direção do transporte nas praias. Neste caso supõe-se, observa-se que as praias recebem sedimento pelas laterais durante o período de frentes e redistribuem o material em período de tempo bom. Salienta-se que as regiões laterais da praia José Menino e Itararé (ao norte da ilha de Urubuqueçaba e ao lado leste do tombolo da ilha Porchat, respectivamente), recebem sedimento e em qualquer condição e o comportamento deposicional encontrado atua como estoque de sedimento.

Já no caso das praias de Santos, observa-se que a zona de surf (faixa erosiva) é deslocada para próximo da costa, reduzindo a região deposicional das praias, consequentemente removendo sedimento da mesma. Após a passagem da frente, esta zona de surf recua, e as praias assumem um caráter deposicional. As taxas de erosão e deposição observadas são muito similares, indicando que o sedimento removido é reposto em quantidades muito próximas e que a região apresenta balanço sedimentar quase nulo. 

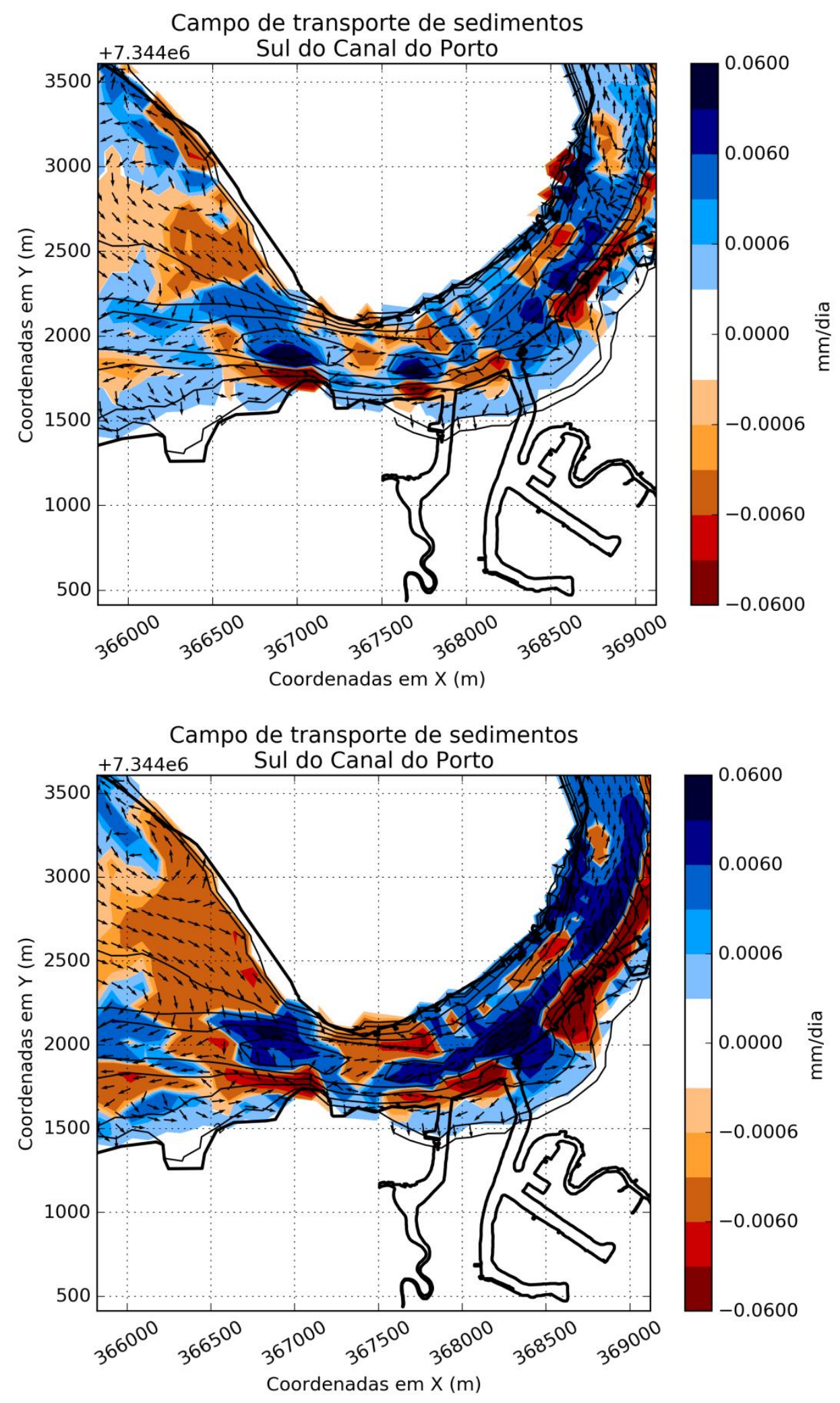

Figura 36 - Taxa de sedimentação em milímetros por dia para a região sul do Canal do Porto nas 120 primeiras horas de simulação (figura superior) e das 240 últimas horas (figura inferior) para a condição de frente fria média 

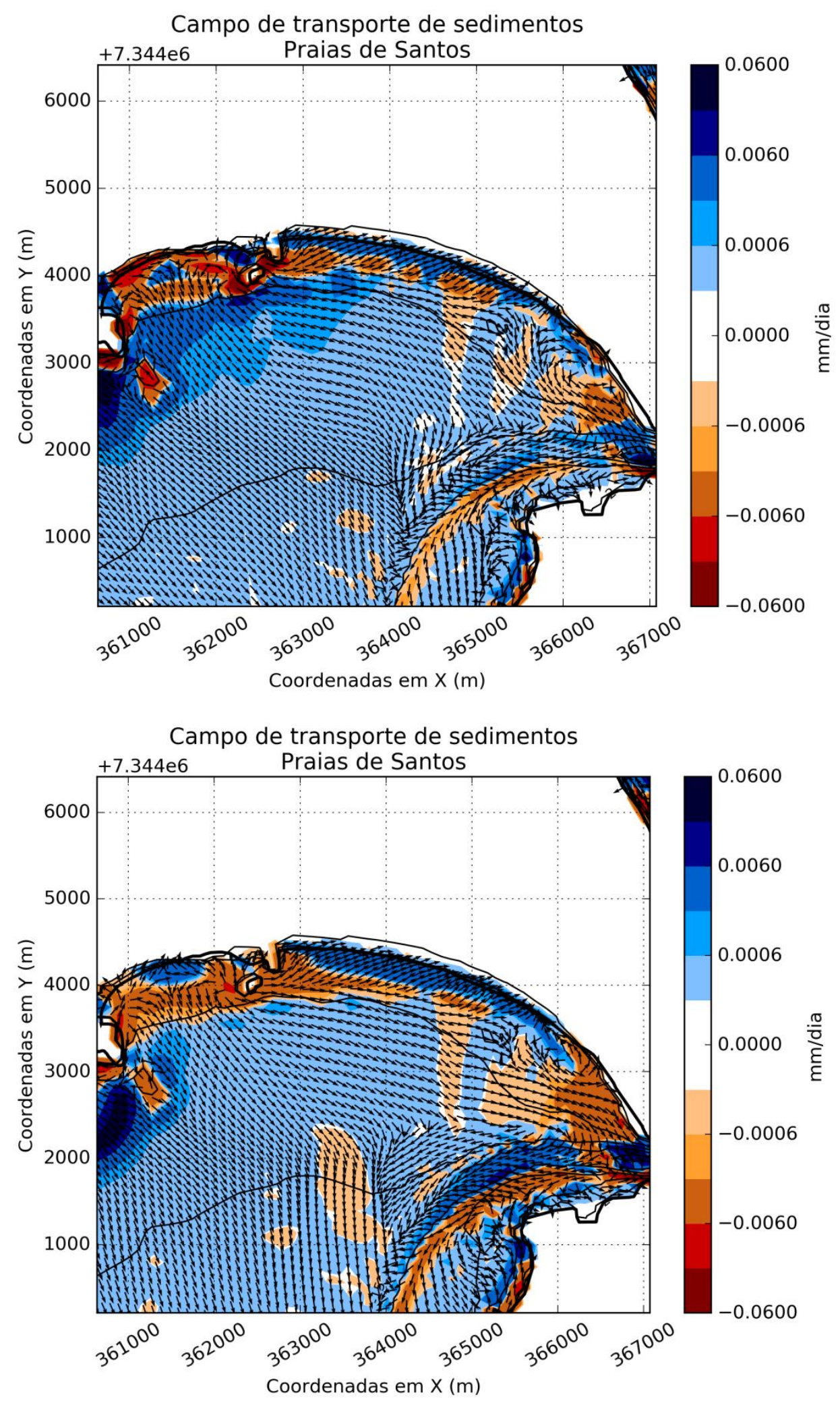

Figura 37 - Taxa de sedimentação em milímetros por dia para a região das praias de Santos e São Vicente nas 120 primeiras horas de simulação (figura superior) e das 240 últimas horas (figura inferior) para a condição de frente fria média - projeção UTM zona 23 datum WGS84. 
Em relação à região da llha Porchat, as frentes frias deslocam a região deposicional para o interior do canal e as áreas e taxas erosivas são reduzidas em função do enfraquecimento das correntes de vazante, quando comparado a uma situação pós-frente fria. Esta dinâmica, similar ao Canal do Porto, é indicativa de que as correntes de maré são as maiores responsáveis pelo maior volume de sedimento transportado nos arredores da desembocadura do canal e na Baía de São Vicente (Figura 38).

Sobre as regiões de erosão e deposição observa-se que a região em frente a llha Porchat, ao sul da ilha no continente e região de maior profundidade de canal, apresentam o mesmo comportamento erosivo/deposicional com e pós frente. A dinâmica da região é diferente principalmente na Baía de São Vicente e no centro do canal entre a sudoeste da ilha. Este comportamento da região deve ser mantido na modelagem até um equilíbrio topobatimétrico da região.

Quanto a comparação entre o período de frente e pós frente observase taxas similares de erosão e deposição no interior da baía o que leva a crer que de modo geral a região encontra-se com balanço sedimentar próximo ao nulo, excetuando-se a região de frente a llha Porchat. 

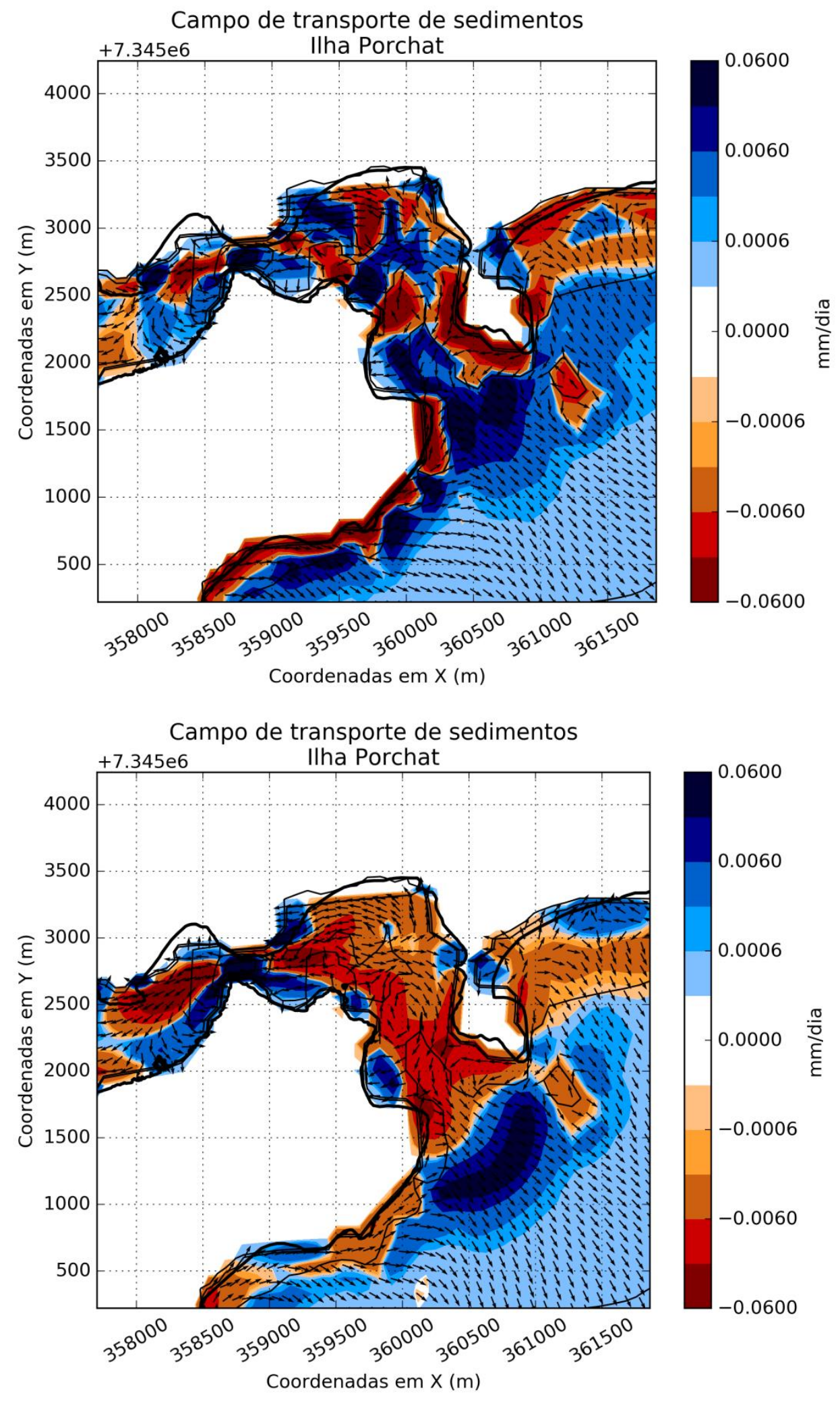

Figura 38 - Taxa de sedimentação em milímetros por dia para a região da desembocadura do estuário de São Vicente nas 120 primeiras horas de simulação (figura superior) e das 240 últimas horas (figura inferior) para a condição de frente fria média - projeção UTM zona 23 datum WGS84. 


\subsubsection{Análise do efeito das frentes frias extremas}

De forma comparativa com os casos anteriores, os resultados dos experimentos com cenários de FFE serão apresentados nesta seção.

Para a Baía de Santos (Figura 39), os resultados apresentaram maiores taxas sedimentares em todas as regiões. Embora a direção de transporte tenha sido mantidas, observa-se novas áreas de erosão na parte oeste da Baía e feições pós-frente com taxas muito menores, acredita-se que para esta condição a região não encontra-se em balanço sedimentar. Em função da direção constante acredita-se que o sedimento erodido foi depositado no fundo do canal de navegação. Esta foi a feição que apresentou maior destaque na região da baía principalmente em função da elevada carga de sedimento erodido na região mais distante da costa e que foi transportado para fora da baía e para dentro do canal. A falta de variação na condição erosiva/deposicional (sinal positivo e negativo da taxa sedimentar) indica que a região não se recuperou da passagem da frente fria e que as feições topobatimetricas ainda não são favoráveis para uma modificação da taxa de sedimentação.

A praia de Bertioga apresentou apenas variação nas taxas sedimentares, mostrando que a mesma não se encontra resiliente a passagem de um sistema frontal (Figura 40) e que independente do sistema atuante a praia mantém a mesma dinâmica.

Nas regiões ao norte do Canal do Porto apresentam características idênticas às observadas no cenário anterior onde o aumento das taxas ocorre nas condições pós-frontais (Figura 41).Para a região do sul do Canal (Figura 42), também ocorre o mesmo que no norte, distinguindo-se na região ao sul da Ponta da Praia que apresenta uma taxa erosiva intensa e deposicional na parte do Canal de Navegação. É evidente a situação erosiva da Ponta da Praia e o assoreamento parcial do canal. No caso da Praia da Aparecida, durante a passagem da frente é depositado um grande volume de sedimento da praia para a região submersa e, embora em taxas menores, no pós-frente, a região apresenta um caráter deposicional na parte norte e erosivo na parte sul. Acredita-se que a região não está em balanço sedimentar na parte sul da praia. 

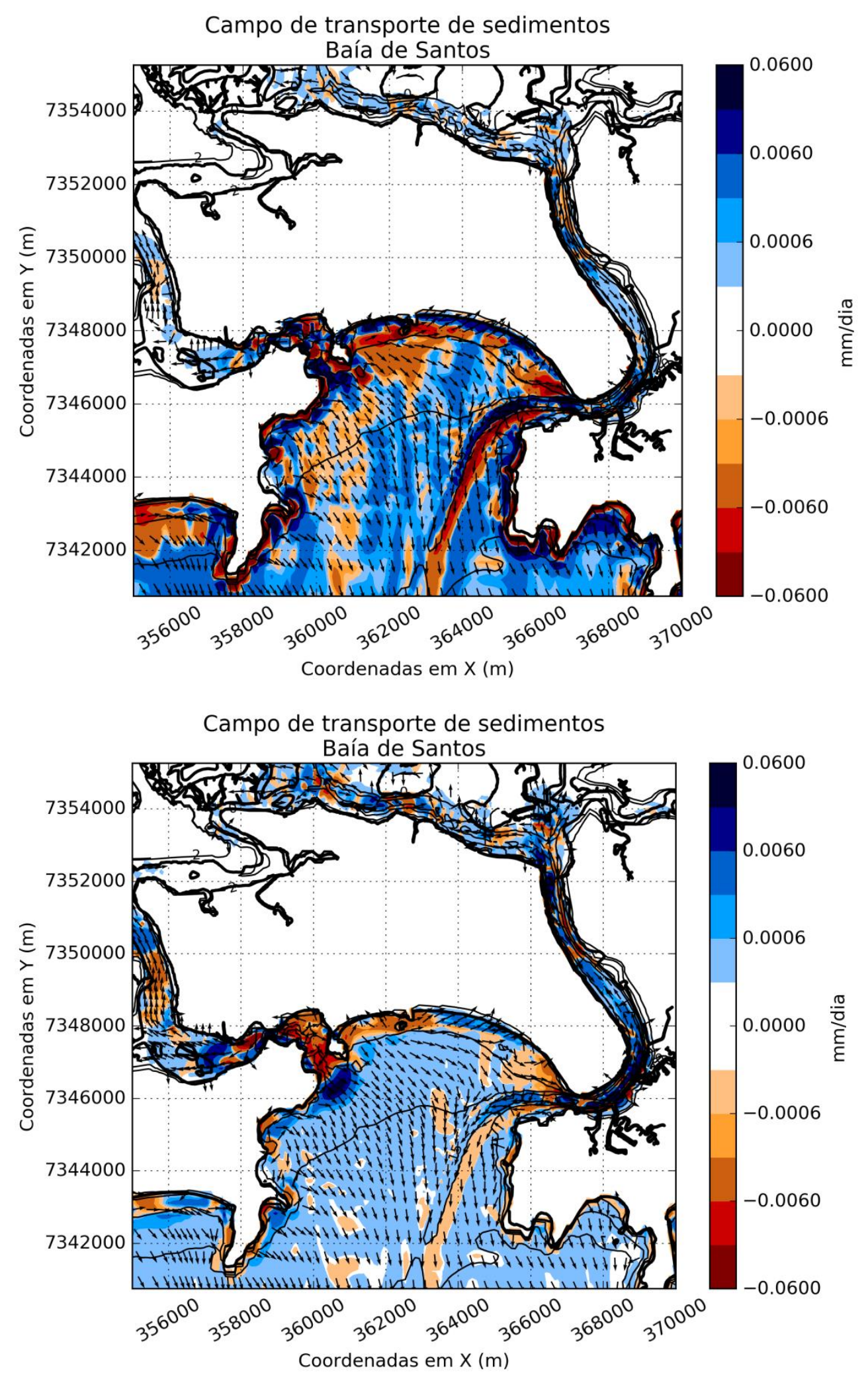

Figura 39 - Taxa de sedimentação em milímetros por dia para a Baía de Santos nas 120 primeiras horas de simulação (figura superior) e das 240 últimas horas (figura inferior) para a condição de frente fria extrema - projeção UTM zona 23 datum WGS84. 

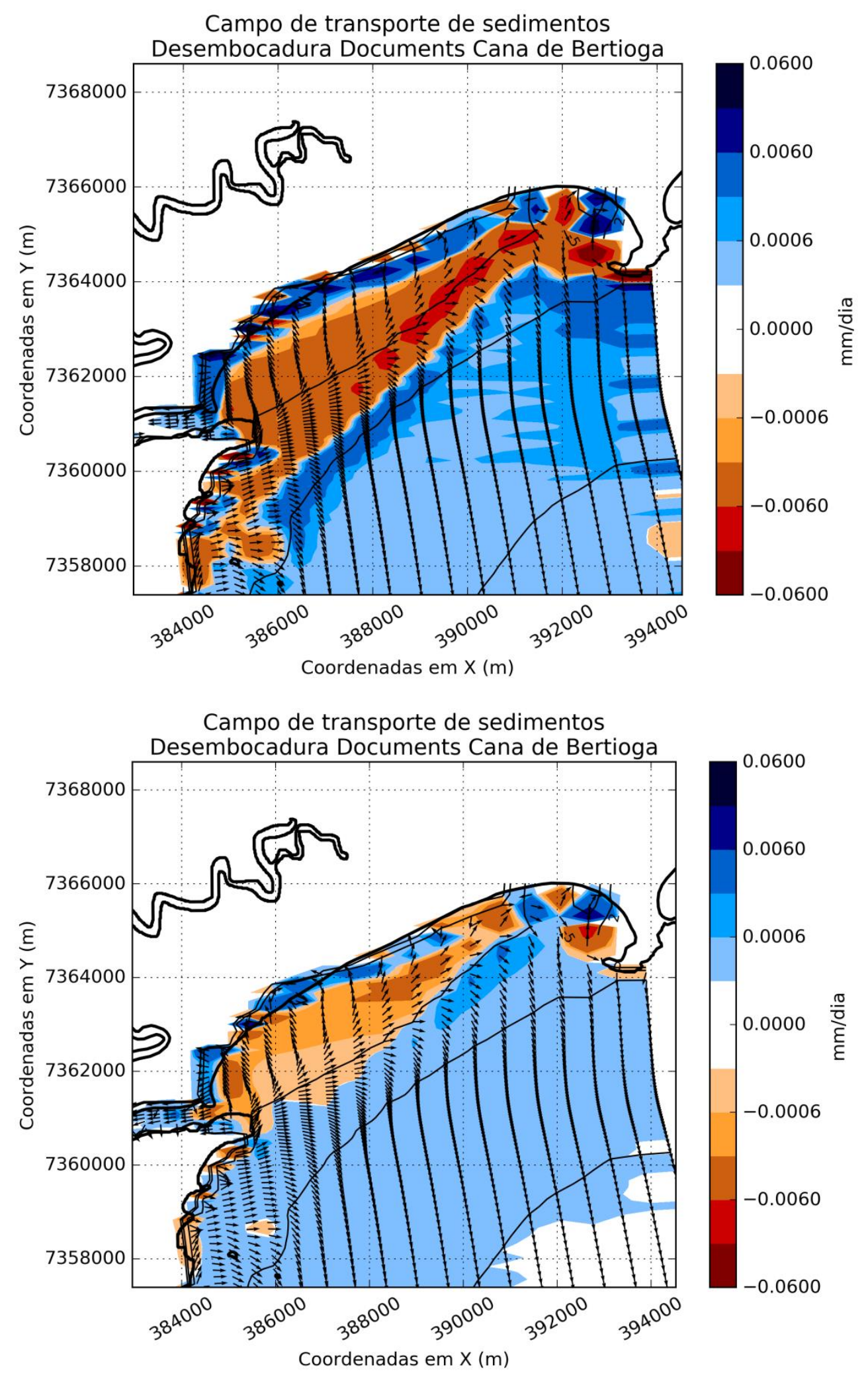

Figura 40 - Taxa de sedimentação em milímetros por dia para a praia de Bertioga nas 120 primeiras horas de simulação (figura superior) e das 240 últimas horas (figura inferior) para a condição de frente fria extrema - projeção UTM zona 23 datum WGS84. 

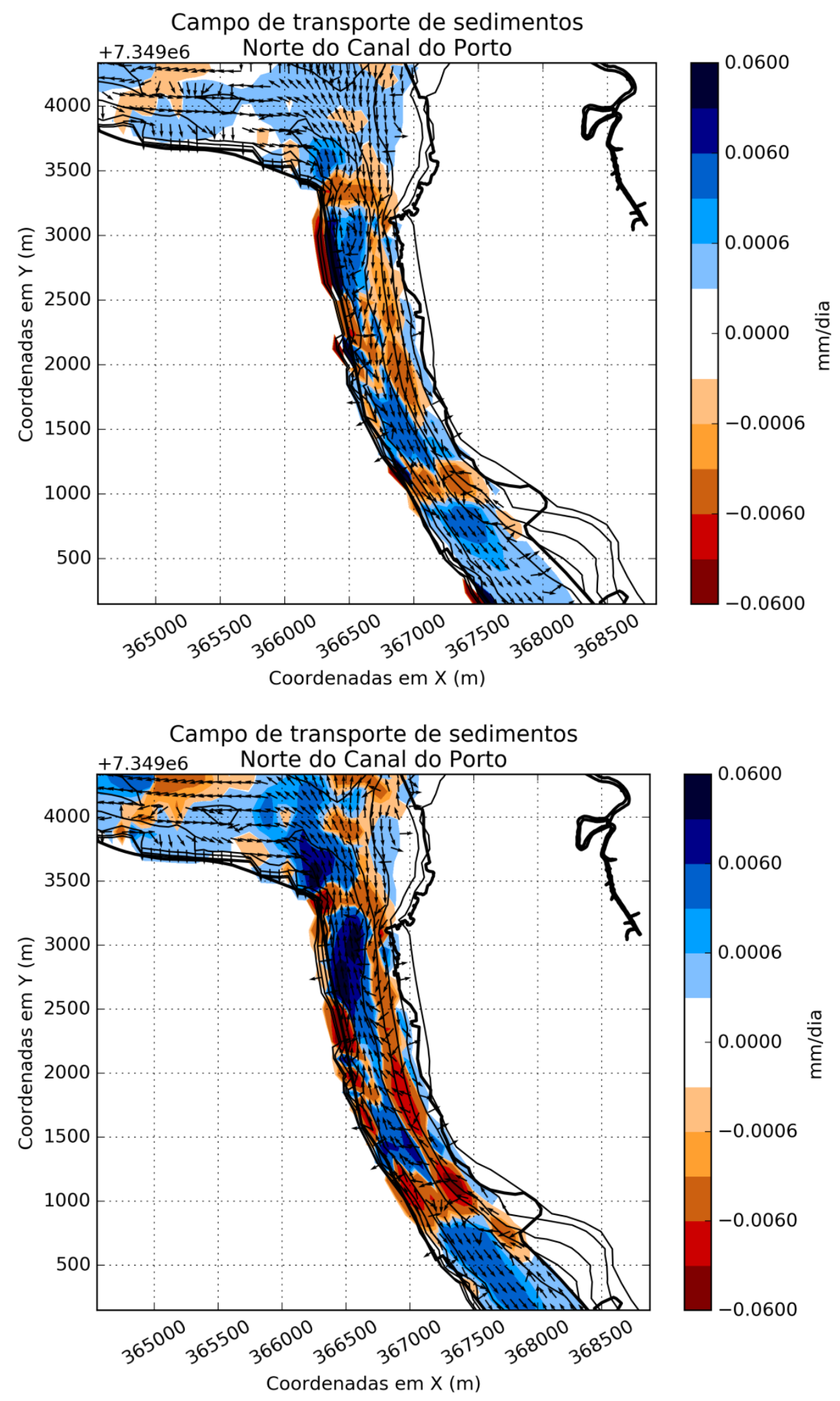

Figura 41 - Taxa de sedimentação em milímetros por dia para a região norte do Canal do Porto nas 120 primeiras horas de simulação (figura superior) e das 240 últimas horas (figura inferior) para a condição de frente fria extrema projeção UTM zona 23 datum WGS84. 

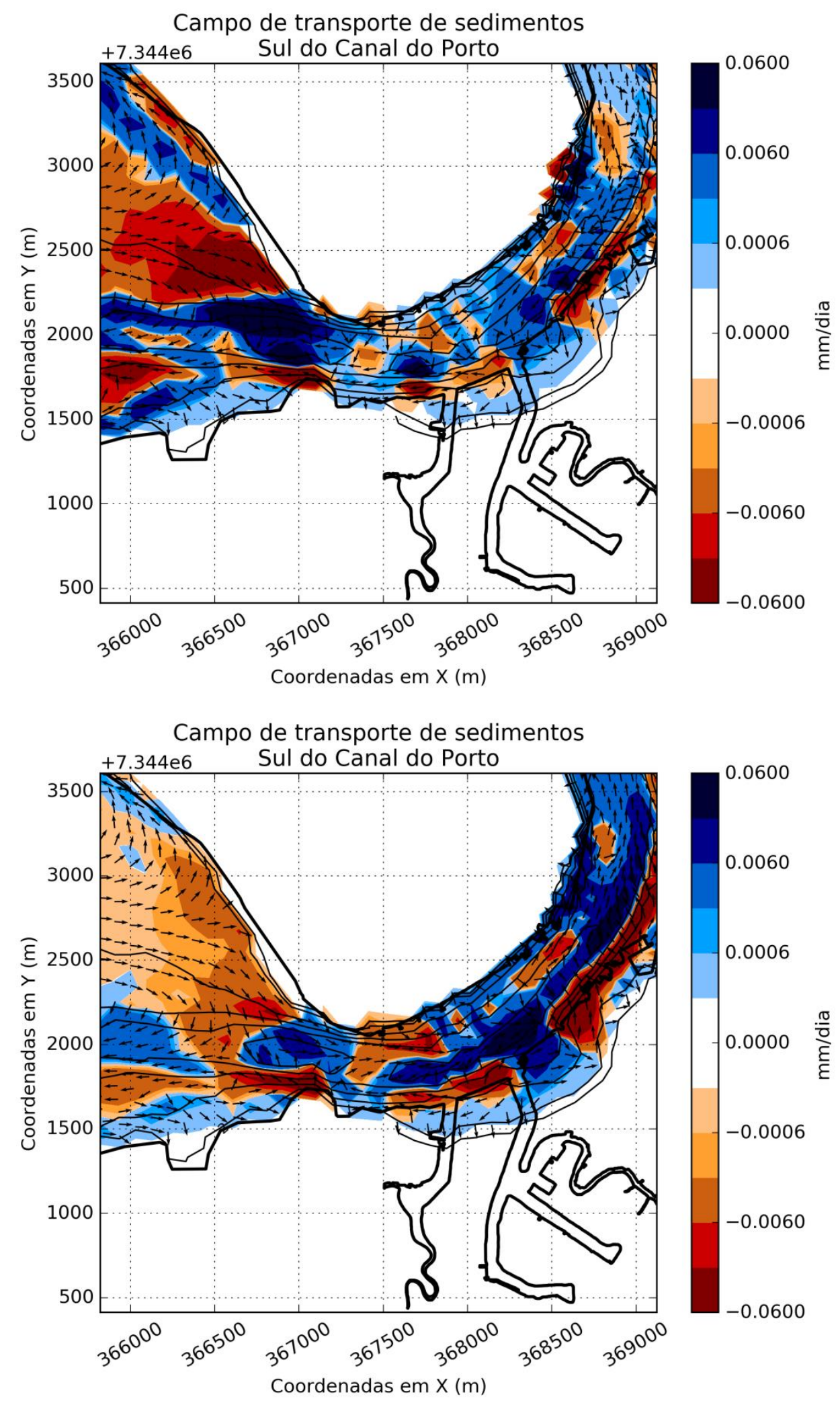

Figura 42 - Taxa de sedimentação em milímetros por dia para a região sul do Canal do Porto nas 120 primeiras horas de simulação (figura superior) e das 240 últimas horas (figura inferior) para a condição de frente fria extrema. 
No caso das Praias de Santos e Itararé (Figura 43) o comportamento é o mesmo, o perfil torna-se mais inclinado já que um grande volume é removido da zona de surf e depositado um na zona emersa. Esta zona de surf não é progradada como no caso observado em uma FFM, a justificativa é que a relação onda nível na condição de FFE é muito maior do que na condição de FFM, portanto a onda sofre efeitos de quebra em regiões mais rasas e, consequentemente, transporta sedimento em regiões mais profundas nas condições extremas do que nas condições médias. Após a passagem da frente o sistema muda as condições de erosão e deposição, porém as taxas são muito pequenas o que leva a crer que não é resiliente a passagem de frentes desta magnitude.Na região da llha Porchat (Figura 44), observa-se a mesma condição que foi encontrada para o cenário de FFM.

Primeiramente observa-se que as regiões das praias e da Baía não apresentam caráter resilinte a frentes frias extremas. Comparando os cenários de frentes observa-se que a Ponta da Praia é uma região de constante erosão independente da condição hidrodinâmica sendo agravada quanto maior forem as ondas. A divergência do transporte que ocorre na borda sul da Praia de Aparecida é permanente e é o principal indício desta constante erosão na região e do transporte deste sedimento em direção ao Canal de Navegação.

No caso da praia de Itararé e José Menino, o lado leste do tômbolo da Ilha Porchat e o tômbolo da llha de Urubuqueçaba são alimentadas por sedimentos durante as frentes frias, e quanto maior a maré meteorológica encontrada maior será o abastecimento para este estoque de sedimentos.

Observa-se também que quanto mais intensa as frentes frias, menor será a dinâmica sedimentar dos estuários em função do enfraquecimento relativo da contribuição da maré astronômica e que a maior dinâmica ocorre sempre em períodos de calmaria. Observa-se que a taxa erosiva/deposicional no período pós-frentes é aproximadamente a mesma na região da desembocadura do Canal de São Vicente, embora quanto mais intensa a frente maiores serão as taxas deposicionais encontradas, portanto quanto mais intensa a frente maior será o tempo para que esta região retorne as feições geomorfológicas precedentes a sobre-elevação do nível do mar. 

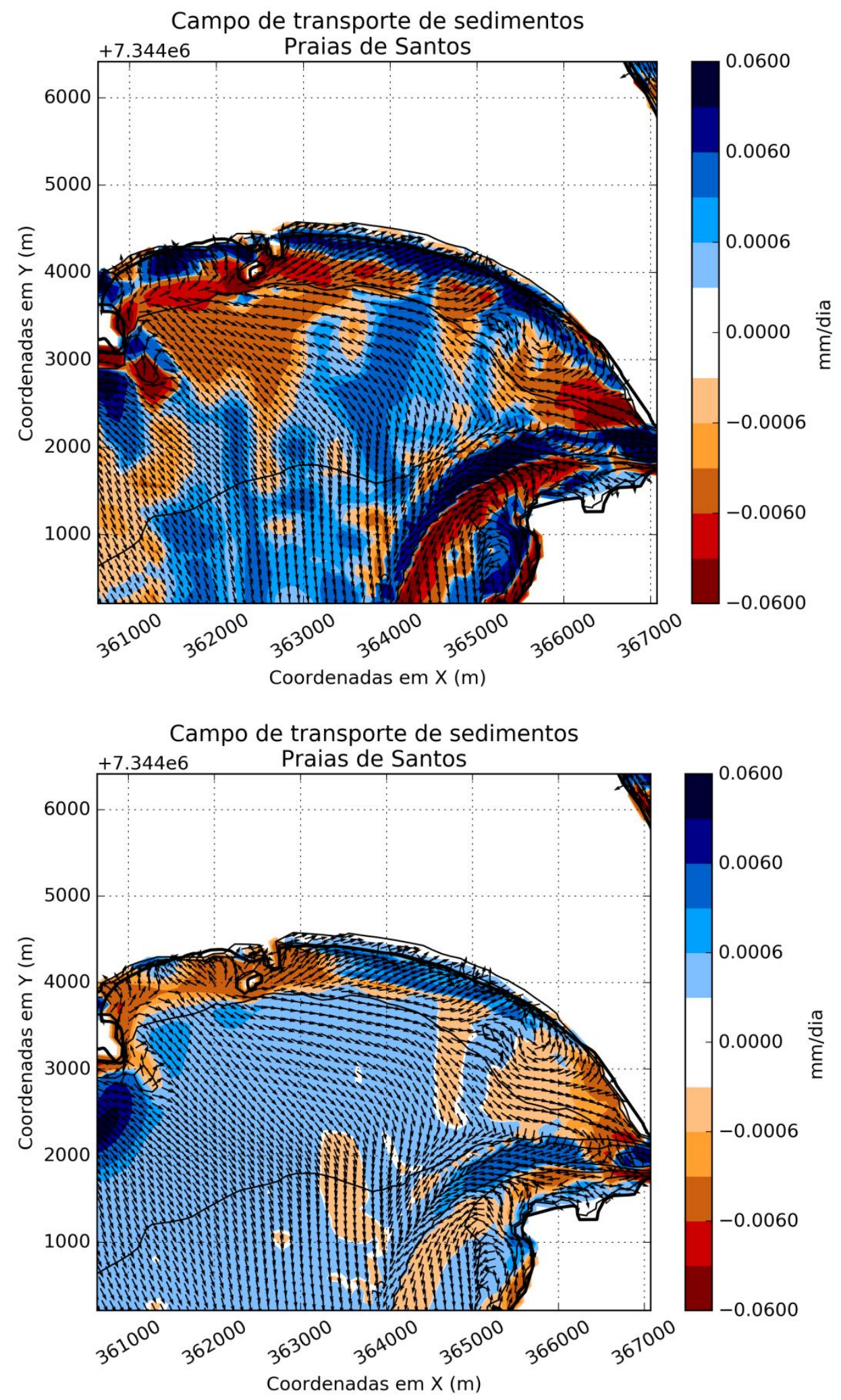

Figura 43 - Taxa de sedimentação em milímetros por dia para a região das praias de Santos e São Vicente nas 120 primeiras horas de simulação (figura superior) e das 240 últimas horas (figura inferior) para a condição de frente fria extrema - projeção UTM zona 23 datum WGS84. 

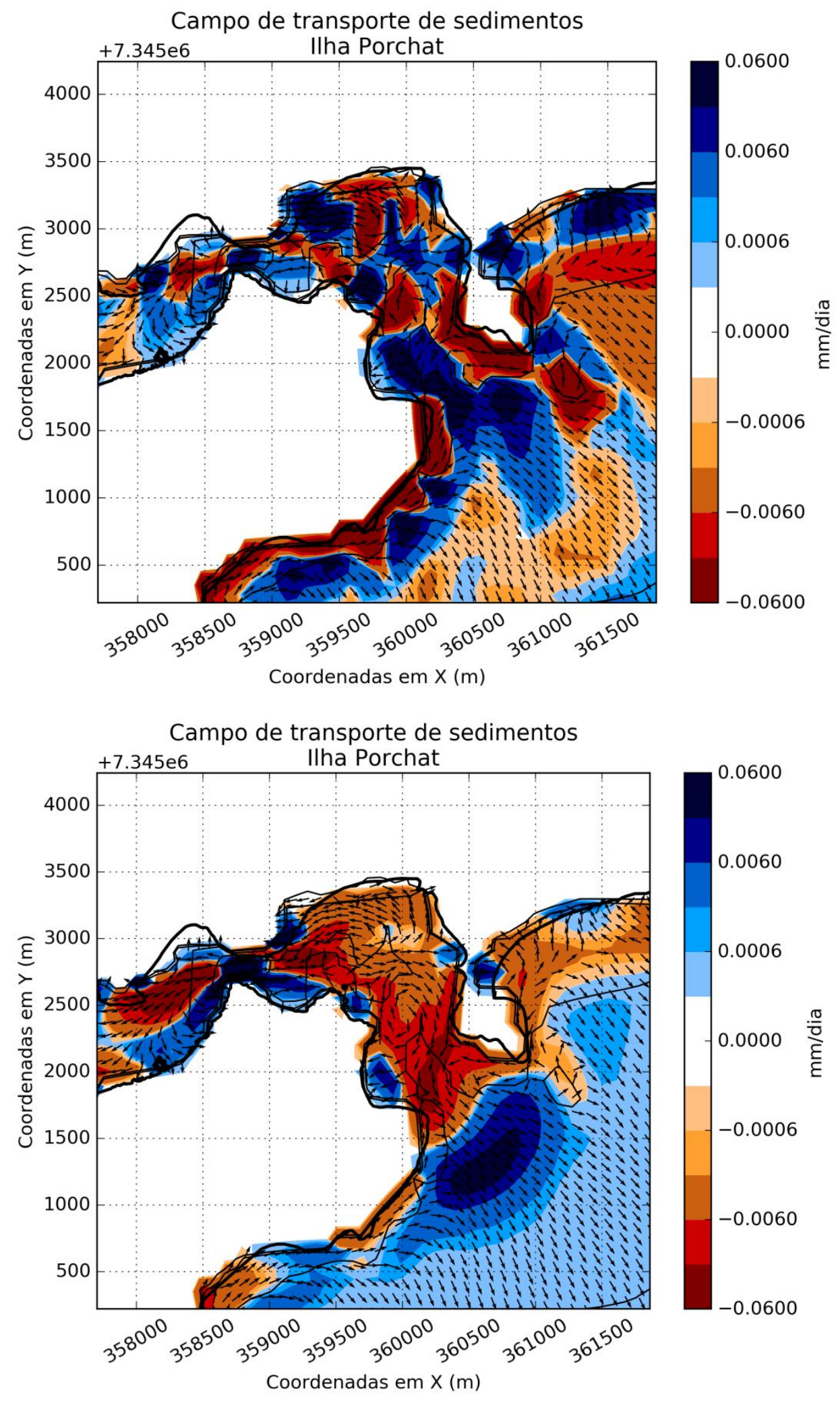

Figura 44 - Taxa de sedimentação em milímetros por dia para a região da desembocadura do estuário de São Vicente nas 120 primeiras horas de simulação (figura superior) e das 240 últimas horas (figura inferior) para a condição de frente fria extrema - projeção UTM zona 23 datum WGS84. 
A região da Baía apresenta comportamento geralmente deposicional, apenas a passagem de um sistema muito intenso propicia erosão do fundo na porção oeste. Possivelmente esta erosão é resposta ao efeito da amplificação das ondas e correntes com mais energia para mobilizar material depositado em regiões mais profundas. O mesmo efeito de acentuação da erosão se dá na área do Canal de Navegação da Baía. Este comportamento de uma FFE difere da FFM principalmente no comportamento do canal após a passagem da frente, no caso da passagem de uma FFM ela atenua as taxas de erosão, que não intensificadas no pós-frente, o que é oposto ao observado na simulação de FFE.

A resposta à elevação do nível do mar causada por maré meteorológica para a baía e praias adjacentes é diferente quando comparada ao canal. As feições erosivas e deposicionais apresentam valores maiores durante a passagem de uma frente fria na região da baía e das praias do que no período sem frentes. No caso dos estuários de Santos e São Vicente, observa-se exatamente o contrário. Isso indica que a hidrodinâmica da baía tem mais energia para movimentar o material em função da intensificação do fluxo e das ondas durante a passagem de um sistema frontal e que, para os canais, o fluxo tem maior energia para mobilizar material durante períodos onde não há frentes frias.

No caso das praias a hidrodinâmica é intensificada com o aumento do gradiente barotrópico e com a altura e energia de ondas. Isto aumenta a área de abrangência de efeito das ondas, porque elas atingem regiões mais elevadas da topografia em função de um maior nível do mar e também mobilizam sedimentos de regiões mais profundas já que ondas maiores atingem o fundo em profundidades maiores (Dean \& Dalrymple, 2004). Já os processos erosivos e deposicionais dos canais são desintensificados durante a passagem de uma frente fria, pois o empilhamento de água na costa reduz a intensidade das correntes de vazante e aumenta a intensidade das correntes de enchente. Embora as correntes de vazante continuem mais intensas (vide a direção do transporte na Figura 35, Figura 38, Figura 41 e Figura 44), a redução da energia diminui a competência do fluxo impedindo que a velocidade crítica de transporte seja atingida para mobilizar uma maior porção do material 
(sedimentos muito finos e muito grossos), além de carregar o material sedimentar por menores distâncias (perda de competência ocorre mais rapidamente) (Dean \& Dalrymple, 2004). Esta diferenciação de resposta á entrada de frentes frias é consequência da configuração geomorfológica do complexo, onde as regiões de estuário são protegidas e dominadas completamente pelo regime de maré e descarga dos rios enquanto que a região da baía tem sua circulação também dominada por maré embora seja uma região onde o regime de ondas é representativo para o transporte de sedimentos e para a circulação costeira.

A redução da importância relativa do sinal de maré astronômica nas correntes, causada pelo empilhamento de água na costa, durante uma maré meteorológica, e a modificação nos processos deposicionais, já foi observada em estudos no estuário de Roterdã por Dronkers (1986). O autor estudou os efeitos de assimetria da elevação do nível do mar sobre o transporte de sedimentos um estuário de maré vazante. Embora aplicado apenas sobre o sedimento coesivo, o autor observou os mesmos resultados encontrados no trabalho onde, durante o período de frentes frias, o sedimento se movimenta menos e as zonas de deposição da boca do estuário estão mais a montante do que em situações de calmaria. Durante os períodos sem frente, o fluxo apresenta maior capacidade de transporte, comportamento mais erosivo exportado um maior volume de sedimento para a plataforma continental, este mesmo padrão é observado em ambos os estuários principalmente no que diz respeito ao Canal de São Vicente, que não sofre efeito da dragagem.

Para além da modelagem numérica, Anthony \& Héquette (2007) analisaram as variações granulometrícas e sedimentológicas em planícies de maré no estuário de Somme na Bélgica. Os autores coletaram ao longo de todos os ambientes costeiros que compõe este estuários e observaram a atuação de energias opostas durante a passagem de frentes frias, onde as correntes de maré astronômica tentam transportar sedimentos para fora do estuário enquanto que a maré meteorológica e as ondas transporta mateiral para a região emersa. Este comportamento é constatado nas regiões de praias santistas, onde o sedimento é erodido em regiões submersas e transportado para regiões emersas. 


\section{Conclusões}

- O modelo XBeach apresentou-se adequado para a representação da hidrodinâmica no complexo estuarino de Santos, portanto, acredita-se que o mesmo é adequado para representar o padrão geral e mudanças relativas ao transporte de sedimentos em função de alterações nas condições forçantes..

- No que diz respeito à análise de frentes frias, os resultados mostraram-se adequados para a elaboração dos cenários comparativos das condições hidrodinâmicas de FFM e FFE, portanto os resultados estatísticos obtidos mostram-se adequados para o presente estudo.

- As frentes frias são relevantes na dinâmica do complexo estuarino apenas nas regiões das praias e da Baía, seus efeitos nos canais são de atenuação do transporte, embora após a passagem de frente ela não tenha relevância significativa. Os efeitos da FFE e FFM sobre o canal não são muito semelhantes entre si quanto às taxas e direções.

- A Baía de Santos apresenta característica geral deposicional para qualquer condição de frente, sendo o sedimento exportado da baía para a região oceânica e tendo como principal fonte 0 material trazido das drenagens continentais que compõe 0 complexo estuarino e a região oeste da baía que traz material oceânico para o interior da mesma. Durante a passagem de sistemas frontais o volume de sedimento depositado tende a ser menor, e por vezes há o surgimento de feições erosivas que ocorrem apenas durante a passagem da frente e assumindo um caráter deposicional após a passagem do sistema.

- A praia de Bertioga apresenta comportamento de balanço sedimentar próximo a zero em uma situação de frente fria comum. No caso de uma frente fria extrema, as regiões de erosão e deposição são intensificadas e o sistema tende a ser recomposto de forma mais vagarosa que em uma situação de frente fria comum. 
- A dinâmica sedimentar do Canal do Porto depende da inclinação das margens do Canal de Navegação em relação ao fundo e das correntes de maré. A inclinação faz com que o sedimento das margens do canal seja depositado no fundo do mesmo por escorregamento. A maré transporta material o longo do canal em direção a Baía de Santos pelas correntes de maré vazante que são mais intensas. Durante a passagem de frentes frias, 0 transporte em direção à baía é reduzido, pois as correntes de vazante tem menos energia para o transporte já que o empilhamento de água na costa em devido ao sistema frontal implica em uma força barotrópica no sentido contrário ao fluxo de vazante. A região do canal não apresenta comportamento reverso quanto as feições erosivas e deposicionais observadas.

- O Canal de Navegação é uma feição deposicional tanto na região da Baía de Santos quanto no Canal do Porto, todo o sedimento depositado do fundo do canal tende a ser transportado para a região oceânica embora haja uma tendência de assoreamento do mesmo.

- Com exceção à Ponta da Praia, as praias de Santos são alimentadas pelo sedimento depositado na zona de surf e em situação de frentes comuns a praia é erodida e depois reconstruída pelas condições pós-frente. Em uma condição de frente extrema o perfil da praia torna-se muito inclinado não alterando as tendências de erosão e deposição durante a situação de pós-frente embora as taxas sedimentares sejam menores. Portanto não há comportamento reconstrutivo após a frente fria extrema.

- A Ponta da Praia e Praia dos Milionários encontram-se em estado erosivo, independentemente da condição climática. No caso da Ponta da Praia o sedimento removido não retorna para as mesmas já que são depositados no fundo do canal de dragagem $\mathrm{e}$ as correntes e ondas não possuem energia suficiente pra redisponibilizar este sedimento. Esta remoção ocorre em virtude 
da divergência na região de divisa entre a Ponta da Praia e Praia da Aparecida. O sedimento de fundo que é transportado ao longo das isobatas entre 10-15 metros não chega a zona de surf responsável pela alimentação da praia isto ocorre, pois 0 sedimento atinge o canal de navegação antes de uma região que pudesse atuar como área fonte. Durante a passagem de uma frente fria comum a taxa de erosão é menor do que uma condição pós-frente, porém em caso de frentes frias muito intensas, encontrou-se uma taxa de erosão muito alta. Portanto independente da situação climática a Ponta da Praia encontra-se em estado erosivo. No caso da Praia dos Milionários, o sedimento que contorna a ilha Porchat é depositado nas regiões mais profundas da Baía de São Vicente não sendo possível que esta praia seja naturalmente alimentada por qualquer condição oceanográfica.

- A praia de Itararé encontra-se em progradação, como também constatado por Faranacio (2005), e independente da condição meteo-ocenaográfica o balanço sedimentar da praia se mantém positivo, pois mesmo em situação de frente extrema tempo de remoção por erosão é superior a 15 dias.

- De modo geral o complexo estuarino é resiliente a passagem de frentes frias comuns, sendo estas frentes cruciais para o equilíbrio sedimentar das praias. No caso de frentes frias extremas, os sistemas saem de uma situação de equilíbrio demandando um tempo maior para se estabilizarem, muito embora a ocorrência deste frentes frias como a simulada no presente trabalho são casos muito raros estando com características de menos de $25 \%$ das frentes encontradas na série de dados analisada.

- De um modo geral, tanto no estuário de Santos como na Baía, o Canal de Navegação é uma zona deposicional constante atuando como armadilha de sedimentos. 


\section{Limitações e Sugestões para trabalhos futuros}

As limitações do presente trabalho encontram-se na quantidade e resolução dos dados obtidos onde podem ser listados:

- Distribuição espacial da granulometria ao longo do estuário

- Dados topobatimétricos - regiões praiais e de manguezal.

- Impossibilidade de calibração quantitativa do balanço sedimentar, portanto os resultados obtidos são de cunho unicamente qualitativo.

- Impossibilidade da calibração de dados de onda

- Falta de informação a respeito do comportamento do espectro de ondas de gravidade e infragravidade na região santista e plataforma adjacente.

- Falta de informação a respeito do volume de sedimentos transportados pelos rios que compõe o estuário.

- As avaliações das zonas deposicionais e erosivas e de transporte de sedimentos só podem ser consideradas qualitativamente. Os valores quantitativos não podem ser calibrados, portanto não devem ser considerados quanto a magnitude, mas sim quanto ao resultado positivo ou negativo (deposicional ou erosivo) das regiões.

Salienta-se que os resultados encontrados neste trabalho restringemse ao conjunto de dados utilizados, a resolução da grade, e a parametrização de onda utilizada.

Para estudos futuros ou continuação deste trabalho sugere-se:

- Estudo dos processos erosivos das regiões de manguezais.

- Sériee temporal longa dos perfis praias

- Medidas de correntes na baía de Santos

- Batimetrias de detalhe para a regiãoda Baía de Santos

- Simulações em que as variabilidades sazonais das frentes frias sejam consideradas. 


\section{Referências bibliográficas}

ANTHONY, E. J. \& HÉQUETTE, A., 2007. The grain-size characterisation of coastal sand from the Somme estuary to Belgium: Sediment sorting processes and mixing in a tide- and storm-dominated setting. Sedimentary Geology, Volume 202, p. 369-382.

ARAKAWA, A. \& LAMB, V., 1977. Computational design of the basic dynamical processes of the UCLA general circulation model. Methods of Computational Physics, Volume 17, p. 173-265.

BEEVERS, L., POPESCU, I., PAN, Q. \& PENDER, D., 2016. Applicability of a coastal morphodynamic model for fluvial. Environmental Modelling \& Software, pp. 83-99.

BERLAMONT, J., OCKENDEN, M., TOORMAN, E. A. \& WINTERWERP, J., 1993. The characterisation of cohesive sediment properties. Coastal Engineering, 21(1), pp. 105-128.

BOLLE, A. et al., 2011. Application and validation of XBeach for three different field sites. Coastal Engineering Proceedings, Volume 1, p. 40.

BOLLEN, M. et al., 2011. Design of a Coastal Protection Scheme for Ada at the Volta-River Mouth. Coastal Engineering Proceedings, Volume 1, p. 36.

CAMPOS, R. M., CAMARGO, R. D. \& HARARI., J., 2010. Caracterização de Eventos Extremos do Nível do Mar em Santos e sua Correspondência com as Reanálises do Modelo do NCEP no Sudoeste do Atlântico Sul. Revista Brasileira de Meteorologia, pp. 175 - 184.

CASSIANO, G. F., RIBEIRO, R. \& YASSUDA, E., 2008. Acquisition of Wave Data and Modeling in Santos Bay, São Paulo, Brazil. Orlando, Florida, Conference on Hydroscience \& Engineering.

CASTRO, B. \& LEE, T. N., 1995. Wind-forced sea level variability on the southeast Brazilian shelf. JOURNAL OF GEOPHYSICAL RESEARCH, pp. 16045-16056.

CAVALCANTI, I. F. D. A., FERREIRA, N. J., SILVA, M. G. A. D. \& DIAS, M. A. F. D. S., 2016. Tempo e Clima no Brasil. São Paulo: Oficina de Textos. 
CODESP, 2008. EIA-RIMA da Dragagem de Aprofundamento do Canal de Acesso e Bacias de Evolução do POrto Organizado de Santos, s.I.: s.n.

DALY, C. et al., 2011. Short wave breaking effects on low frequency waves. Coastal Engineering Proceedings, Volume 1, pp. 1-20.

DAVIS JR, R. \& FITZGERALD, D., 2003. Beaches and Coasts. s.I.:Wiley-Blackwell.

DEAN, R. G. \& DALRYMPLE, R. A., 2004. Coastal Process with Engineering Application. Cambridge: Cambridge University Press.

DRONKERS, J., 1986. Tidal Asymmetry and Estuarine Morphology. Netherlands Journal of Sea Research, Volume 2, pp. 117-131.

DU BOIS, P. B. \& DUMAS, F., 2005. Fast hydrodynamic model for medium-and long-term dispersion in seawater in the English Channel and southern North Sea, qualitative and quantitative validation by radionuclide tracers. Ocean Modelling, Volume 9, pp. 169-210.

EGBERT, G. D. \& EROFEEVA, S. Y., 2002. Efficient inverse modeling of barotropic ocean tides. Journal of Atmospheric and Oceanic Technology, Volume 19, pp. 183-204.

ERLANDSON, J. M. \& RICK, T. C., 2008. Archeology, marine ecology and human impacts on marine environments.. In:: Human Impacts on Ancient Marine Ecosystems: A Global Perspective.. California: University of California, p. 366.

ESTEVES, L. S., JR., E. E. T., DILLENBURG, S. R. \& TOMAZELLI, L. J., 2002. Long- and Short-Term Coastal Erosion in Southern Brazil. Journal of Coastal Research, pp. 273-282.

FARINNACCIO, A., GOYA, S. C. Y. \& TESSLER, M. G., 2009. Variações da linha de costa nas baías de Santos e São Vicente. Quaternary and Environmental Geosciences, pp. 42-48.

FERNANDEZ, G., CHESCHEIR, G., SKAGGS, R. \& AMATYA, D., 2006. DRAINMOD-GIS: a lumped parameter watershed scale drainage and water quality. Agricultural Water Management, Volume 81, pp. 77-97.

FIELDER, M. F. M., 2015. Dinamica estuarina em cenário de aumento do nível do mar: estuário de Santos,SP. São Paulo: Dissertação de Mestrado apresentadao no Instituto Oceanográfico, Universidade de São Paulo. 
FLATHER, R. A., 1994. A storm surge prediction model for the northern Bay of Bengal with application to the cyclone disaster in April 1991. Journal of Physical Oceanography, Volume 24, pp. 172-190.

FUKUMOTO, M. M., 2003. Caracterização da sedimentação atual e reconstituição da história deposicional recente na Baía de Santos, a partir das características composicionais e isotópicas da matéria orgânica. s.l.:Dissertação de Mestrado apresentadao no Instituto Oceanográfico, Universidade de São Paulo.

GREGÓRIO, H., 2009. Modelagem numérica da dispersão da pluma do emissário submarino de Santos. s.l.:Dissertação de Mestrado apresentadao no Instituto Oceanográfico, Universidade de São Paulo.

GUPTA, A. K., GUPTA, S. K. \& PATIL, R. S., 2005. Environmental management plan for port and harbour protects. Clean Techn Environ Policy, Volume 7, pp. 133--141.

GUTIERREZ, B. T., PLANT, N. G., THIELER, E. R. \& TURECEK, A., 2015. Using a Bayesian network to predict barrier island. Journal of Geophysical Research, Volume 120, pp. 2452-2475.

HARARI, J. \& CAMARGO, R., 1998. Modelagem numérica da região costeira de Santos (SP): circulação de maré. Revista Brasileira de Oceanografia, Volume 46, pp. 135-156.

HARARI, J. \& CAMARGO, R. D., 2006. Numerical simulation of the tidal propagation in the coastal region of Santos (Brazil, $24^{\circ} \mathrm{S} 46^{\circ} \mathrm{W}$ ). Journal of Coastal Research, pp. 1560-1563.

HARARI, J., CAMARGO, R. \& MIRANDA, L., 2002. Modelagem numérica hidrodinâmica tridimensional da região costeira e estuarina de São Vicente e Santos (SP)-Pesquisa Naval. Revista Marítima Brasileira, Suplemento Especial, pp. 79-97.

ITALIANI, D. M., 2014. Resposta Morfodinâmica à alimentação artifical da Ponta da Praia, Santos, SP. s.I.:Dissertação de Mestrado apresentadao no Instituto Oceanográfico, Universidade de São Paulo.

KRIEBEL, D. L. \& DEAN, R. G., 1985. Numerical Simulation Of TimeDependent Beach And Dune. Coastal Engineering, Volume 9, pp. 221--245. 
MAGINI, C., HARARI, J. \& ABESSA, D., 2007. Circulação recente de sedimentos costeiros nas praias de Santos durante eventos de tempestades: Dados para a gestão de impactos físicos costeiros.. Geociências, Volume 26, pp. 349-355.

MANZANO, A. B., 2009. Distribuição, taxa de entrada, composição química e identificação de fontes de grânulos plásticos na Enseada de Santos, SP, Brasil. s.l.:Dissertação de Mestrado apresentadao no Instituto Oceanográfico, Universidade de São Paulo.

MITCHENER, H. \& TORFS, H., 1996. Erosion of mud/sand mixtures. Coastal Engineering, Volume 29, pp. 1-25.

ONU, 2014. World Urbanization Prospects: The 2014 Revision, Nova York: s.n.

PENG, M., XIE, L. \& PIETRAFESA, L. J., 2004. A Numerical Study of Storm Surge and Inundation in the Croatan--Albemarle--Pamlico Estuary System. Estuarine, Coastal and Shelf Science, 59(1), pp. 121-137.

PONÇANO, W. L., 1985. Sedimentação atual aplicada a portos no Brasil. s.l.:Tese de Doutorado apresentada no Instituto de Geociências da Universidade de São Paulo.

ROCHA, A. C., 2003. Aplicação de métodos diretos e indiretos na análise da dispersão de sedimentos na baía de Santos-SP. s.l.:Dissertação de Mestrado Apresentada no Intituto Oceanográfico, Universidade de São Paulo.

RODRIGUES, M. L. G., FRANCO, D. \& SUGAHARA, S., 2004. Climatologia de frentes frias no litoral de Santa Catarina. Revista Brasileira de Geofísica, 22(2), pp. 135-151.

RODRIGUES, M., MAHIQUES, M. M., TESSLER, M. G. \& FURTADO, V. V., 1999. Uma revisão histórica acerca do conhecimento sobre a sedimentação atual, em ambientes marinhos submersos, do Estado de São Paulo, Brasil. Revista Brasileira de Oceanografia, Volume 47, pp. 91-106.

ROELVINK, J., 2006. Coastal morphodynamic evolution techniques. Coastal Engineering, Volume 53, pp. 277-287.

ROELVINK, J. A., 1993. Dissipation in random wave groups incident on a beach. Coastal Engineering, Volume 19, pp. 127-150. 
ROELVINK, J. A., 1993b. Surf beat and its effect on cross-shore profiles. s.I.:Tese de Doutorado apresentada no Intituto Tecnológico de Delft.

ROVERSI, F., 2012. Estudo Hidrodinâmico e de Renovação das Águas do Sistema. s.I.:Dissertação de Mestrado apresentada no Intituto Alberto Luiz Coimbra, Universidade do Rio de Janeiro.

SAHA, S. et al., 2010. Bulletin of the American Meteorological Society, Volume 91, p. 1015.

SAHA, S. et al., 2014. The NCEP Climate Forecast System Version 2. Journal of Climate, Volume 27, pp. 2185-2208.

SIEGLE, E. \& CALLIARI, L. J., 2008. High-Energy Events And ShortTerm Changes In Superficial Beach Sediments.. Brazilian Journal Of Oceanography, Volume 56(2), pp. 149-152.

SOUZA, C. R. d. G., 2015. Variabilidade morfológica e granulométrica e balanço sedimentar de uma praia em rotação praial. Quaternary and Environmental Geosciences, Volume 6, pp. 01-19.

STOICA, P. \& MOSES, R. L., 1997. Introduction to Spectral Analisys. Upper Saddle River: Prentice hall.

TOLMAN, H. L., 2014. User manual and system documentation of WAVEWATCH III version 4.18, s.I.: National Centers for Environmental Prediction.

TOORMAN, E. A., 2001. Cohesive sediment transport modeling: European perspective. Coastal and Estuarine Fine Sediment Processes.

VAN RIJN, L. et al., 2003. The predictability of cross-shore bed evolution of sandy beaches at the time scale of storms and seasons using process-based profile models. Coastal Engineering, Volume 47, pp. 295-327.

VERLAAN, M., ZIJDERVELD, A., DE VRIES, H. \& KROOS, J., 2005. Operational storm surge forecasting in the Netherlands: developments in the last decade. Mathematical, Physical and Engineering Sciences, Volume 363, pp. 1441-1453.

WARNER, J. C., GEYER, W. R. \& LERCZAK, J. A., 2005. Numerical modeling of an estuary: A comprehensive skill assessment. Journal of Geophysical Research: Oceans, Volume 110. 
WEISBERG, R. H. \& ZHENG, L., 2006. Hurricane storm surge simulations for Tampa Bay. Estuaries and Coasts, Volume 29(6), pp. 899-913.

ZIJLEMA, M., STELLING, G. \& SMIT, P., 2011. SWASH: An operational public domain code for simulating wave fields and rapidly. Coastal Engineering, p. 992-1012. 